\title{
Radioluminescent Emergency Egress Lighting for U.S. Navy Surface Ships
}
D. K. Adrian
G. A. Jensen
H. C. Pusey
R. J. Traub

December 1988

Prepared for the

U.S. Department of Energy

and the U.S. Navy

under Contract DE-AC06-76RLO 1830

Pacific Northwest Laboratory

Operated for the U.S. Department of Energy

by Battelle Memorial Institute 


\title{
DISCLAIMER
}

This report was prepared as an account of work sponsored by an agency of the United States Government. Neither the United States Government nor any agency thereof, nor Battelte Memorial Institute, nor any or their employees, makes any warranty, expressed or implied, or assumes any legal liability or responsibility for the accuracy, completeness, or usefulness of any information, apparatus, product, or process disclosed, or represents that its use would not infringe privately owned rights. Reference herein to any specific commercial product, process, or service by trade name, trademark, manufacturer, or otherwise does not necessarily constitute or imply its endorsement, recommendation, or favoring by the United States Government or any agency thereof, or Battelle Memorial Institute. The views and opinions of authors expressed herein do not necessarily state or reflect those of the United States Government or any agency thereof.

\author{
PACIFIC NORTHWEST LABORATORY \\ operated by \\ BATTELLE MEMORIAL INSTITUTE \\ for the \\ UNITED STATES DEPARTMENT OF ENERGY \\ under Contract DE-AC06-76RLO 1830
}

Printed in the United States of America
Available from
National Technical information Service
United States Department of Commerce
5285 Port Royal Road
Springfieid, Virginia 22161
NTIS Prict Codes
Microfiche A01
Printed Copy
Pages
$001-025$
$026-050$


$\mathrm{PNL}-6774$

UC -510

RADIOLUMINESCENT EMERGENCY EGRESS LIGHTING FOR U.S. NAVY SURFACE SHIPS
D. K. Adrian (a)
H. C. Pusey (a)
G. A. Jensen
R. J. Traub

December 1988

Prepared for

the U.S. Department of Energy and the U.S. Navy under Contract DE-ACD6-76RLO 1830

Pacific Northwest Laboratory

Richland, Washington 99352

(a) P\&A Associates, Washington, DC 


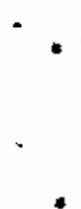




\section{PREFACE}

Under emergency conditions at sea, and especially under the added stress of combat, the lightless labyrinth of a modern warship's interior can be terrifying to crew members trying to perform vital duties or merely trying to survive. Having some form of light for guidance at such times can mean the difference between life and death, or even the ultimate survival of the ship if that light permits a critical task to be executed at the right time. But to be worthwhile in a true emergency at sea, that light source must perform unfailingly.

There was a time when such a light source was part of the routine emergency preparedness capability on U.S. Navy ships. There are no records as to how often this system made the crucial difference to sailors or ships during the Second World War, but intuition suggests that many men are alive today who would have been lost had it not been for the unassuming "beta button," unnoticed until needed. Yet also unrecorded are the effects on the health and safety of crews who lived continually with the units and the alpha and gamma radiation these little radium light sources emitted.

The balance of the risk versus benefit equation of the "beta button" on Navy ships may never be known. It is clear, however, that within the fleet today no emergency egress system exists that provides the same reliability for egress as the "beta button." This study revisited the basic concept of the "beta button" to determine whether radioluminescent technology and radiation safety have advanced sufficiently after 40 years to permit a new emergency egress lighting system to be developed, one of superior performance and having maximum radiation safety.

To accomplish this, both the Department of the Navy and the Department of Energy contributed a modest amount to sponsor this preliminary feasibility study. It was conducted by the Department of Energy's Pacific Northwest Laboratory $^{(a)}$ and their contractors under supervision of program managers from both the Navy and the Department of Energy headquarters.

(a) Pacific Northwest Laboratory (PNL) is operated by Battelle Memorial Institute for the Department of Energy under Contract DE-AC06-76RL0 1830. 
The results appear favorable that radioluminescent technology can contribute to safety on shipboard. Additional work is needed to ensure that the technology can make a difference at sea. It is our hope that such work will continue and that one day this study might be viewed as the beginning of an effort that resulted in a valuable contribution to the safety and survivability of U.S. Navy ships and their crews.

L. E. Leonard

U.S. Department of Energy 


\section{EXECUTIVE SUMMARY}

Radioluminescence (or simply RL) is the process by which radiation, given off during radioactive decay of isotopes, excites adjacent phosphors and causes them to emit light. The glib clichē "glow-in-the-dark," applied in general to nuclear materials technologies, dismisses the fact that for much of the twentieth century RL has played an important role in producing vitally important light sources.

During the Second World War the naturally occurring isotope radium-226 was mixed with phosphorescent paint to make "beta buttons," small markers which glowed green to provide emergency route marking throughout the interior spaces of Navy ships. It was a foolproof system that performed with the $100 \%$ reliability demanded by emergencies on shipboard. If the beta button wasn't covered up or missing when the lights went out it worked, and it is likely that between 1941 and 1945 these RL devices led many a sailor to safety or to a critical duty station.

During the war and in the intervening years, the use of nuclear materials and processes led to greater understanding of the effects of alpha, gamna, and other radiation emitted by the beta buttons, resulting in their removal from the fleet. The tedious task of removal spanned three decades, a time not of idleness for the Navy but a time when our ships would not face battle at sea. The absence of the beta buttons was hardly noticed.

In May of 1987 two Exocet missiles fired from an Iraqi war plane struck the USS Stark (FFG31). As P. M. Bennis wrote in "Aftermath of a Tragedy" in the spring 1988 issue of Fathom: "The Stark tragedy confirmed the correctness of much of our training. It aiso illuminated problems that needed solving," i.e., the need for reliable emergency egress lighting. The beta button was now conspicuously absent.

This study has been a preliminary investigation of the feasibility of again using RL technology for emergency egress marking on surface ships. It considers only currently available technologies but is mindful of the advanced RL concepts currently under development. It considers an egress lighting system that will perform the necessary mission with absolute reliability. It has rigorously applied state-of-the-art health physics 
analysis to the issue of radiological health and safety on shipboard. It has also considered the regulation and licensing of these RL devices and the administrative accountability required.

The conclusions are very favorable for RL to make a valuable contribution to safety aboard ship:

1. RL lighting using state-of-the-art tritium gas technology can be configured to perform as highly efficient egress markers for shipboard application. Totally independent of external energy sources, they function at temperatures and pressures far beyond the limits of human tolerance, in toxic or smoke-filled environments and under water indefinitely. They can be made impervious to the marine environment with a nearly maintenance-free service life of about 10 years or more.

2. An egress marking system has been devised and can be modified such that the continued presence of RL devices on shipboard will not pose any health or safety hazard to the ship's personnel under normal operating conditions. Under maximum credible damage scenarios, the safety benefits derived from the system far outweigh any potential health risk to personnel.

3. The potential for radiation exposure with a properly designed $R L$ egress system appears very low. Consequently, a high probability exists that for Navy applications the system would fall within a Nuclear Regulatory Comission licensing category exempt from nuclear materials accountability like common smoke detectors containing americium sources. This implies minimal or no added administrative burden placed on radiation control personnel if such a system were implemented.

4. The initial and life-cycle cost of the system is reasonable, and the system is much more reliable than existing alternatives. Extrapolating cost data developed in this study indicates that it may be possible to retrofit 400 surface ships with a complete $\mathrm{RL}$ egress marking system for less than the cost of one-medium priced combat aircraft.

5. The U.S. Department of Energy has a program that supports defense applications of existing and other advanced RL technologies. Through 
this program it will cooperate with the Navy to address the adaptation of RL systems to Navy requirements.

This very limited study examines only one of a number of shipboard applications to which RL might be applied. A detailed analys is is needed to fully explore the potential for use of state-of-the-art RL systems in the Navy. A more comprehensive study is highly recommended. It was also not possible to assess the implications of emerging RL technologies such as solid matrix light development and advanced gas techniques; it is strongly recommended that continued 6.2 (research) level efforts do this. Nonetheless, for the emergency egress application, enough conclusive evidence was developed and critical questions answered to indicate that the RL option using current technology can economically improve emergency egress and crew safety significantly on Navy ships. 
. 


\section{ACKNOWLEDGMENTS}

We wish to thank Albert Nelson of ORI, Andrew J. Tompkins of Oak Ridge National Laboratory, and Lee Leonard of the Department of Energy for their outstanding contributions to this effort. Our thanks also to Steven Cohen of the David Taylor Research Center for his many valuable suggestions.

Donald K. Adrian

Henry C. Pusey

$P \&$ A Associates 


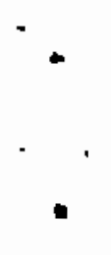

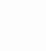

- 


\section{CONTENTS}

PREFACE ............................

EXECUTIVE SUMMARY .................. v ACKNOWLEDGMENTS ........................... ix

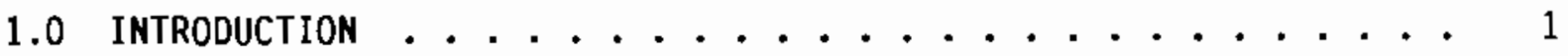

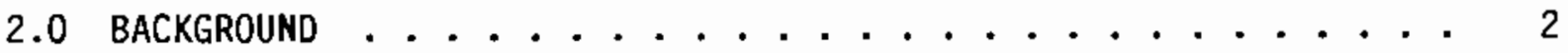

2.1 HISTORY OF RADIOLUMINESCENT LIGHTS . . . . . . . . 2

2.2 TRITIUM RADIOLUMINESCENT LIGHTS. . . . . . . . 4

3.0 SCOPE OF THE STUDY. .................. 4

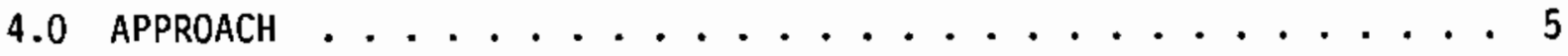

5.0 REQUIREMENTS FOR EMERGENCY EGRESS LIGHTING. . . . . . . . . 6

5.1 EXISTING EGRESS SYSTEMS ............. 7

5.2 OTHER EGRESS OPTIONS ................... 8

6.D RADIOLUMINESCENT EGRESS LIGHTING FOR SHIPS . . . . . . . 8

6.1 DESIGN CRITERIA ....................... 9

The Nature of the Risk ............ . 9

Performance Parameters . . . . . . . . . 10

6.2 PROPOSED RADIOLUMINESCENT SYSTEM . . . . . . . . . . 11

Selection of Egress Routes ............ 11

Selection of Radioluminescent Lights ......... 17

Types of Markers ............... . 18

6.3 GENERAL CONCEPT FOR RADIOLUMINESCENT LIGHT DESIGN . . . . 18

6.4 PRE-PROTOTYPE RADIOLUMINESCENT BULKHEAD MARKER . . . . . 20

6.5 GLASS REQUIREMENTS .................. 20

7.0 RADIOLOGICAL ASSESSMENT . . . . . . . . . . . 26 


\section{Contents (cont'd)}

7.1 DOSE ASSESSMENT FOR DIFFUSION AND BREAKAGE . . . . . . 26 Diffusion Through Glass ............ 27 Destruction of One Light in Each Compartment ...... 29 Destruction of Al1 Fixtures in a Space ........ 31

7.2 DOSE ASSESSMENT FOR FIRES AND MISSILE HIT . . . . . . . 31 Scenario 1: Fire in the Galley Area .......... 34

Discussion of Fire in the Galley Area ....... 34 Scenario 2: Fire in the Engine Room ......... 34

Discussion of Engine Room Fire ....... 36 Scenario 3: Hit by a Missile.......... 36

Discussion of Missile Fires ......... 38

7.3 CONCLUSIONS CONCERNING RADIATION HAZARD . . . . . . 38

7.4 CONTAMINATION OF THE SHIP FOLLOWING RELEASES AND FIRES . . . 38

7.5 DEPOSITION OF CONTAINED TRITIUM ON SURFACES . . . . . 39

7.6 INFLUENCE OF FIREFIGHTING METHODS . . . . . . . . 40

7.7 LOGISTICS ISSUES . . . . . . . . . . . . 40

7.8 RADIOLUMINESCENT EGRESS LIGHTING ON NUCLEAR-POWERED SHIPS • 41

8.0 BENEFITS OF RADIOLUMINESCENT EGRESS LIGHTS . . . . . . . 41

8.1 CREW SURVIVABILITY .................... 41

8.2 PeRfORMANCE .......................... 42

8.3 RADIOLOGICAL SAFETY ................... 43

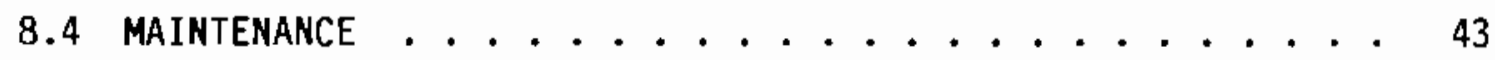

$8.5 \operatorname{cost} \ldots \ldots \ldots . \ldots . \ldots . \ldots . \ldots 44$

8.6 DOE SUPPORT OF DOD RADIOLUMINESCENT PROGRAM . . . . . . 44

8.7 LICENSING ISSUES . . . . . . . . . . . . 45 
Contents (cont'd)

9.0 SUMMARY AND CONCLUSIONS . . . . . . . . . . . . . . 46

10.0 RECOMGENDATIONS . . . . . . . . . . . . . . . . . . . 49

REFERENCES .......................... 51

APPENDIX A: DETAILED DRAWINGS OF SHIP'S SECTIONS USED FOR

EGRESS LIGHTING DESIGN . . . . . . . . . . . . . A.1

APPENDIX B: UNDERSTANDING RADIATION DOSIMETRY . . . . . . . . . . . B.1

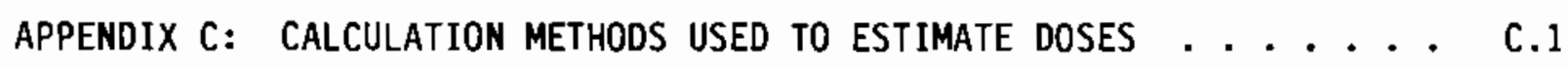

APPENDIX D: INVESTIGATION OF TRITIUM RADIOLUMINESCENT (RL) LIGHT

SOURCES FOR U.S. NAVY REQUIREMENTS ........... D. 1 


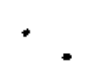

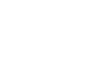




\section{FIGURES}

1 CG 47, 02 Level, Proposed RL Egress Lighting System . . . . . . . 12

2 CG 47, 01 Leve1, Proposed RL Egress Lighting System . . . . . . 13

3 CG 47, Main Deck, Proposed RL Egress Lighting System . . . . . . 14

4 CG 47, First Platform, Proposed RL Egress Lighting System . . . . 15

5 CG 47, Second Platform, Proposed RL Egress Lighting System . . . 16

6 Marker Designs Being Considered . . . . . . . . . . . . . 19

7 Design Concept for RL Fixture . . . . . . . . . . . . 21

8 Photograph of Demonstration Bulkhead Marker . . . . . . . . 22

9 Drawing of Demonstration Bulkhead Marker . . . . . . . . . 23

\section{$\underline{\text { TABLES }}$}

1 Typical Properties of Commercial Glasses . . . . . . . . . 25

2 CG 47 System Information Data Sheet . . . . . . . . . 28

3 Effective Dose Equivalent from Tritium Gas Diffusing

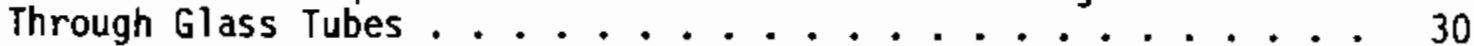

4 Effective Dose Equivalent Due to Breakage of Single Largest Activity Device in a Space . . . . . . . . . . . 32

5 Effective Dose Equivalent Due to Breakage of All Radioluminescent Devices in a Space ... . . . . . . . . . 33

6 Tritium Doses Following a Galley Fire... . . . . . . . . . 34

7 Tritium Doses Following a Missile Hit . . . . . . . . . . 37 


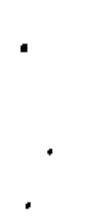




\section{RADIOLUMINESCENT EMERGENCY EGRESS LIGHTING FOR U.S. NAVY SHIPS}

\subsection{INTRODUCTION}

The United States Navy has long recognized the need to provide some type of emergency egress lighting on its ships. During World War II, small radioluminescent lights, commonly called "beta buttons," were installed as exit or route markers at appropriate locations throughout the ship. Radium was the radioactive material used in these lights as the seriousness of the radiation heaith hazard was not yet appreciated. With significant progress in health physics, the risk was recognized and the use of "beta buttons" was discontinued. Since then, there has been no acceptable replacement for the radium egress lights. This is partly because no significant wartime emergencies have occurred to highlight the need and partly because of the current widespread concern about radiological safety.

For many years the agency that is now the Department of Energy (DOE) has sponsored Congressionally mandated programs to identify, perfect and extend the practical use of nuclear byproducts for both civilian and military applications. The current DOE Advanced Radiation Technology (ART) Program encompasses all efforts related to byproduct utilization, including the Radioluminescent (RL) Lighting Program (DOE 1988). Simple RL devices, such as aircraft and building "exit" signs, have served necessary functions in society for several years. Under DOE's RL Program, visible RL airfield runway lighting is being used successfully in remote communities in Alaska. There the RL lighting is providing medical evacuation capabilities and other services at night. Infrared RL markers for helipads also have been developed that are not detectable without the aid of special viewers. RL runway lights for the U.S. Air Force have been developed and have proved acceptable. Current efforts under the RL Program are to consolidate past accomplishments and to develop RL devices and systems for new applications, using the existing glass tube technology as well as advanced RL technologies as they emerge.

Those responsible for acquiring ships for the Navy recognize that totally reliable emergency lighting systems that have a long life, require no 
batteries or backup electrical power, and are essentially maintenance-free would provide maximum opportunity for the survival of naval personnel during emergencies. Such lighting systems would not only assist in rapid evacuation of ships, but could enhance damage control operations and significantly reduce the time required to return ships to full combat readiness.

With these benefits in mind, DOE and the Navy have joined under the ART Program to investigate a potential solution to the need for more reliable egress lighting on surface ships. This study is a preliminary investigation to determine whether or not tritium RL lighting can be a safe, efficient and cost-effective alternative to existing or proposed egress systems. It is a 6.2 effort co-sponsored by the Navy's David Taylor Research Center (Work Order No. N0001487WX4B401) and by the Department of Energy.

\subsection{BACKGROUND}

To place radioluminescent technology in perspective, a brief look at the historical development of RL lights is instructive. This review begins with the earliest work and leads to the selection of tritium as the most promising radioactive source for RL lights.

\subsection{HISTORY OF RADIOLUMINESCENT LIGHTS}

Radium was the first radiation source for radioluminescent lights. During World War I, luminescent paint made by mixing radium with zinc sulfide was used to illuminate dials and to fabricate markers for personnel and vehicles. The light produced was green, corresponding to the peak color response of the human eye. During World War II, radium was still used as the source of alpha particles to excite phosphors to produce light. At the same time, advances in phosphor technology allowed orange, blue and red lights to be produced. Obviously, throughout these developments, there was little knowledge or concern about radiological safety. Following World War II, with the availability of nuclear reactors, radioactive materials other than radium were evaluated for light production. Most of the radium devices were disposed of as radioactive waste. Since radium was determined to be a severe biological hazard and was also expensive, its use was discontinued. 
The new isotopes produced that were of interest were beta emitters; they included strontium-90, promethium-147, carbon-14, thallium-204, krypton-85, and tritium. Promethium, a pure beta emitter, provided good-intensity light and was used for docking lights in the space program. Promethium-147 technology was such that the phosphor was mixed with promethium oxide and viewed through a transparent window. Its short half-1ife (2-1/2 yr) and potential contamination problems, however, reduced its utility.

Carbon-14, with a half-life greater than $5000 \mathrm{yr}$, can be used for fabricating light standards because the light yield is quite constant compared with some isotopes with shorter half-lives. Some isotopes, including strontium-90 and americium-241, were rejected chiefly because their high biological hazard precluded use in the public domain.

The use of fission product krypton-85 was promoted for RL lights until the weight problems associated with shielding the gamma and $x$-ray (bremsstrahlung) emissions, resulting from the isotopic decay process, were recognized. The energetic beta made it possible to produce brighter lights than could be achieved with tritium, and damage to the phosphor was less than that observed with alpha particles. A number of emerging applications for RL lights therefore spurred the organization of the DOE By-Product Utilization Program in 1979. Liaison was established with the U.S. Air Force to ensure that the program was relevant to national needs and to define particular military needs.

Lights using krypton-85 were fabricated under the DOE program and tested as airfield threshold markers, runway edge markers, and taxiway markers. The lights were configured in various geometries and required a light pipe and shield for gamma rays, which are produced along with beta particles during the decay of krypton-85. Demonstrations with these lights stimulated interest in RL lights, which had the obvious advantage of requiring no power supplies and thus provided a highly reliable and combat-ready lighting capability. However, partly because of the gamma, $x$-ray hazard and partly because of a question of the future availability of krypton-85, attention was turned to tritium as the most likely candidate to meet current and future needs. 


\subsection{TRITIUM RADIOLUMINESCENT LIGHTS}

Tritium, an isotope of hydrogen, is available to the Department of Defense (DOD) through the DOE Defense Programs office as well as from commercial sources. As a gas contained in a seated glass tube, its beta emissions activate phosphor powders coating the tube's inner surface, thereby producing light in a choice of colors. It has a relatively low biological hazard and a half-life of about 12 years; being a gas, it is quickly dispersed if released from a light tube. With proper design, however, the probability of accidental release is very low. Furthermore, since tritium is a pure beta emitter, there is no external radiation through the light tube. DOE has already produced rugged tritium RL light fixtures for airfield runways and other applications (Tompkins, Haff and Schultz 1988).

\subsection{SCOPE OF THE STUDY}

This study was conducted to evaluate the potential use of tritium RL lights as emergency egress lighting on surface ships of the U.S Navy. It is essential that crews on naval ships be assured of maximum probability of survival in combat or other emergencies. Loss of a ship's power from any cause renders conventional electric lighting systems useless. Battle lanterns and other auxiliary systems are often unreliable. Without reliable egress lighting to guide personnel during emergency evacuation, lives can be lost unnecessarily.

The only application considered in this study is emergency egress lighting for naval ships; the CG 47 class Navy ship is taken as the example. The study defines emergency egress lighting requirements for the CG 47 and establishes minimum realistic lighting needs for evacuation procedures. Existing and potential egress lighting options other than RL are reviewed. $\mathrm{RL}$ lights are then evaluated as a potential solution to the need on the bas is of performance as well as on an assessment of health and safety issues. The results of this study will accomplish the following:

1. establish health, safety and installation limits on the use of tritium lighting for emergency egress on surface ships 
2. provide a risk/benefit analysis of RL lights for ship egress applications

3. provide conceptual designs for shipboard egress RL lights

4. establish theoretical performance limits of RL lights in smoke and fire

5. define worst-case contamination and cleanup requirements for accidental breakage

6. compare RL system performance with that of other proposed systems

7. provide qualitative cost comparisons with conventional lighting.

\subsection{APPROACH}

The work plan for the study was established as four separate, but related, tasks as follows:

Task 1. Study, and define in detail, emergency egress lighting requirements for CG 47 class Navy ships. Establish minimum lighting requirements for optimum evacuation procedures.

Task 2. In parallel to Task 1, establish current maximum allowable Timits of tritium for RL lights on CG 47 class ships based on present Navy radiological safety requirements. Determine whether tritium RL egress lighting can be designed to provide adequate egress lighting within these limits. If designs can be implemented without exceeding present 1 imits, proceed with Task 3 . If present limits must be exceeded to meet lighting requirements, proceed with Task 4.

Task 3. Consistent with the results of Tasks 1 and 2, create conceptual designs of prototype tritium RL lights and fixtures for emergency egress lighting on CG $47 \mathrm{class}$ ships. Examine Navy qualification requirements for fleet acceptance of these devices. 
Task 4. Develop conceptual designs of proposed RL lighting systems that will meet minimum emergency egress lighting requirements for the CG 47 class. Determine the quantities of tritium that will be required for the proposed systems. Develop worst-case combat damage scenarios for these devices. Using guidelines provided by radiological safety personnel (SEA 06GN and PNL) and by other NAVSEA personnel, evaluate hazards to the ship's crew, using a combination of analytical and experimental techniques. Conduct a risk/ benefits analysis of proposed RL systems and establish guidelines for their use that are acceptable to NAVSEA 06GN.

In pursuing Task 2, the Navy Radiation Safety Committee was approached through the NAVSEA Radiological Controls Program Office. The comittee was requested to define maximum allowable radiation levels under present Navy radiological safety requirements. The committee chose not to define these levels. As a result, Task 3 was eliminated and Task 4 work proceeded in cooperation with radiological safety experts at PNL.

\subsection{REQUIREMENTS FOR EMERGENCY EGRESS LIGHTING}

The most probable events that can create a need for emergency egress lighting are combat damage--such as the Exocet missile strike on the USS Stark--shipboard fires, or collisions at sea. In all these cases, the chief driving factor for the requirement is the potential for saving human life.

without artificial light, the interior portions of naval ships are as dark as caverns deep underground. Loss of a ship's electrical power renders conventional electric lights useless, making it impossible for crew members to move about the ship with any confidence. Should evacuation of the ship, or any spaces within, be required under these conditions, the crew's probability of survival would be seriously reduced.

Crews' survival would be greatly enhanced if highly reliable emergency lighting systems were available. Such systems should require no batteries or backup electrical power and should be essentially maintenance-free. In 
addition to increasing crew members' chance at survival, the emergency lighting system would enhance damage control operations and significantly reduce the time needed to return a damaged ship to full combat readiness.

\subsection{EXISTING EGRESS SYSTEMS}

Current requirements for emergency lighting on surface ships are specified in NAVSEA 0964-LP-000-2000, Technical Manual Lighting on Naval

Ships (NAVSEA 1977) and in the General Specifications for Ships of the United States Navy (1987), Section 332, "Illumination Requirements." The first backup system depends upon an emergency power supply (generator) and an emergency switchboard providing a selective service to vital spaces fed through automatic bus transfer equipment. Such systems are not needed routinely and are consequently subject to long periods of inactivity. They require regular maintenance, however, to ensure that they will function in emergencies.

In addition to the installed emergency power supply, all ships are fitted with several sources of temporary, portable illumination for use in extreme conditions of damage or during power interruptions. These sources include portable hand lanterns; relay lanterns that automatically turn on when all power fails; storage battery-powered lanterns (primarily for use by damage-control parties); and battery-powered flashlights. All portable lights, including the relay lanterns are battery-powered, and their usefulness in emergencies depends on proper maintenance procedures and battery charging or replacement when required. As with the emergency generator system, inattention to maintenance requirements could result in their failure in an emergency.

A limited study of Navy procedures reveals no formal plan or procedures for emergency evacuation of a ship. Relay lanterns are required to be placed at strategic locations throughout the ship to mark escape routes. Should these lanterns fail to operate, crew members must find their way out in total darkness. It is understood that on some ships blindfold drills are conducted in an attempt to meet such a contingency, but such drills are not formally required by Navy regulations. 


\subsection{OTHER EGRESS OPTIONS}

Other technologies, either being used or studied by the Navy incTude chemicat luminescence, electroluminescence, and luminescent paint. of these, the only viable option for egress lighting is the luminescent paint or tape which glows for 5 to $6 \mathrm{hr}$ following lengthy exposure to white light. The chief disadvantages of this option, aside from its limited life, are that it is subject to wear, must be reapplied often, and has potential toxicity problems. There is also some doubt that there is sufficient ambient white light throughout the ship interiors to "charge" the paint for an emergency. In some cases, routine maintenance may result in the luminescent markers being "painted over" by regular paint. Even so, luminescent devices are currently being installed on some ships.

\subsection{RADIOLUMINESCENT EGRESS LIGHTING FOR SHIPS}

Self-luminous RL light sources have particular usefulness and appeal for safety lighting and continuous markering devices such as are required for egress lighting. The appeal derives largely from several strong advantages over conventional sources of light. From the Navy's viewpoint in particular, the main advantages are as follows:

1. RL lights are fully self-contained. No external power source is required.

2. RL systems provide continuous uniform light over an extended time (years). RL sources are not visible in the presence of ambient white light even though the fixture design may assist in orientation (see later discussion under Types of Markers). Their visible light output increases, however, as ambient light decreases, with maximum visibility in otherwise total darkness.

3. RL lights are essentially maintenance-free. They will not "burn out" during the normal expected life.

4. RL light sources will operate over a wide temperature range and will continue to operate in many hostile environments, including some types of fires. 
5. RL systems are unaffected by electromagnetic pulse (EMP) environments or by excessive humidity.

6. RL sources are free of spark and electrical shock hazards.

7. The use of RL lights, including the most common green sources, does not reduce the crew's night vision.

8. It has been demonstrated that RL systems can be designed so that they are highly resistant to damage from static and dynamic loads.

As indicated in the Scope, this study will suggest some conceptual designs of tritium RL lights for use as emergency egress lighting on U.S. Navy surface ships and will provide evidence to support a recomnended feasibility demonstration of these concepts.

\subsection{DESIGN CRITERIA}

Tritium RL lights employing we1l-established glass tube technology are proposed for use as emergency egress lighting on Navy ships. Before describing the proposed design concepts, however, it is instructive to examine some important criteria that affect the designs. Broadly, the two areas of major concern are safety and performance. As a radioactive material is involved, safety is the primary consideration. Consequently, a desirable goal is to minimize the quantities of tritium used while optimizing the performance of the RL lights. This report later suggests how this can be done. Meanwhile, the nature of the overall risks are examined.

The Nature of the Risk

The tritium used for egress lighting will be in the form of elemental gas. If an individual is directly exposed to gaseous tritium, a radiation dose may be transmitted to Tung tissue during inhalation of contaminated air. In addition, a small fraction of the tritium gas may be dissolved in the blood, thereby transmitting some radiation to the whole body. Some dosage may result also from a small fraction of the inhaled tritium gas that is converted to tritiated water in the body.

Tritium-activated lights will also contain a small amount of tritiated water within the glass tube. This water is normally bound on the interior 
surface of the glass and/or contained in the phosphoric acid binder. During exposure, tritiated water can enter the body by inhalation, ingestion, or perfusion through the skin. On a per-curie ( $\mathrm{C} i$ ) basis, tritiated water is a much greater radiation hazard than tritium gas.

If a person were exposed to large quantities of tritium as described above, a significant radiation health hazard would exist. The fact is that risk of significant exposure through the use of tritium RL lights is minimal. This is particularly true for egress lighting for which the quantities of tritium involved are very small, as is true for this proposed system. With RL lights, individuals may be exposed to varying quantities of tritium in any one of three major ways: 1) diffusion of tritium gas through the glass tube into the room air, 2) from tritium gas and tritiated water released in damage to a fixture, and 3) from tritiated water formed consequent to a fire in a space within a ship.

Later in this section, specific design concepts for surface ship egress lighting will be proposed. Quantities of tritium will be specified for each light fixture and for each ship's compartment considered in the design. Using the parameters set forth for the proposed system together with information on ship spaces and ventilation, a risk analysis will be conducted for all cases discussed above. It will be shown that the risk is negligible for the RL light system proposed in this study.

\section{Performance Parameters}

As a fundamental goal, the proposed RL devices must provide enough light and visual acuity that egress routes throughout the ship are clearly visible and meaningful to the crew. Previous studies relating to building egress signs have shown that this objective is achievable with minimum quantities of tritium. Tritium self-luminous signs were shown to be legible at 40 or more feet even under smoke-filled conditions.

Secondary design goals are to maximize the system's mechanical hardness and fire resistance, which in turn minimizes the probability of accidental tritium release under combat and other emergency scenarios. All these issues will be addressed as the proposed RL egress lighting system is described. 


\subsection{PROPOSED RADIOLUMINESCENT SYSTEM}

For this study, the CG 47 class of ships was selected as representative of a typical Navy ship of about 11,000 tons. The CG 47 supports state-ofthe-art weapons and propulsion systems and employs the latest ship's ventilation system design. The overall internal ship's arrangement represents the latest knowledge in naval architectural techniques required to maximize ship survivability in combat, including cases of potential damage from enemy weapons. Since the DD 963 class of ships has essentially the same hull and compartmentation design used for the CG 47 , this choice is generically typical of a large number of Navy combat ships.

Following selection of the CG 47 as a typical Navy ship, it was recognized that to propose a conceptual egress lighting system for the entire ship would be beyond the scope of this study. Hence the next step was to determine what sections within the hull and superstructure should be used for a typical egress lighting design.

It was decided to take a vertical athwartship slice out of the ship from port to starboard and from Frame 260 to Frame 346 on the ship's drawings (see the figures in Appendix A). Deck levels involved are the 02, 01, Main Deck, First Platform and Second Platform. Within this section of the ship are three watertight bulkheads, inclined and vertical ladders, vertical escape trunks, metal joiner bulkheads, and watertight and nonwatertight doors. This section represents an interior arrangement with at least as widely varied requirements for egress lighting as a typical ship. It also contains a number of different types of ship compartments.

For each compartment, RL light fixtures have been selected and positioned as self-luminous markers for the egress routes. Figures 1 through 5 locate all proposed RL lights and indicate the proposed egress routes. Depending on the illumination required, the RL light fixtures contain quantities of tritium ranging from $0.5 \mathrm{Ci}$ to $10 \mathrm{Ci}$ as indicated in the figure legends, where all symbols and markings are also defined.

\section{Selection of Egress Routes}

Selection of the most efficient evacuation routes on surface ships is dependent on the class of ship. In any "abandon ship" scenario, the prime 


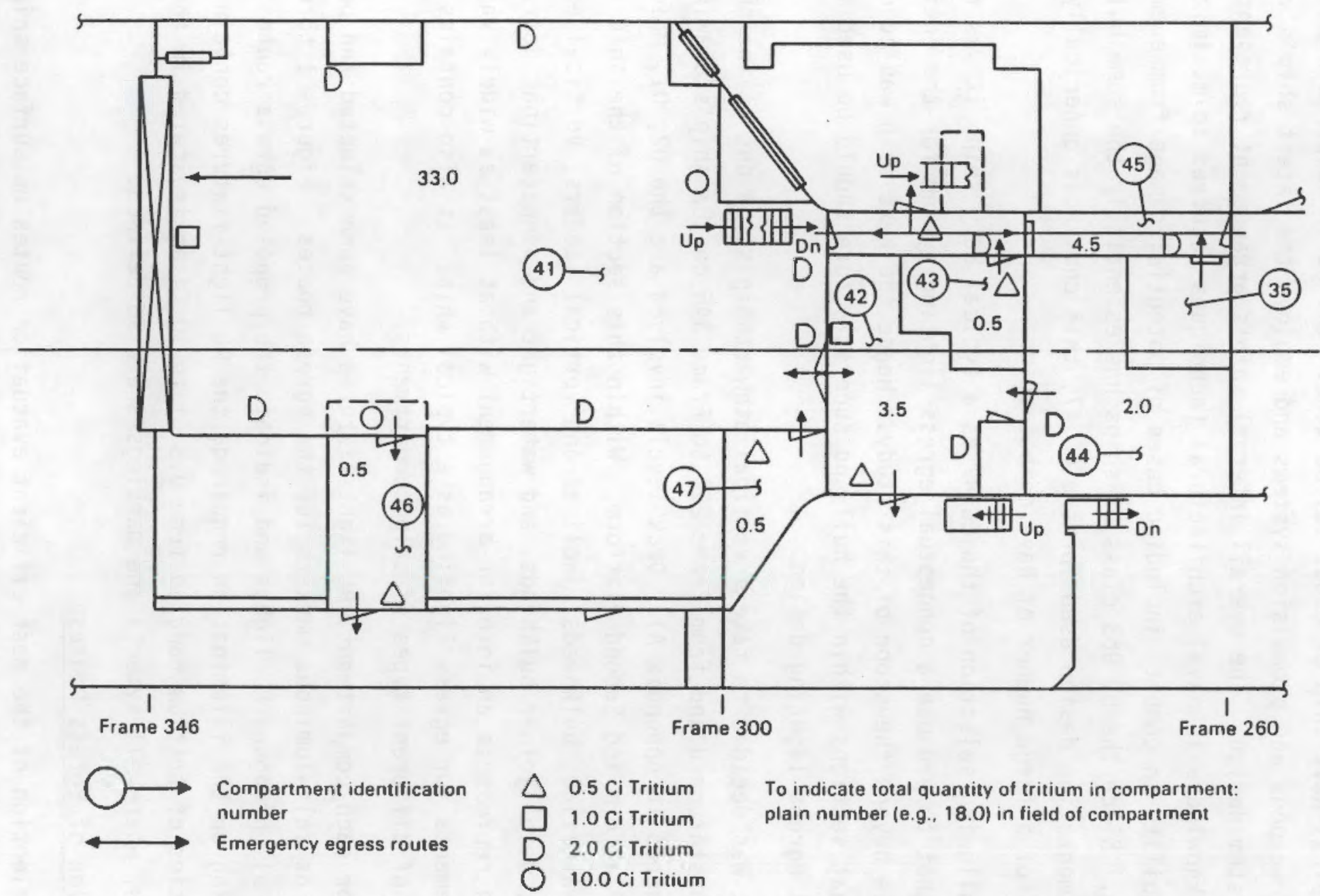

FIGURE 1. CG 47, 02 Level, Proposed RL Egress Lighting System 


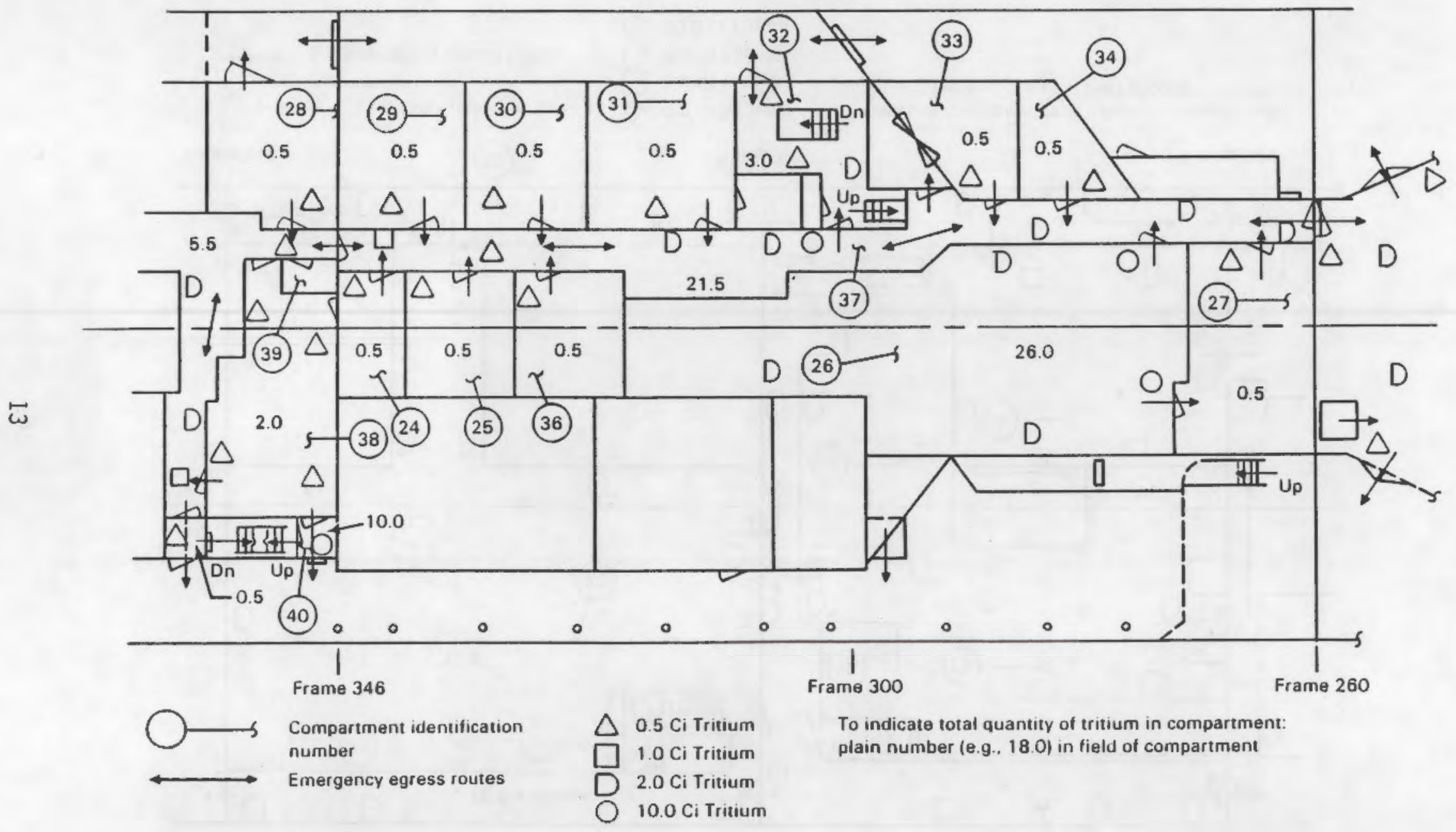

FIGURE 2. CG 47, 01 Level, Proposed RL Egress Lighting System 


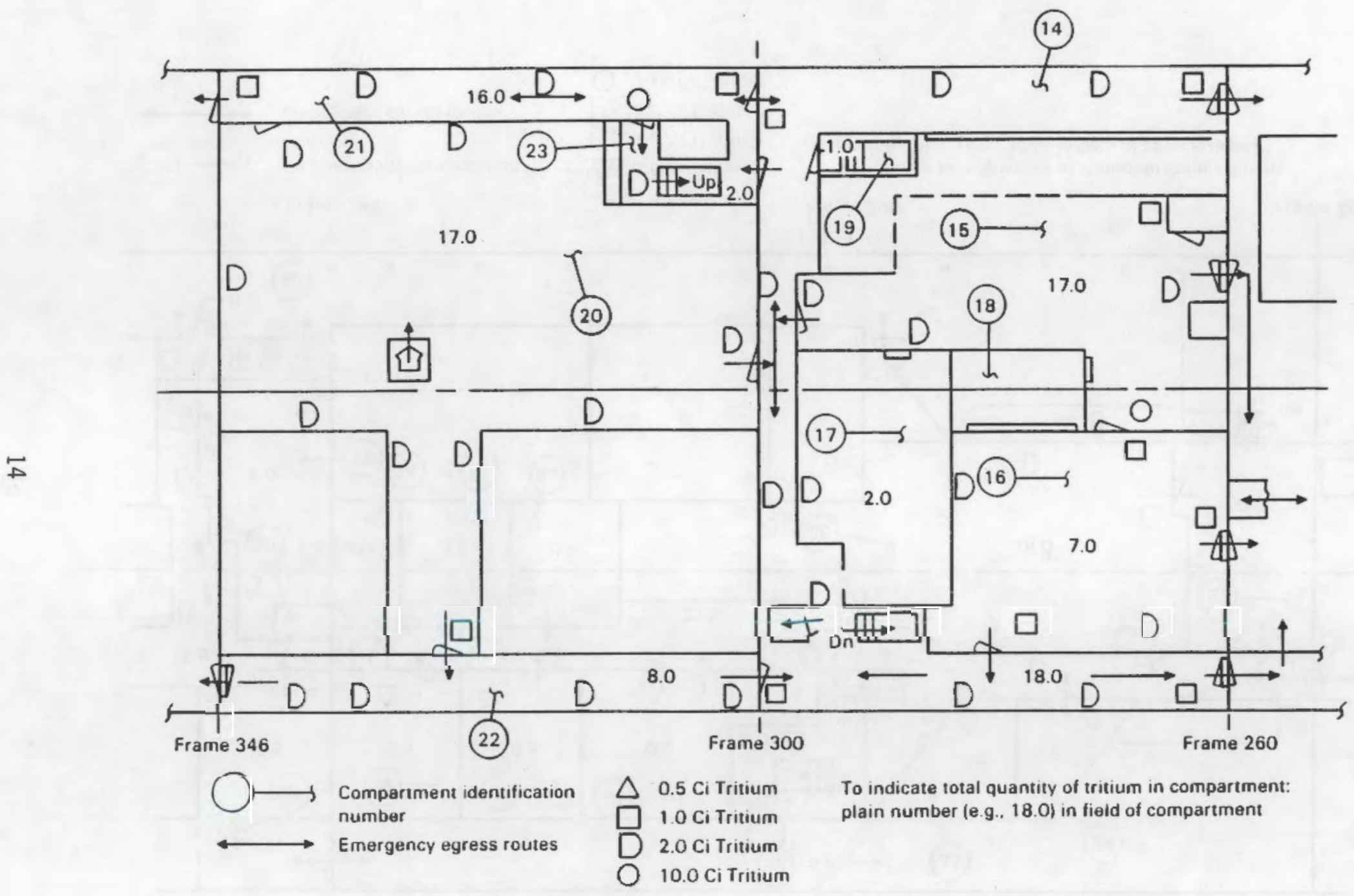

FIGURE 3. CG 47, Main Deck, Proposed RL Egress Lighting System 


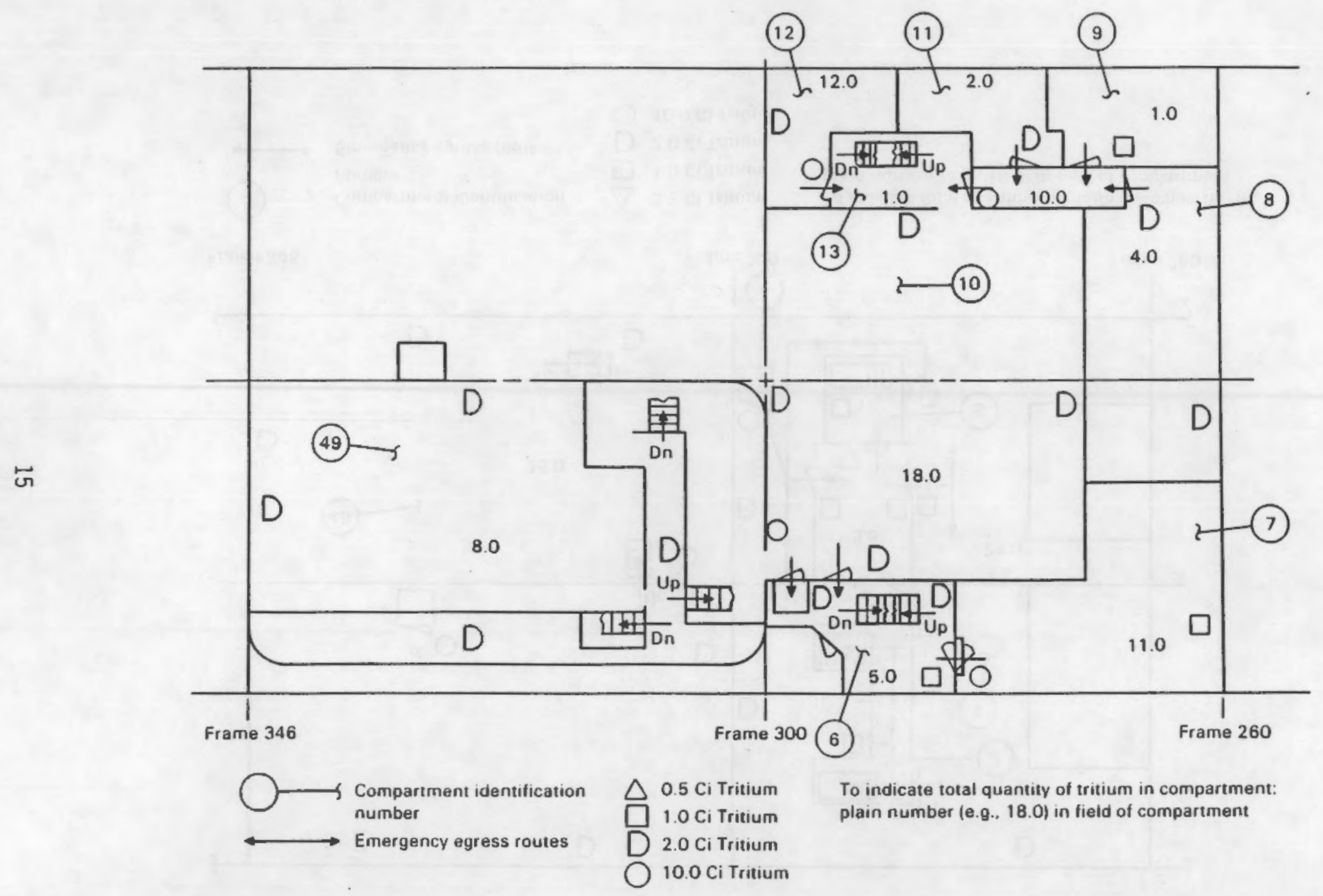

FIGURE 4. CG 47, First Platform, Proposed RL Egress Lighting System 


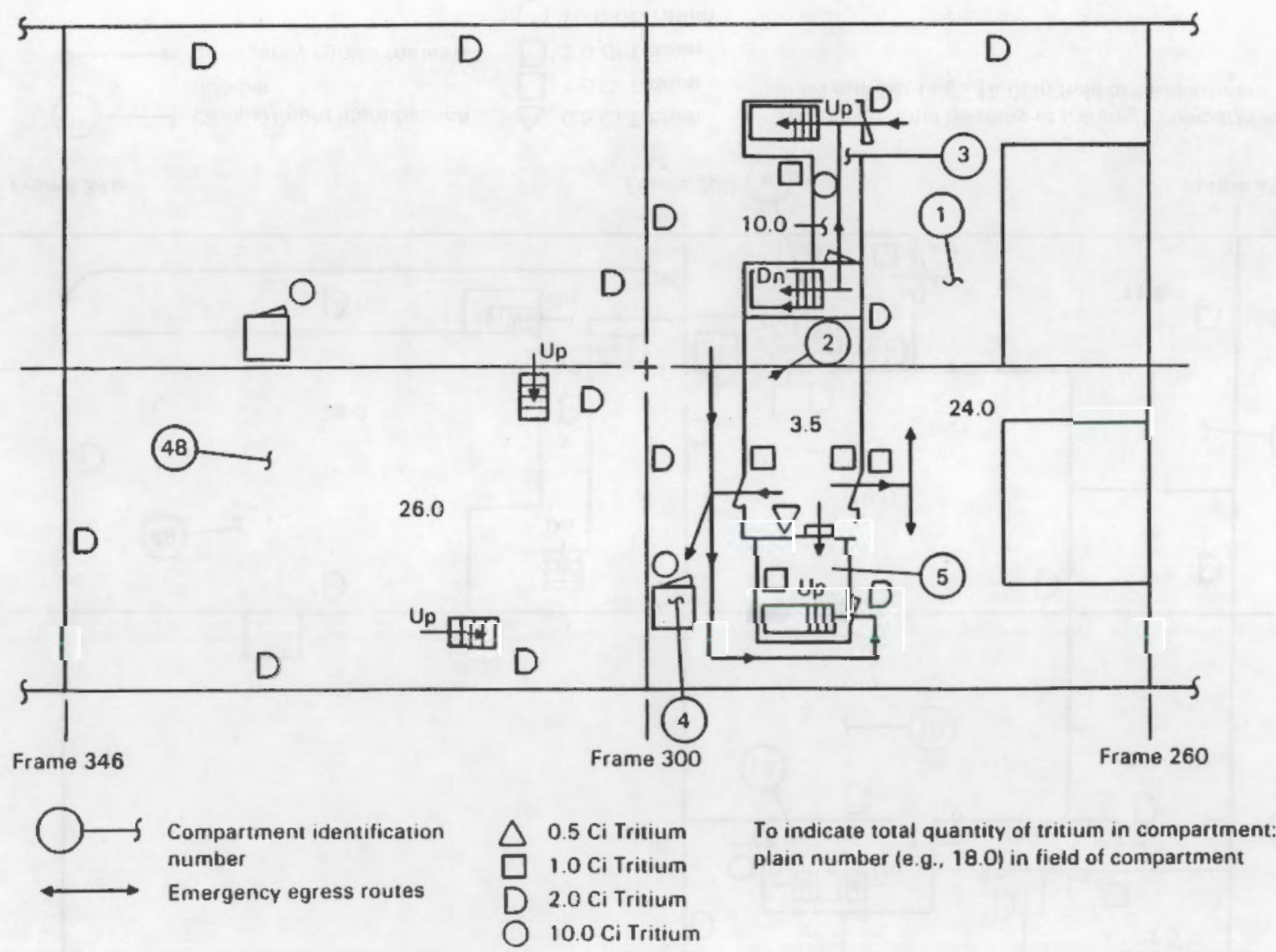

FIGURE 5. CG 47, Second Platform, Proposed RL Egress Lighting System 
goal is to provide the shortest egress routes for all crew members from any point in the ship to the locations of lifeboats or rafts. As indicated in Figures A.1 and A.2 (of Appendix A), the lifesaving craft for the CG 47 are located on the 02 and 01 levels. With this goal in mind, suggested egress routes are indicated on Figures 1 through 5 by directional arrows. Personnel located on the main deck or below would need to move up in the ship so that they could abandon the ship from the 01 or 02 levels.

Beyond this basic premise, the selection of realistic egress routes is largely a matter of judgement, and hence for the CG 47 other egress routes may be equally effective as those suggested here. For the egress routing proposed here, it is noted that a crew member departing a given compartment will usually have more than one choice for continuing the evacuation. All choices will be clearly indicated by appropriate RL lights. Any change in egress routes would require a corresponding change in the location of the lights.

\section{Selection of Radioluminescent Lights}

The choice of RL lights for this study was based on a combination of judgement and experience. Experience, including some qualitative experimentation, has shown that lights containing $0.5 \mathrm{Ci}$ to $10 \mathrm{Ci}$ of tritium are all visible and that some are legible from $40 \mathrm{ft}$ or more. It has also been demonstrated that the RL lights perform as well as, or better than, incandescent lights under smoky conditions. The relative brightness of the lights for specific locations on the ship was chosen based on an experienced naval architect's judgement of the minimum required at each location.

Most RL lights selected for the CG 47 section (Figures 1 through 5) contain tritium in quantities of $2 \mathrm{Ci}$ or less. The occasional 10-Ci lights were selected when increased legibility at greater distance was likely to be required. If there was any doubt as to the brightness required, the choice was always on the conservative side, that is, the higher number of curies. In this way the analyses on the safety of tritium RL lights would also be conservative. In any case, specific determinations of brightness criteria are best left to a feasibility demonstration using RL lights. 


\section{Types of Markers}

Figure 6 illustrates some of the many potential options for RL markers. The figure shows two basic types: 1) dark identification markers in a field illuminated by RL lights and 2) illuminated markings on a dark background. The latter type is generally preferred because its performance is equal or better, it requires less tritium, and the fixture design can provide more protection for the light tube. Figure 6 shows how the markers give ship's personnel a self-explanatory code by which they can readily determine their location and their next move toward safety. The direction one is facing is shown by horizontal or vertical lines. Triangles are ladders, circles are watertight doors, and squares are hatches. The numbers indicate deck level and could obviously be extended to "M" for main, and 01 or 02 for the upper deck.

Tests by sailors in a feasibility demonstration of RL lights may well show that simple directional arrows (Figure 6) provide adequate egress markings. Or tests may show that a combination of directional arrows and "dot" markers (at the bottom of Figure 6) is the optimum choice to identify escape routes. Whatever the final choice of markings, RL lights can be constructed in the preferred configurations using quantities of tritium within the limits of $10 \mathrm{Ci}$ set in this study.

\subsection{GENERAL CONCEPT FOR RADIOLUMINESCENT LIGHT DESIGN}

As stated earlier, the two primary concerns regarding the design of RL lights are performance and safety. It has now been qualitatively demonstrated that the RL lights proposed for the CG 47 will perform satisfactorily as shipboard egress lighting. Furthermore, under normal use the lights will continue to perform at the same level for at least 10 years with no external power required and essentially no maintenance. Now the design of the RL lights must be examined from the viewpoint of minimizing radiological safety hazard.

The design goal is to provide a light fixture very difficult to damage or destroy either mechanically or by fire or vandalism. This mechanical hardness greatly reduces the probability that the ship's crew will be exposed 


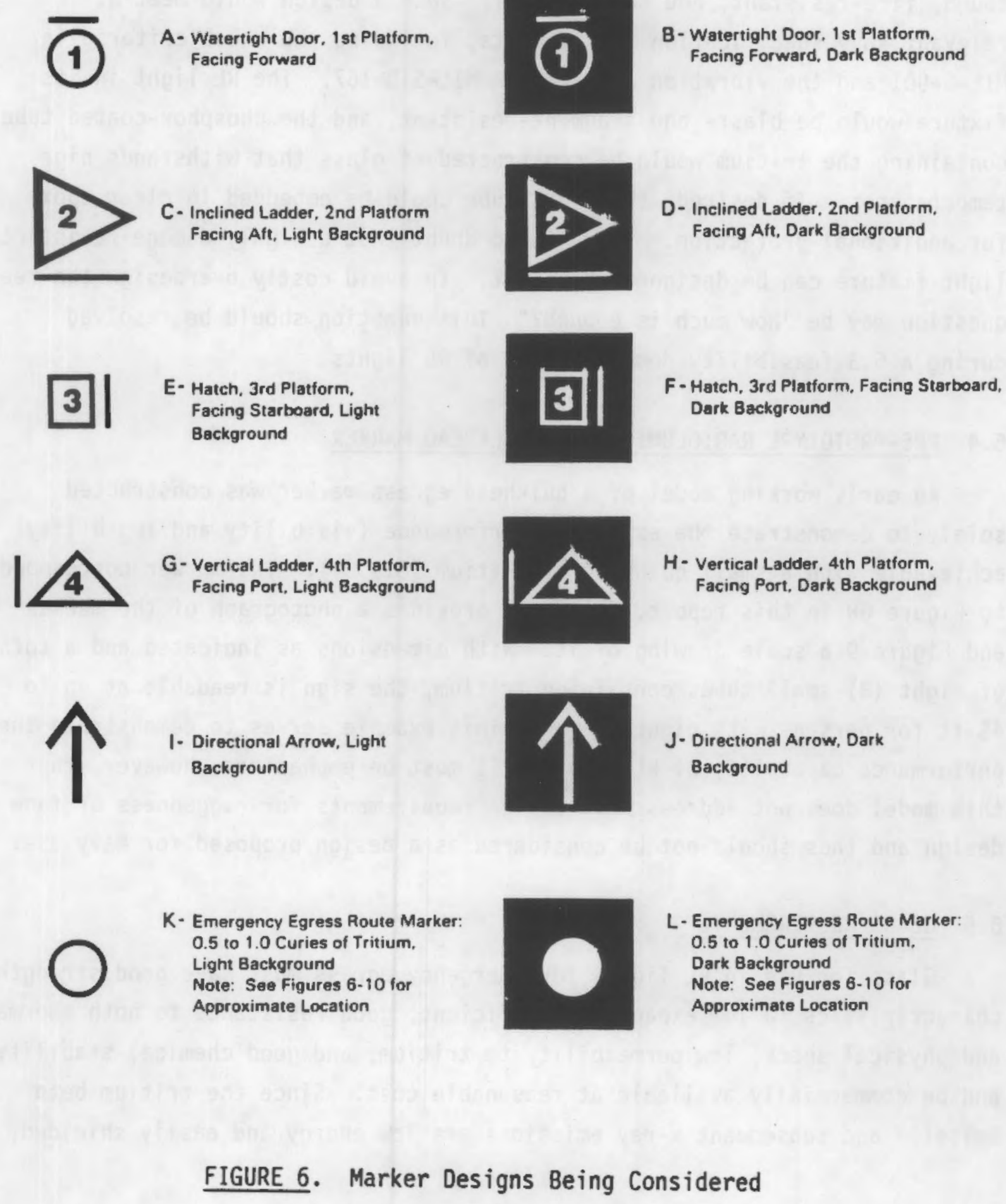


to radiation hazard from the lights. (The hazards of exposure and the mechanisms by which personnel might be exposed were discussed earlier under $\underline{\text { The }}$ Nature of the Risk.)

Figure 7 presents a design concept for an RL light that is mechanically tough, fire-resistant, and tamper-proof. Such a design would meet all relevant Navy specification requirements, including the shock criteria in MIL-S-901 and the vibration criteria in MIL-STD-167. The RL light in its fixture would be blast-and fragment-resistant, and the phosphor-coated tube containing the tritium would be constructed of glass that withstands high temperatures. If desired, the light tube could be embedded in clear epoxy for additional protection. There is no doubt that a highly damage-resistant light fixture can be designed and built. To avoid costly overdesign the real question may be "How much is enough?" This question should be resolved during a 6.3 feasibility demonstration of RL 1 ights.

\subsection{PRE-PROTOTYPE RADIOLUMINESCENT BULKHEAD MARKER}

An early working model of a bulkhead egress marker was constructed solely to demonstrate the extent of performance (visibility and legibility) achievable with a small quantity of tritium $(8.9 \mathrm{Ci})$. The marker corresponds to Figure $6 \mathrm{H}$ in this report. Figure 8 provides a photograph of the marker and Figure 9 a scale drawing of $i t$. With dimensions as indicated and a total of eight (8) small tubes containing tritium, the sign is readable at up to $45 \mathrm{ft}$ for persons with night vision. This example serves to demonstrate the performance capability of RL lights. It must be emphasized, however, that this model does not address Navy design requirements for ruggedness or face design and thus should not be considered as a design proposed for Navy use.

\subsection{GLASS REQUIREMENTS}

Glass for use in RL lights for emergency egress must have good strength characteristics, a low expansion coefficient, good resistance to both thermal and physical shock, low permeability to tritium, and good chemical stability, and be commercially available at reasonable cost. Since the tritium beta emission and subsequent $x$-ray emissions are low energy and easily shielded, 

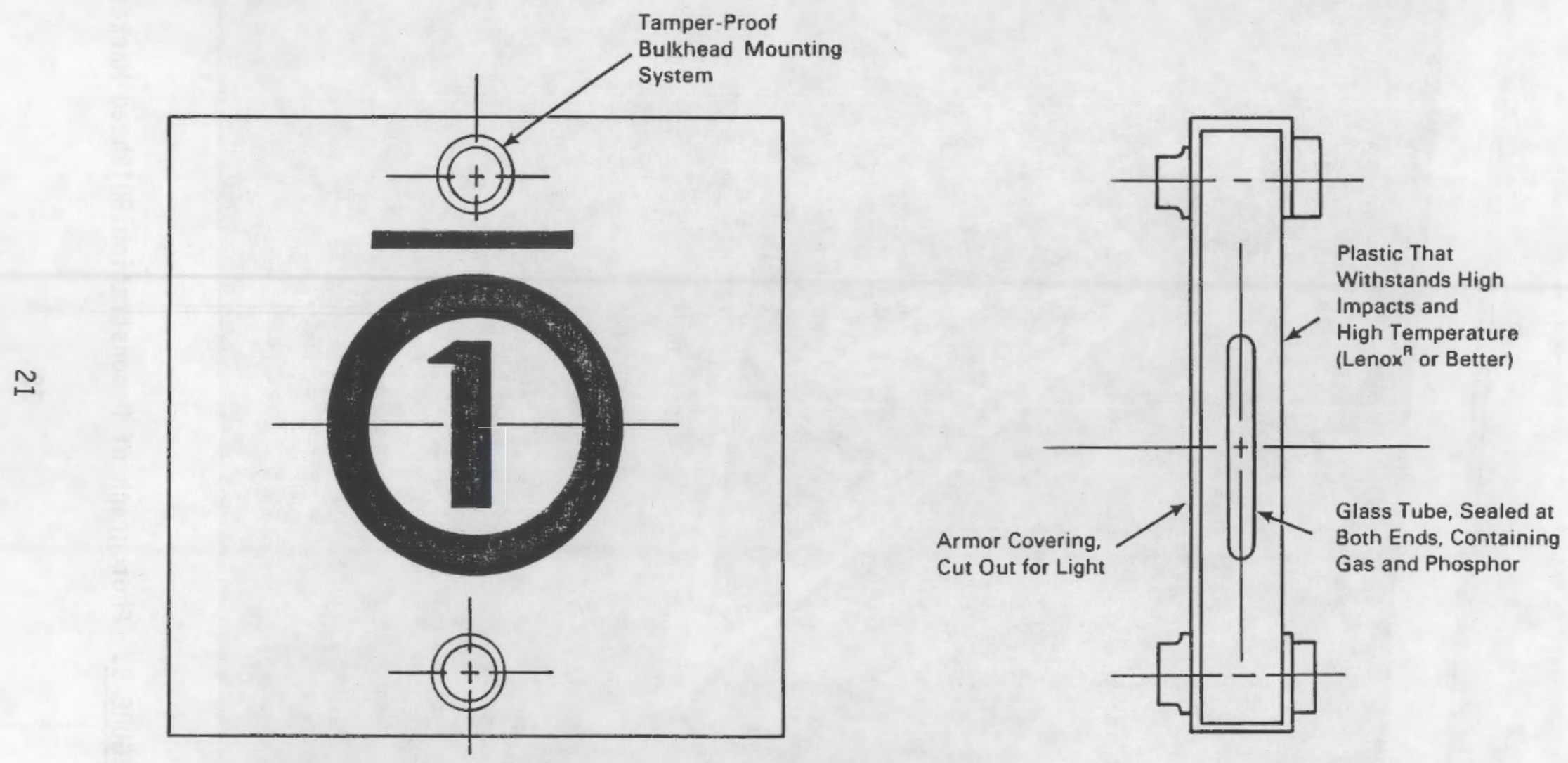

FIGURE 7. Design Concept for RL Fixture (designed to meet requirements of WR-11, MIL-S-901 and MIL-STD-167) 

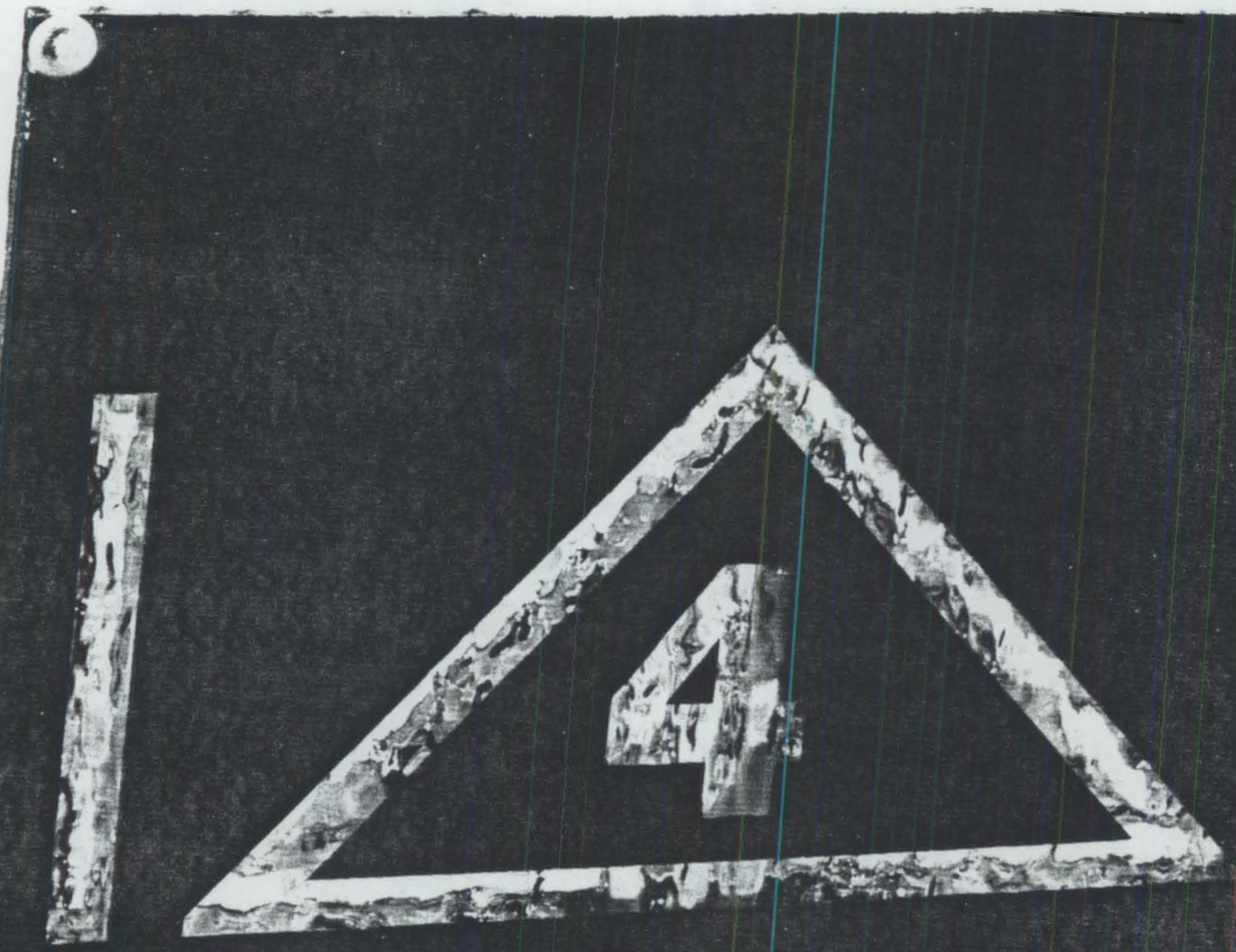

Trom

FIGURE 8. Photograph of Demonstration Bulkhead Marker 


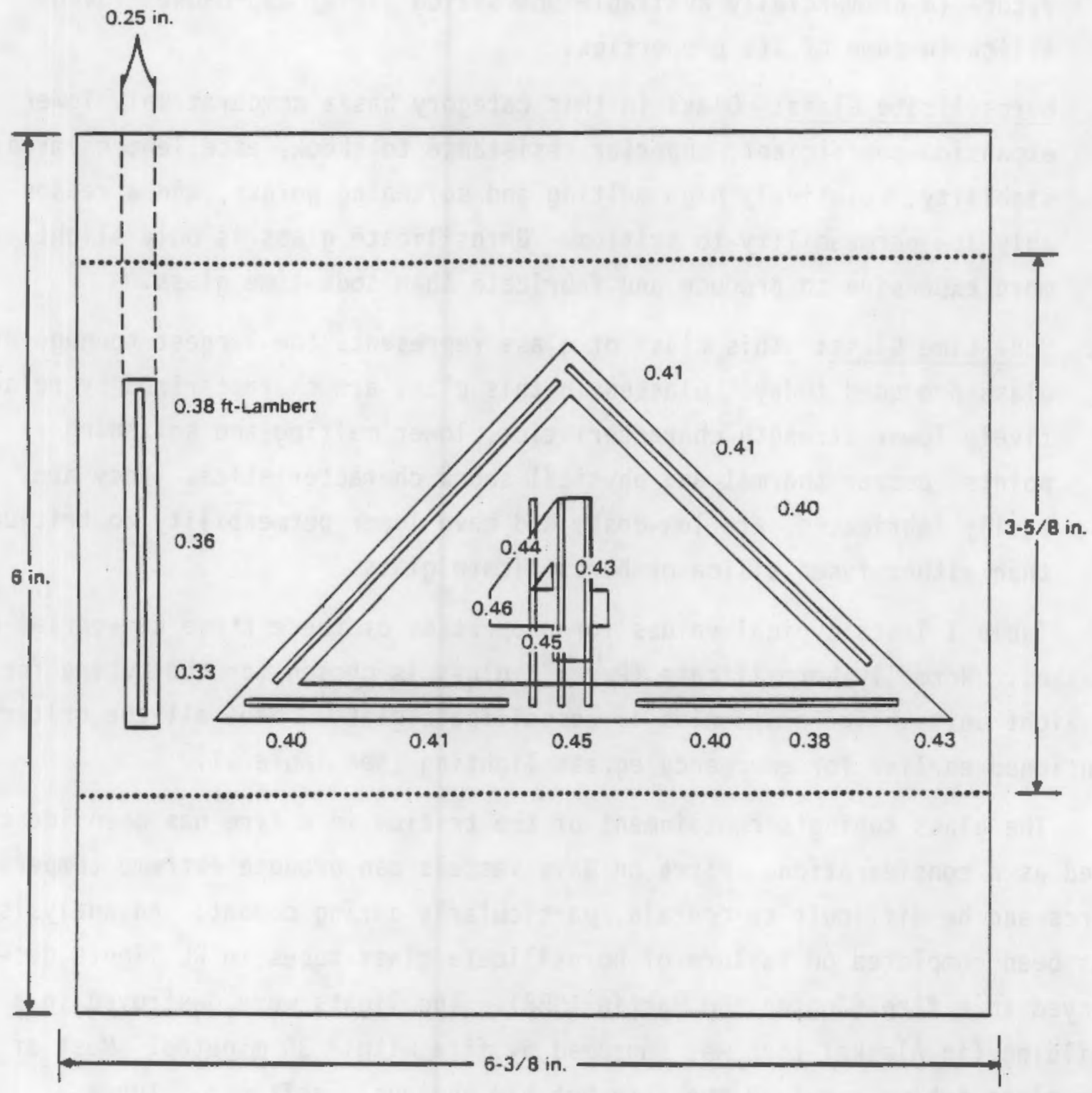

FIGURE 9. Drawing of Demonstration Bulkhead Marker

shielding properties are not a major consideration. In general, candidate glasses that could meet the above requirements fall into the following categories:

1. Fused or Vitreous Silica: Glasses in this category have high melting and softening points, low expansion coefficients, and good chemical resistance. They are, however, expensive and difficult to fabricate. 
Vycor $^{3}$ (a commercially available $96 \%$ silica glass) approaches fused silica in some of its properties.

2. Borosilicate Glass: Glass in this category has a comparatively lower expansion coefficient, superior resistance to shock, excellent chemical stability, relatively high melting and softening points, and a reasonably low permeability to tritium. Borosilicate glass is only slightly more expensive to produce and fabricate than soda-lime glass.

3. Soda-Lime Glass: This class of glass represents the largest tonnage of glass produced today. Glasses in this class are characterized by relatively lower strength characteristics, lower melting and softening points, poorer thermal and physical shock characteristics. They are easily fabricated, are low-cost, and have lower permeability to tritium than either fused silica or borosilicate glass.

Table 1 lists typical values for properties of these three categories of glasses. Normally borosilicate (Pyrex) glass is chosen for the tubing for RL light units. The properties of borosilicate glasses meet all the criteria mentioned earlier for emergency egress lighting (see Table 1).

The glass tubing's containment of the tritium in a fire has been identified as a consideration. Fires on Navy vessels can produce extreme temperatures and be difficult to contain, particularly during combat. An analysis has been completed on failure of borosilicate glass tubes in RL lights destroyed in a fire (Jensen and Martin 1988). The lights were destroyed in a building (in Alaska) that was consumed by fire within 30 minutes. Most of the glass tubing survived the fire but had obviously softened. Tubes appeared to fail by means of the tritium gas within increasing pressure to 2 or $3 \mathrm{~atm}$ and then escaping by blowing a small hole as the glass at a specific location reached its softening point. For borosilicate glass the softening point is near $820^{\circ} \mathrm{C}\left(1508^{\circ} \mathrm{F}\right)$. Most shipboard locations will not experience extreme temperature unless the fire is severe; thus borosilicate glass is expected to be adequate. For some specific locations in ships,

\footnotetext{
Vycor and Pyrex are registered trademarks of Corning Glass, Corning, New York.
} 
TABLE 1. Typical Properties of Conmercial Glasses

\begin{tabular}{|c|c|c|c|}
\hline Glass/Property & Soda-Lime & $\begin{array}{l}\text { Borosilicate } \\
\text { (Pyrex) }\end{array}$ & $\begin{array}{l}\text { Fused Silica } \\
\text { (Vycor) }\end{array}$ \\
\hline Softening Point, ${ }^{\circ} \mathrm{C}\left({ }^{\circ} \mathrm{F}\right)(\mathrm{a})$ & $696(1285)$ & $820(1508)$ & $1426(2600)$ \\
\hline Annealing Point, ${ }^{\circ} \mathrm{C}\left({ }^{\circ} \mathrm{F}\right)(\mathrm{a})$ & $399(750)$ & $552(1027)$ & $1074(1965)$ \\
\hline $\begin{array}{l}\text { Upper Use Temperature, }{ }^{\circ} \mathrm{C}\left({ }^{\circ} \mathrm{F}\right) \\
\text { (normal service) }(\mathrm{C})\end{array}$ & $110(230)$ & $230(446)$ & $1652(900)$ \\
\hline $\begin{array}{l}\text { Upper Use Temperature, }{ }^{\circ} \mathrm{C}\left({ }^{\circ} \mathrm{F}\right) \\
\text { (extreme service) }(\mathrm{d})\end{array}$ & $460(860)$ & $490(914)$ & $1200(2192)$ \\
\hline $\begin{array}{l}\text { Coefficient of Linear } \\
\text { Expansion, }{ }^{\circ} \mathrm{F}-1 \times 10^{-7}\end{array}$ & 92 & 18 & 54 \\
\hline $\begin{array}{l}\text { Permeability to Tritium (e) } \\
\text { mol } / \mathrm{m} \bullet \mathrm{s} \bullet \mathrm{Pa}\end{array}$ & $1.7 \cdot 10^{-23}$ & $1.2 \cdot 10^{-21}$ & $3.5 \cdot 10^{-20}$ \\
\hline Specific Gravity(a) & 2.47 & 2.23 & 2.18 \\
\hline $\begin{array}{l}\text { Thermal Shock Resistance }(\mathrm{b}) \\
\text { Plates } 15 \times 15 \mathrm{~cm} \text { and } \\
3.2 \mathrm{~mm} \text { thick, }{ }^{\circ} \mathrm{C}(\mathrm{f})\end{array}$ & 65 & 60 & -- \\
\hline
\end{tabular}

(a) Ref. Shreve and Brink, Table 11.3, p. 183.

(b) Ref. Kirk and Othmer, Table 4, p. 828.

(c) No breakage from excessive thermal shock is assumed.

(d) Glass is subject to breakage from thermal shock. Data are approximate, and additional testing for stability is required before final design is established.

(e) Ref. Souers, Table B.1, p. 371.

(f) Based on plunging heated sample into cold water. For example: A value of 100 means that no breakage occurs after heating sample to $110^{\circ} \mathrm{C}$ and plunging it into cold water at $10^{\circ} \mathrm{C}$.

however, where very high temperatures might be encountered, a silica glass such as vycor may be needed. Benefit against cost and fabricability would have to be carefully evaluated for these applications.

Tritium diffusion out of tubing was another concern expressed in discussions with Navy radiation protection personnel. As shown in Table 1, fused silica, borosilicate, and soda-lime glass differ in permeability to tritium 
by three orders of magnitude. The permeability rate is dependent on the percentage of network formers in the glass. Network formers are the materials that form the lattice holding the glass together; non-network formers disrupt this lattice and give an individual glass its desirable properties. Fused silica glass, Vycor, and to a degree borosilicate glass, Pyrex, have the highest permeabilities for tritium and contain low quantities of nonnetwork formers. Increasing the percent of non-network formers in the glass as is done in soda-lime glass decreases the permeability of a glass as long as silica is the main ingredient and the percentage of non-network formers does not exceed $30 \%$ (Souers 1986). Thus soda-lime glasses have lower permeabilities than either fused silica, vycor, or borosilicate glass.

Permeation data are very unreliable for use with diffusion calculations. Since they are ordinarily not obtained at ambient temperatures but at several hundred degrees centigrade, their extrapolation to room temperature produces large errors in permeability values. As a result, using these values for diffusion calculations will nearly always show a much higher loss of tritium than is actual (Souers 1986). This assertion is borne out in recent work reported by 0ak Ridge Laboratory (Tompkins et al. 1988) for RL lights. This work showed that the real diffusion of tritium from glass tubing at room temperature is at least four orders of magnitude below that calculated from extrapolated permeability data and produces a negligible tritium loss.

In surmary, it appears that existing borosilicate glass will meet nearly all requirements for emergency egress lighting except where very high temperature will be encountered during normal operations. For these specific hightemperature applications, high-silica glasses such as vycor are an aiternative and could meet the criteria for strength, service temperature, etc.

\subsection{RADIOLOGICAL ASSESSMENT}

\subsection{DOSE ASSESSMENT FOR DIFFUSION AND BREAKAGE}

The use of tritium RL egress lights, as proposed in this study, presents minimal and acceptable radiological safety risks to the ship's crew. To illustrate this point, three situations are proposed and analyzed using the CG 47 egress lighting system in Figures 1 through 5 as the model. As the 
analysis required knowledge of the ship's ventilation system, the CG 47 ventilation requirements were obtained from its Air Conditioning, Ventilation and Heating Design Criteria Manual (NAVSEA 1987).

The 49 ship compartments shown in Figures 1 through 5 are listed in Table 2, the System Information Data Sheet. For each space listed, Table 2 provides the following information: 1) compartment identification number; 2) compartment description; 3) type of ventilation system; 4) air exchange rate in cubic feet per minute; and 5) number of curies of tritium per compartment. In determining each compartment's volume, it was assumed that the bulkhead height was $7 \mathrm{ft}$ and that the volume was not reduced by the equipment contained there.

Appendix $B$ provides the reader background on understanding radiation dosimetry, and Appendix $C$ describes the calculation methods used to estimate the doses that are shown in the tables in this section.

The assumptions made in the following three noncombat situations were chosen to be excessively conservative. Even so, the maximum radiation dose from tritium, under the Code of Federal Regulations (CFR) 10CFR32.24, was never exceeded for crew members in any ship's compartment, not even for the worst case wherein all fixtures were broken. These results indicate that it should be possible to manufacture these lights as exempt items.

Diffusion Through Glass

Elemental hydrogen will diffuse through most items, including the glass walls of the tubes (see Appendix C; Souers 1986; and Niemeyer 1969). Hydrogen diffuses through glass as a molecule $\left(\mathrm{T}_{2}\right)$, rather than as an atom ( $T$ ): consequently, it is reasonable to assume that tritium that has diffused through glass will remain as a $T_{2}$ molecule and will emerge in the gaseous state rather than form water as it exits the glass tubes. As the tritium diffuses through the glass, the tritium concentration in a space will build up with time. Because the space is ventilated, the tritium concentration will eventually reach a steady state. At this time the tritium entering the space by diffusing through the glass will equal that being removed by ventilation. Thus the tritium concentration at steady state depends on the number of lights in the space, the size of the space, and the ventilation rate. 
TABLE 2. CG 47 System Information Data Sheet

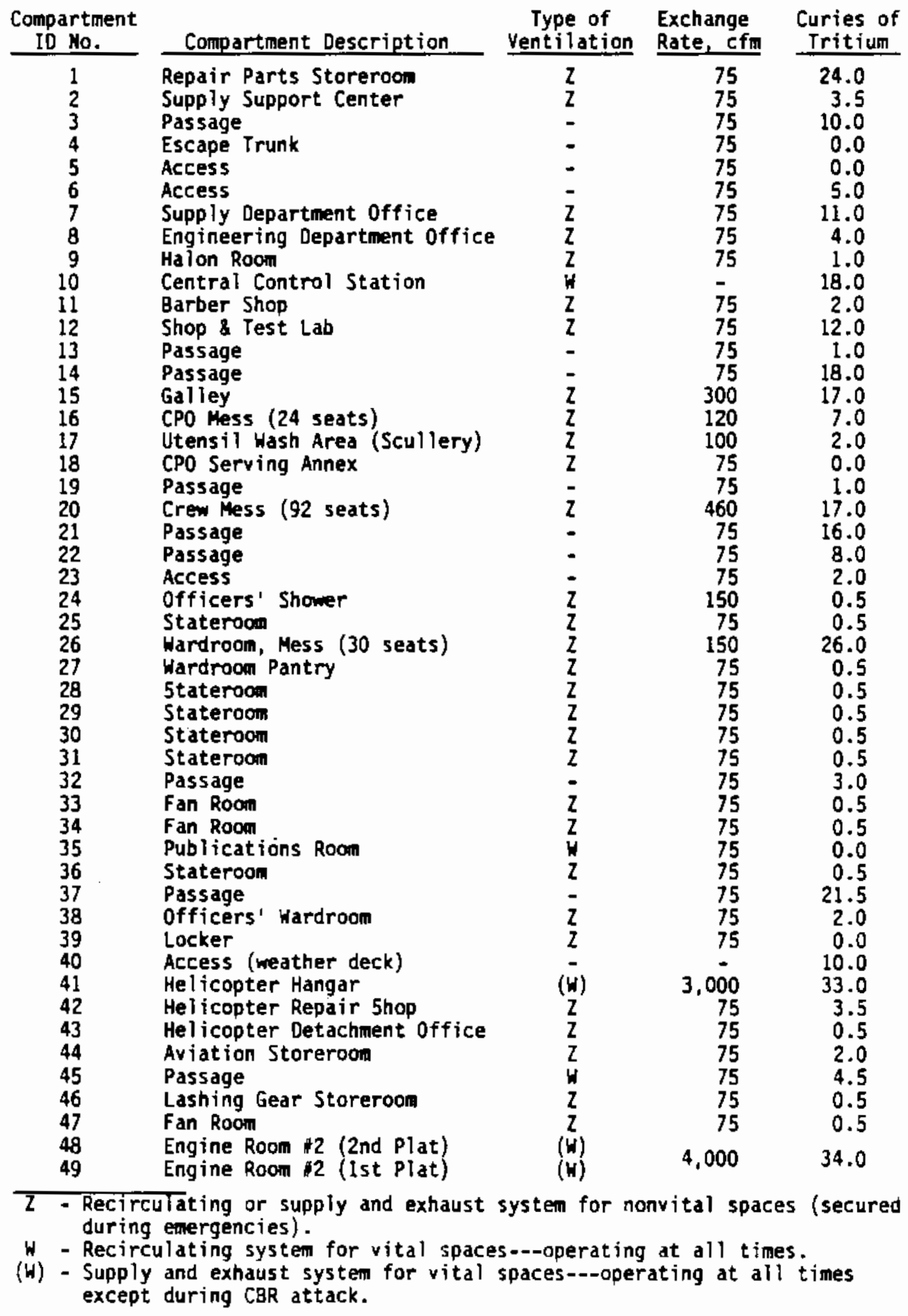


The estimate of the committed effective dose equivalents to individuals from tritium that has diffused through glass is based on the following assumptions:

1. The individual is exposed to the equilibrium concentration of tritium that will be attained in the first or second year that the lights are in the space.

2. The individuat is exposed to the tritium gas for one calendar year.

3. No allowance is made for decreased permeation due to tritium decay during the year of exposure.

The results of the calculations are shown in Table 3 . All computed doses are extremely smal1, on the order of tens of nanorem. They are well below the value 0.001 rem that is required by 10CFR32.24 for maximum doses to individuals during routine use of exempt quantities of tritium in selfluminous devices. Due to the small doses, further discussion of this case is not warranted. It is appropriate, however, to provide a brief explanation of the safety criteria set forth in the Code of Federal Regulations.

The government has set forth safety criteria for applicants for licenses of products containing radioactive materials in 10CFR32.23 and 10CFR32.24. In effect, the applicant must prove it is uniikely that radiation exposure in any one year will exceed the following specified doses for whole body exposure for four different circumstances: I - normal usage $(0.001$ rem); II - normal handling and storage $(0.01 \mathrm{rem})$; III - failure of containment or shielding for a single unit $(0.5 \mathrm{rem})$; and IV - failure of containment or shielding for all units in a space $(15.0 \mathrm{rem})$. For other parts of the body (hands, feet, etc.) and for some body organs, the allowable doses are several orders of magnitude higher.

Destruction of One Light in Each Compartment

Accidents can possibly happen that will compromise the lights' integrity. The doses from tritium consequent to an accident of this type have been estimated, employing the following assumptions: 
TABLE 3. Effective Dose Equivalent from Tritium Gas Diffusing Through Glass Tubes. No oxidation of the tritium gas.

\begin{tabular}{|c|c|c|c|c|}
\hline $\begin{array}{l}\text { Compartment } \\
\text { ID No. }\end{array}$ & $\begin{array}{l}\text { Ventilation } \\
\text { Rate, cfm }\end{array}$ & $\begin{array}{l}\text { Compartment } \\
\text { Volume, } \mathrm{ft}^{3} \\
\end{array}$ & $\begin{array}{l}\text { Activity, } \\
\text { Ci } \\
\end{array}$ & $\begin{array}{l}\text { Conmitted Dose, } \\
\text { rem }(0=1.7) \\
\end{array}$ \\
\hline $\begin{array}{r}1 \\
2 \\
3 \\
4 \\
5 \\
6 \\
7 \\
8 \\
9 \\
10 \\
11 \\
12 \\
13 \\
14 \\
15 \\
16 \\
17 \\
18 \\
19 \\
20 \\
21 \\
22 \\
23 \\
24 \\
25 \\
26 \\
27 \\
28 \\
29 \\
30 \\
31\end{array}$ & $\begin{array}{r}75 \\
75 \\
75 \\
75 \\
75 \\
75 \\
75 \\
75 \\
75 \\
75 \\
75 \\
75 \\
75 \\
75 \\
300 \\
120 \\
100 \\
75 \\
75 \\
460 \\
75 \\
75 \\
75 \\
150 \\
75 \\
150 \\
75 \\
75 \\
75 \\
75 \\
75 \\
75 \\
75 \\
75 \\
75 \\
75 \\
75 \\
75 \\
75 \\
3,000 \\
75 \\
75 \\
75 \\
75 \\
75 \\
75 \\
4,000\end{array}$ & $\begin{array}{r}10,473 \\
1,259 \\
755 \\
113 \\
358 \\
740 \\
2,380 \\
2,293 \\
826 \\
6,559 \\
579 \\
739 \\
882 \\
4,908 \\
4,034 \\
3,593 \\
541 \\
516 \\
161 \\
7,485 \\
1,147 \\
1,577 \\
194 \\
636 \\
882 \\
5,040 \\
1,140 \\
961 \\
946 \\
946 \\
985 \\
735 \\
1,051 \\
466 \\
882 \\
2,488 \\
1,429 \\
1 \\
315 \\
33,906 \\
1,285 \\
645.3 \\
1,692 \\
1,032 \\
1,233 \\
803 \\
29,000\end{array}$ & $\begin{array}{c}24 \\
3.5 \\
10 \\
0 \\
0 \\
5 \\
11 \\
4 \\
1 \\
18 \\
2 \\
12 \\
1 \\
18 \\
10 \\
7 \\
2 \\
0 \\
1 \\
17 \\
16 \\
8 \\
2 \\
0.5 \\
0.5 \\
26 \\
0.5 \\
0.5 \\
0.5 \\
0.5 \\
0.5 \\
3 \\
0.5 \\
0.5 \\
0.5 \\
21.5 \\
2 \\
0 \\
10 \\
33 \\
3.5 \\
0.5 \\
2 \\
4.5 \\
0.5 \\
0.5 \\
34.0\end{array}$ & $\begin{array}{l}2.47 \mathrm{E}-07 \\
3.53 \mathrm{E}-08 \\
1.06 \mathrm{E}-07 \\
1.76 \mathrm{E}-08 \\
1.76 \mathrm{E}-08 \\
5.29 \mathrm{E}-08 \\
1.06 \mathrm{E}-07 \\
5.29 \mathrm{E}-08 \\
1.76 \mathrm{E}-08 \\
1.76 \mathrm{E}-07 \\
3.53 \mathrm{E}-08 \\
1.24 \mathrm{E}-07 \\
1.76 \mathrm{E}-08 \\
1.76 \mathrm{E}-07 \\
2.65 \mathrm{E}-08 \\
4.41 \mathrm{E}-08 \\
2.65 \mathrm{E}-08 \\
1.76 \mathrm{E}-08 \\
1.76 \mathrm{E}-08 \\
2.59 \mathrm{E}-08 \\
1.59 \mathrm{E}-07 \\
8.82 \mathrm{E}-08 \\
3.53 \mathrm{E}-08 \\
8.82 \mathrm{E}-09 \\
1.76 \mathrm{E}-08 \\
1.24 \mathrm{E}-07 \\
1.76 \mathrm{E}-08 \\
1.76 \mathrm{E}-08 \\
1.76 \mathrm{E}-08 \\
1.76 \mathrm{E}-08 \\
1.76 \mathrm{E}-08 \\
3.53 \mathrm{E}-08 \\
1.76 \mathrm{E}-08 \\
1.76 \mathrm{E}-08 \\
1.76 \mathrm{E}-08 \\
1.94 \mathrm{E}-07 \\
3.53 \mathrm{E}-08 \\
1.76 \mathrm{E}-08 \\
1.06 \mathrm{E}-07 \\
7.50 \mathrm{E}-09 \\
3.53 \mathrm{E}-08 \\
1.76 \mathrm{E}-08 \\
3.53 \mathrm{E}-08 \\
5.29 \mathrm{E}-08 \\
1.76 \mathrm{E}-08 \\
1.76 \mathrm{E}-08 \\
5.96 \mathrm{E}-09\end{array}$ \\
\hline
\end{tabular}


1. In each space, the light fixture with the largest amount of tritium is broken. The tritium is instantaneously distributed through the space and is removed at the normal air turnover rate.

2. Of the activity in the lights, $1 \frac{\circ}{6}$ is in the form of tritiated water.

3. The individual receiving the dose remains in the area for an infinite time.

The results of the calculations are shown in Table 4 . The doses for all spaces are less than the value $(0.5$ rem) given in 10CFR32.24 as maximum dose that may be received consequent to an accident that has a low probability of occurrence (i.e., less than one accident per year for $10^{4}$ units). Destruction of All Fixtures in a Space

This accident is similar to the previous one except that it is now assumed that all fixtures in a space are broken. The remaining assumptions are identical to those for the previous accident.

The results of the calculations are shown in Table 5 . In this case as well, the doses for all spaces are below even the value $(0.5 \mathrm{rem})$ given in 10CFR32.24 as the maximum dose that may be received consequent to an accident that has a low probability of occurrence (i.e., less than one accident per year for $10^{4}$ units).

\subsection{DOSE ASSESSMENT FOR FIRES AND MISSILE HIT}

The risks associated with the normal diffusion of tritium through glass have been analyzed and discussed. The risks associated with the release of tritium from one or all proposed RL devices in a ship's space were also analyzed. In all cases, it was shown that radiation doses resulting from the tritium release were always below the acceptable guidelines listed in the Code of Federal Regulations. However, the real radiation hazards could potentially occur as a result of fires or combat damage.

Presented in this section are the estimated radiation doses to individuals consequent to major accidents involving RL egress markers. In all cases it is assumed that the ship is ventilated via a one-pass type system. This means that air is brought into the ship, is heated or cooled as 
TABLE 4. Effective Dose Equivalent Due to Breakage of Single Largest Activity Device in a Space

\begin{tabular}{|c|c|c|c|c|c|}
\hline $\begin{array}{l}\text { Compartment } \\
\text { I0 No. }\end{array}$ & $\begin{array}{l}\text { Ventilation } \\
\text { Rate, cfin }\end{array}$ & $\begin{array}{l}\text { Compartment } \\
\text { Volume, } \mathrm{ft}^{3} \\
\end{array}$ & $\begin{array}{c}\text { Activity, } \\
\mathrm{Ci}\end{array}$ & $\begin{array}{l}\text { Dose from } \\
\text { Gas, rem } \\
(0=1.7) \\
\end{array}$ & $\begin{array}{l}\text { Dose from } \\
\text { Water, rem } \\
(0=1.7)\end{array}$ \\
\hline $\begin{array}{r}1 \\
2 \\
3 \\
4 \\
5 \\
6 \\
7 \\
8 \\
9 \\
10 \\
11 \\
12 \\
13 \\
14 \\
15 \\
16 \\
17 \\
18 \\
19 \\
20 \\
21 \\
22 \\
23 \\
24 \\
25 \\
26 \\
27 \\
28 \\
29 \\
30 \\
31 \\
32 \\
33 \\
34 \\
36 \\
37 \\
38 \\
39 \\
40 \\
41 \\
42 \\
43 \\
44 \\
45 \\
46 \\
47 \\
48 / 49\end{array}$ & 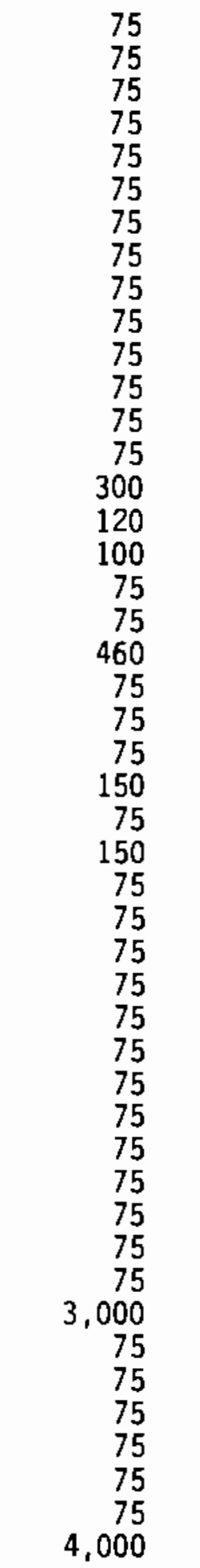 & $\begin{array}{r}10,473 \\
1,259 \\
755 \\
113 \\
358 \\
740 \\
2,380 \\
2,293 \\
826 \\
6,559 \\
579 \\
739 \\
882 \\
4,908 \\
4,034 \\
3,593 \\
541 \\
516 \\
161 \\
7,485 \\
1,147 \\
1,577 \\
194 \\
636 \\
882 \\
5,040 \\
1,140 \\
961 \\
946 \\
946 \\
985 \\
735 \\
1,051 \\
466 \\
882 \\
2,488 \\
1,429 \\
1 \\
315 \\
33,906 \\
1,285 \\
645.3 \\
1,692 \\
1,032 \\
1,233 \\
803 \\
29,000\end{array}$ & $\begin{array}{c}10 \\
1 \\
10 \\
0 \\
0 \\
2 \\
10 \\
2 \\
1 \\
10 \\
2 \\
10 \\
1 \\
2 \\
2 \\
2 \\
2 \\
0 \\
1 \\
2 \\
2 \\
2 \\
2 \\
0.5 \\
0.5 \\
1 \\
0.5 \\
0.5 \\
0.5 \\
0.5 \\
0.5 \\
2 \\
0.5 \\
0.5 \\
0.5 \\
10 \\
0.5 \\
0 \\
10 \\
10 \\
2 \\
0.5 \\
2 \\
2 \\
0.5 \\
0.5 \\
10.0\end{array}$ & $\begin{array}{l}1.01 \mathrm{E}-03 \\
1.01 \mathrm{E}-04 \\
1.01 \mathrm{E}-03 \\
0.00 \mathrm{E}+00 \\
0.00 \mathrm{E}+00 \\
2.02 \mathrm{E}-04 \\
1.01 \mathrm{E}-03 \\
2.02 \mathrm{E}-04 \\
1.01 \mathrm{E}-04 \\
1.01 \mathrm{E}-03 \\
2.02 \mathrm{E}-04 \\
1.01 \mathrm{E}-03 \\
1.01 \mathrm{E}-04 \\
2.02 \mathrm{E}-04 \\
5.04 \mathrm{E}-05 \\
1.26 \mathrm{E}-04 \\
1.51 \mathrm{E}-04 \\
0.00 \mathrm{E}+00 \\
1.01 \mathrm{E}-04 \\
3.29 \mathrm{E}-05 \\
2.02 \mathrm{E}-04 \\
2.02 \mathrm{E}-04 \\
2.02 \mathrm{E}-04 \\
2.52 \mathrm{E}-05 \\
5.54 \mathrm{E}-05 \\
5.04 \mathrm{E}-05 \\
5.04 \mathrm{E}-05 \\
5.04 \mathrm{E}-05 \\
5.04 \mathrm{E}-05 \\
5.04 \mathrm{E}-05 \\
5.04 \mathrm{E}-05 \\
2.02 \mathrm{E}-04 \\
5.04 \mathrm{E}-05 \\
5.04 \mathrm{E}-05 \\
5.04 \mathrm{E}-05 \\
1.01 \mathrm{E}-03 \\
5.04 \mathrm{E}+05 \\
0.00 \mathrm{E}+00 \\
1.01 \mathrm{E}-03 \\
2.52 \mathrm{E}-05 \\
2.02 \mathrm{E}-04 \\
5.04 \mathrm{E}-05 \\
2.02 \mathrm{E}-04 \\
2.02 \mathrm{E}-04 \\
5.04 \mathrm{E}-05 \\
5.04 \mathrm{E}-05 \\
1.89 \mathrm{E}-05\end{array}$ & $\begin{array}{l}2.02 \mathrm{E}-01 \\
2.02 \mathrm{E}-02 \\
2.02 \mathrm{E}-01 \\
0.00 \mathrm{E}+00 \\
0.00 \mathrm{E}+00 \\
4.03 \mathrm{E}-02 \\
2.02 \mathrm{E}-01 \\
4.03 \mathrm{E}-02 \\
2.02 \mathrm{E}-02 \\
2.02 \mathrm{E}-01 \\
4.03 \mathrm{E}-02 \\
2.02 \mathrm{E}-01 \\
2.02 \mathrm{E}-02 \\
4.03 \mathrm{E}-02 \\
1.01 \mathrm{E}-02 \\
2.52 \mathrm{E}-02 \\
3.02 \mathrm{E}-02 \\
0.00 \mathrm{E}+00 \\
2.02 \mathrm{E}-02 \\
6.57 \mathrm{E}-03 \\
4.03 \mathrm{E}-02 \\
4.03 \mathrm{E}-02 \\
4.03 \mathrm{E}-02 \\
5.04 \mathrm{E}-03 \\
1.01 \mathrm{E}-02 \\
1.01 \mathrm{E}-02 \\
1.01 \mathrm{E}-02 \\
1.01 \mathrm{E}-02 \\
1.01 \mathrm{E}-02 \\
1.01 \mathrm{E}-02 \\
1.01 \mathrm{E}-02 \\
4.03 \mathrm{E}-02 \\
1.01 \mathrm{E}-02 \\
1.01 \mathrm{E}-02 \\
1.01 \mathrm{E}-02 \\
2.02 \mathrm{E}-01 \\
1.01 \mathrm{E}-02 \\
0.00 \mathrm{E}+00 \\
2.02 \mathrm{E}-01 \\
5.04 \mathrm{E}-03 \\
4.03 \mathrm{E}-02 \\
1.01 \mathrm{E}-02 \\
4.03 \mathrm{E}-02 \\
4.03 \mathrm{E}-02 \\
1.01 \mathrm{E}-02 \\
1.01 \mathrm{E}-02 \\
3.78 \mathrm{E}-03\end{array}$ \\
\hline
\end{tabular}


TABLE 5. Effective Dose Equivalent Due to Breakage of All Radioluminescent Devices in a Space

\begin{tabular}{|c|c|c|c|c|c|}
\hline $\begin{array}{l}\text { Compartment } \\
\text { ID No. } \\
\end{array}$ & $\begin{array}{l}\text { Ventilation } \\
\text { Rate, cfm }\end{array}$ & $\begin{array}{l}\text { Compartment } \\
\text { Volume, } \mathrm{ft}^{3} \\
\end{array}$ & $\begin{array}{c}\text { Activity, } \\
\mathrm{Ci}\end{array}$ & $\begin{array}{c}\text { Dose from } \\
\text { Gas, rem } \\
(Q=1.7) \\
\end{array}$ & $\begin{array}{l}\text { Dose from } \\
\text { Water, rem } \\
(0=1.7)\end{array}$ \\
\hline $\begin{array}{r}1 \\
2 \\
3 \\
4 \\
5 \\
6 \\
7 \\
8 \\
9 \\
10 \\
11 \\
12 \\
13 \\
14 \\
15 \\
16 \\
17 \\
18 \\
19 \\
20 \\
21 \\
22 \\
23 \\
24 \\
25 \\
26 \\
27 \\
28 \\
29 \\
30 \\
31 \\
32 \\
32 \\
33 \\
34 \\
36 \\
37 \\
38 \\
39 \\
40 \\
40 \\
\end{array}$ & $\begin{array}{r}75 \\
75 \\
75 \\
75 \\
75 \\
75 \\
75 \\
75 \\
75 \\
75 \\
75 \\
75 \\
75 \\
75 \\
300 \\
120 \\
100 \\
75 \\
75 \\
460 \\
75 \\
75 \\
75 \\
150 \\
75 \\
150 \\
75 \\
75 \\
75 \\
75 \\
75 \\
75 \\
75 \\
75 \\
75 \\
75 \\
75 \\
75 \\
75 \\
3000 \\
75 \\
75 \\
75 \\
75 \\
75 \\
75\end{array}$ & $\begin{array}{r}10,473 \\
1,259 \\
755 \\
113 \\
358 \\
740 \\
2,380 \\
2,293 \\
826 \\
6,559 \\
579 \\
739 \\
882 \\
4,908 \\
4,034 \\
3,593 \\
541 \\
516 \\
161 \\
7,485 \\
1,147 \\
1,577 \\
194 \\
636 \\
882 \\
5,040 \\
1,140 \\
961 \\
946 \\
946 \\
985 \\
735 \\
1,051 \\
466 \\
882 \\
2,488 \\
1,429 \\
1 \\
39,000 \\
315 \\
33,906 \\
1,285 \\
645.3 \\
1,692 \\
1,032 \\
1,233 \\
803 \\
\end{array}$ & $\begin{array}{c}24 \\
3.5 \\
10 \\
0 \\
0 \\
5 \\
11 \\
4 \\
1 \\
18 \\
2 \\
12 \\
1 \\
18 \\
10 \\
7 \\
2 \\
0 \\
1 \\
17 \\
16 \\
8 \\
2 \\
0.5 \\
0.5 \\
26 \\
0.5 \\
0.5 \\
0.5 \\
0.5 \\
0.5 \\
3 \\
0.5 \\
0.5 \\
0.5 \\
21.5 \\
2 \\
0 \\
10 \\
33 \\
3.5 \\
0.5 \\
2 \\
4.5 \\
0.5 \\
0.5 \\
34.0\end{array}$ & $\begin{array}{l}2.62 \mathrm{E}-03 \\
3.53 \mathrm{E}-04 \\
1.01 \mathrm{E}-03 \\
0.00 \mathrm{E}+00 \\
0.00 \mathrm{E}+00 \\
5.04 \mathrm{E}-04 \\
1.11 \mathrm{E}-03 \\
4.03 \mathrm{E}-04 \\
1.01 \mathrm{E}-04 \\
1.82 \mathrm{E}-03 \\
2.02 \mathrm{E}-04 \\
1.21 \mathrm{E}-03 \\
1.01 \mathrm{E}-04 \\
1.82 \mathrm{E}-03 \\
2.52 \mathrm{E}-04 \\
4.41 \mathrm{E}-04 \\
1.51 \mathrm{E}-04 \\
0.00 \mathrm{E}+00 \\
1.01 \mathrm{E}-04 \\
2.80 \mathrm{E}-04 \\
1.61 \mathrm{E}-03 \\
8.07 \mathrm{E}-04 \\
2.02 \mathrm{E}-04 \\
2.52 \mathrm{E}-05 \\
5.04 \mathrm{E}-05 \\
1.31 \mathrm{E}-03 \\
5.04 \mathrm{E}-05 \\
5.04 \mathrm{E}-05 \\
5.04 \mathrm{E}-05 \\
5.04 \mathrm{E}-05 \\
5.04 \mathrm{E}-05 \\
3.03 \mathrm{E}-04 \\
5.04 \mathrm{E}-05 \\
5.04 \mathrm{E}-05 \\
5.04 \mathrm{E}-05 \\
2.17 \mathrm{E}-03 \\
2.02 \mathrm{E}+04 \\
0.00 \mathrm{E}+00 \\
1.01 \mathrm{E}-03 \\
8.32 \mathrm{E}-05 \\
3.53 \mathrm{E}-04 \\
5.04 \mathrm{E}-05 \\
2.02 \mathrm{E}-04 \\
4.54 \mathrm{E}-04 \\
5.04 \mathrm{E}-05 \\
5.04 \mathrm{E}-05 \\
6.43 \mathrm{E}-05\end{array}$ & $\begin{array}{l}4.84 \mathrm{E}-01 \\
7.05 \mathrm{E}-02 \\
2.02 \mathrm{E}-01 \\
0.00 \mathrm{E}+00 \\
0.00 \mathrm{E}+00 \\
1.01 \mathrm{E}-01 \\
2.22 \mathrm{E}-01 \\
8.06 \mathrm{E}-02 \\
2.02 \mathrm{E}-02 \\
3.63 \mathrm{E}-01 \\
4.03 \mathrm{E}-02 \\
2.42 \mathrm{E}-01 \\
2.02 \mathrm{E}-02 \\
3.63 \mathrm{E}-01 \\
5.54 \mathrm{E}-02 \\
8.82 \mathrm{E}-02 \\
3.02 \mathrm{E}-02 \\
0.00 \mathrm{E}+00 \\
2.02 \mathrm{E}-02 \\
5.59 \mathrm{E}-02 \\
3.22 \mathrm{E}-01 \\
1.61 \mathrm{E}-01 \\
4.03 \mathrm{E}-02 \\
5.04 \mathrm{E}-03 \\
1.01 \mathrm{E}-02 \\
2.62 \mathrm{E}-01 \\
1.01 \mathrm{E}-02 \\
1.01 \mathrm{E}-02 \\
1.01 \mathrm{E}-02 \\
1.01 \mathrm{E}-02 \\
1.01 \mathrm{E}-02 \\
6.05 \mathrm{E}-02 \\
1.01 \mathrm{E}-02 \\
1.01 \mathrm{E}-02 \\
1.01 \mathrm{E}-02 \\
4.33 \mathrm{E}-01 \\
4.03 \mathrm{E}-02 \\
0.00 \mathrm{E}+00 \\
2.02 \mathrm{E}-01 \\
1.66 \mathrm{E}-02 \\
7.05 \mathrm{E}-02 \\
1.01 \mathrm{E}-02 \\
4.03 \mathrm{E}-02 \\
9.07 \mathrm{E}-02 \\
1.01 \mathrm{E}-02 \\
1.01 \mathrm{E}-02 \\
1.28 \mathrm{E}-02\end{array}$ \\
\hline
\end{tabular}


appropriate, is ducted to a space in the ship, and then is exhausted from the space to the outside. Exhaust air from one space is not introduced to a different one.

Scenario 1: Fire in the Galley Area

For this case, a fire is assumed to begin in the space numbered 15, and to spread to No. 16 (the CPO mess) and No. 17 (utensil wash area and scullery). (See Table 2.) For purposes of dose projections, the ventilation system is assumed to continue running because a grease fire in the galley area will probably not be large enough to require that it be shut down. Furthermore, it seems unlikely that a fire of this nature will become hot enough to melt tritium-containing tubes. It is possible, however, that a marker might be damaged by the firefighting equipment. Even if the lights are damaged, it seems that not all of the tritium will be burned to form tritiated water. Nonetheless, for conservatism Table 6 shows the doses that would result if all the tritium gas were converted to water.

\section{Discussion of Fire in the Galley Area}

The doses in Table 6 are 100 times those for the same spaces shown in Tables 4 and 5 . For destruction of a single marker, the computed dose equivalents exceed the limits of 10CFR32.23 ff (which limits the dose equivalents that may be received due to radioactive material in licenseexempt items) for destruction of a single item. However, for destruction of all markers in a space, the computed dose equivalents are less than the limits in 10CFR32.23 ff for the destruction of all items in a space.

Scenario 2: Fire in the Engine Room

In this case a fuel fire originates in Engine Room No. 2. The temperature reached by this fire 950 to $1100^{\circ} \mathrm{C}\left(1700\right.$ to $\left.2000^{\circ} \mathrm{F}\right)$ is hot enough to

TABLE 6. Tritium Doses Following a Galley Fire

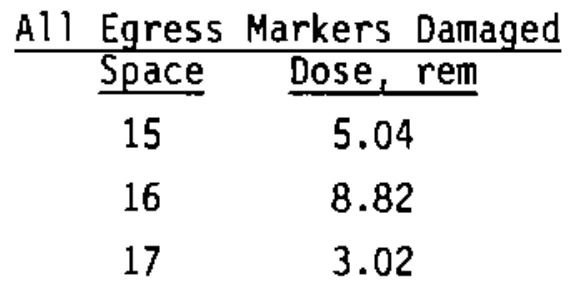

\begin{tabular}{cc} 
Largest Egress & Marker Damaged \\
\cline { 2 - 2 } Space & Dose, rem \\
& 1.01 \\
16 & 2.52 \\
17 & 3.02
\end{tabular}


melt the tritium-containing tubes and ignite the tritium gas. For this accident, an attempt was made to bound the dose that may be received due to damage to the RL egress markers and the consequent dose from the tritium. Three different situations were examined (a, b and $c$ below). The first two situations are those in which the activity from the lights is released to the air and, for purposes of estimating dose, remains in the air. The third situation is one in which all the tritium activity is washed from the air and is found in the water that was used to fight the fire; any airborne activity is from evaporation of the firefighting water.

In all the calculations that follow, it is assumed that all RL egress markers in the space are destroyed and that the tritium is converted to water by the fire.

a) Release of all tritium into the engine room, the space is ventilated. In this situation, it is assumed that all $34 \mathrm{Ci}$ are released into the atmosphere, the tritium is oxidized to water, and an individual is exposed to the contaminated air for an indefinite period (actually about $1 \mathrm{hr}$ ). The atmosphere of the engine room is vented, either by the ventilation system or due to actions of the fire, at the normal ventilation rate of $4000 \mathrm{cfm}$. In this case the individual is exposed to a cumulative air concentration of $0.03 \mu \mathrm{Cj}-\mathrm{min} / \mathrm{mL}$, which will result in a committed dose of about 1.28 rem.

b) Release of all tritium into the engine room, air concentration remains constant for $1 \mathrm{hr}$ prior to venting. This situation is identical to the one given above except that for some reason the air concentration of tritium remains constant for $1 \mathrm{hr}$ prior to venting of the atmosphere. In this situation an individual will be exposed to a cumulative air concentration of $2.78 \mu \mathrm{Ci}-\mathrm{min} / \mathrm{mL}$, which will result in a committed dose of 11.9 rem.

c) The tritium activity is washed out of the air by water spray. In this situation, it is assumed that all the activity of the RL egress markers is released, converted to water, and then washed from the air by the firefighting water sprays. Under the worst conditions, the water used to fight the fire collects on the engine room floor to a depth of $1 \mathrm{ft}$, resulting in the collection of $1.08 \mathrm{E} 3 \mathrm{ft}^{3}$ of water. The specific 
concentration of tritium in the collected water is $1.11 \mu \mathrm{Ci} / \mathrm{g}$. At entry into the engine room, the air is $50^{\circ} \mathrm{C}\left(122^{\circ} \mathrm{F}\right)$, and the relative humidity in the room is $100 \%$ (absolute humidity is $83 \mathrm{~g}$ water $/ \mathrm{m}^{3}$ air). Any ventilation of the space does not appreciably reduce the air concentration. An individual working in the area is assumed to be performing heavy work and to be inhaling $43 \mathrm{~L}$ air/min (ICRP-23, Table 120). In $1 \mathrm{hr}$ the individual will have taken in about $3.5 \mathrm{E} 2 \mu \mathrm{Ci}$ tritiated water, which results in a committed dose equivalent of $2.2 \mathrm{E}-2$ rem. It is assumed that the individual is able to work in these conditions no more than $4 \mathrm{hr}$, for a total committed dose equivalent of about $8.8 \mathrm{E}-2$ rem.

It should be emphasized that if the ship's pumps are working, no significant amount of water will collect on the engine room floor. Furthermore, in a fire of this type, firefighters will be using oxygen breathing apparatus and wearing protective clothing, thereby minimizing the chances for significant radiation exposure.

\section{Discussion of Engine Room Fire}

The situation in which an individual is exposed to the initial concentration of the release of all activity into the engine room (situation b) is an overestimate of the dose. Any fire that reaches $950^{\circ} \mathrm{C}\left(1700^{\circ} \mathrm{F}\right)$ is probably being vented somewhere; thus the actual situation is probably somewhere between $a$ and $b$, perhaps closer to $a$. Water spray will remove much of the tritiated water from the air; however, at the expected temperatures, some water will be converted to steam. At present, there is no easy way to estimate how much activity will be in the collected water and how much in the air. A partitioning of activity equally between air $(50 \%)$ and the collected water $(50 \%)$ seems reasonable. Using this partitioning, a reasonable maximum committed dose equivalent to an individual involved in this fire is about 6 rem (average of $b$ and $c$ ). This dose $(6$ rem) is below the 15 -rem committed effective dose equivalent allowed for exempt items involved in an accident having a negligible probability.

Scenario 3: Hit by a Missile

In this case a missile is assumed to hit the ship at the main deck level. Spaces Nos. 14, 15, 16, 17, and 18 are essentially destroyed, and a 
missile fuel fire spreads throughout them. Fire is assumed to spread upward to spaces $26,27,32,33,34$, and 37 , and downward to spaces $6,7,8,9,10$, 11,12 , and 13. As in the previous accident, an attempt was made to bound the doses that may be received. Two situations were considered. In the first (a), all activity in the spaces is released, converted to water, and then vented from the ship. In the second situation (b), all tritium in the spaces is converted to water and is then washed out of the air by the firefighting sprays.

a) Release of all activity into the air. In this situation it is assumed that all tritium in the affected spaces is released and is converted to water. Mechanical ventilation of the areas may not be possible;

however, damage to the ship will allow the tritiated water vapor to escape. It is assumed that the activity is removed from the areas at a rate equivalent to a ventilation rate of six turnovers of air per hour. As in the engine room fire, an individual is assumed to be exposed to the contaminated air for the duration of the release, about $2 \mathrm{hr}$. The resulting radiation doses are given in Table 7 .

b) Washout of the tritium into firefighting spray. In this situation it is assumed that all tritium in the spaces is converted to water and then washed from the air by the firefighting sprays. It is assumed that the volume of the water is $2 \mathrm{E} 3 \mathrm{ft}^{3}$ ( $1 \mathrm{ft}$ deep on the first platform). The working conditions are identical to those described for the engine room fire. In this case, workers take in about $2.6 \mu \mathrm{Ci} / \mathrm{mL}$ of tritium. The consequent doses are $8.9 \mathrm{E}-2 \mathrm{rem} / \mathrm{hr}$ exposure with a total dose of about 0.35 rem from a 4 -hr exposure.

TABLE 7. Tritium Doses Following a Missile Hit

\begin{tabular}{|c|c|}
\hline Ship Level & $\begin{array}{l}\text { Tritium } \\
\text { Dose, rem }\end{array}$ \\
\hline 01 Level & 7.2 \\
\hline Main Deck & 4.6 \\
\hline 1st Platform & 5.4 \\
\hline
\end{tabular}




\section{Discussion of Missile Fires}

This fire situation is nearly identical to the engine room fire. Because of the damage by the missile explosion, the doses on each level of the ship have been treated together rather than looking at individual spaces. As discussed for the engine room fire, the tritium will actually be partitioned between the air and the firefighting water. If the actual dose is an average of the two situations, the doses to individuals following a missile hit should be on the order of about 2.3 rem. This dose $(2.3$ rem) is below the 15-rem committed effective dose equivalent allowed for exempt items involved in an accident having a negligible probability. In addition, as discussed earlier, the use of oxygen breathing apparatus will tend to minimize the risk.

\subsection{CONCLUSIONS CONCERNING RADIATION HAZARD}

The radiation doses to individuals due to release of tritium from RL egress markers have been estimated for both normal and off-normal events, including those for a major fire and a missile hit. Based on the above calculations, in all cases the radiation doses are sufficiently low to meet the dosimetric criteria of the U.S. Nuclear Regulatory Commission (as published in 10CFR32.23 and 10CFR32.24) for classification as exempt radioluminous devices.

\subsection{CONTAMINATION OF THE SHIP FOLLOWING RELEASES AND FIRES}

There are few data available concerning contamination of an enclosed area following a release of tritium within it. One study (Flanagan et al. 1978), discussed later, indicates that contamination is negligible following release of tritium gas. If RL devices are damaged and releases of tritiated water occur, it can be expected that areas surrounding the markers will be contaminated. The contamination, in the form of tritiated water, should be removed readily by washing the area with soap and water. The persons performing the decontamination should wear rubber gloves and should decontaminate and dispose of the wash water according to established procedures. 
The situation following a fire depends chiefly on the circumstances of the fire. In the grease fire, any tritium converted to tritiated water will probably be taken into the ventilation system, which is assumed not to have recirculation. If the air is drawn from each space and vented to the outside without routing through other spaces, then contamination is limited to the space that contained the fire and the exhaust ductwork.

Following a major conflagration such as the engine room fire or the missile hit, large areas of the ship will probably become contaminated. Much of the tritium will be oxidized to tritiated water, become airborne, and probably spread throughout the ship's affected section. The tritiated water will condense out of the plume as the plume encounters cooler surfaces. The analys is also assumes that a large quantity of tritium-contaminated water will be found on the floor(s) of the affected spaces. The spaces can probably best be initially decontaminated by washing with fire hoses. Then prompt removal of the water from the ship by the pumping system will result in the lowest doses to Navy personnel.

\subsection{DEPOSITION OF CONTAINED TRITIUM ON SURFACES}

Consider a hypothetical situation in which the ventilation system for a ship's compartment ceases to function, either by accident or because it is deliberately shut down. Assume that at the same time all RL fixtures are broken and the tritium is released. Obviously, without ventilation the radiation dose would rise above the allowable $0.5 \mathrm{rem}$, at least in some compartments. Emergency procedures for the ship would have to account for this contingency and ensure that crew members would not remain unprotected in the contaminated area for more than short periods. But what is the extent of the contamination and cleanup problem under the circumstances?

When the ventilation system is restarted, all tritium gas would quickly be exhausted to the outside. Any remaining contamination would be deposits on floor, furniture, and bulkheads. An experiment at DOE's Mound Laboratory (Flanagan et al. 1978) offers some clues on the extent of such contamination. Although the experiment was conducted primarily to test an automatic system to contain tritium emergencies, controlled quantities of tritium were released in a test laboratory and then tritium deposits on laboratory 
surfaces were measured. For a release of $0.87 \mathrm{Ci}$ of elemental tritium, the tritium deposits on most surfaces were nondetectable. For one surface (a desk top) the deposit was measured at $4 \mathrm{pCi} / 100 \mathrm{~cm}^{2}$. In this study, the largest concentration of tritium in a CG 47 compartment with standard ventilation $(75 \mathrm{cfm})$ was $26 \mathrm{Ci}$. That is nearly 30 times the quantity of tritium released in the test and should result in a maximum surface contamination of $120 \mathrm{pCi} / 100 \mathrm{~cm}^{2}$. The problem of decontamination would be minimal.

\subsection{INFLUENCE OF FIREFIGHTING METHODS}

In this study, the analyses of potential radiation hazards during fires have assumed that the fire-extinguishing agent is water. The fact is that the recommended firefighting agent for spaces on the CG 47 where there are fuels, gases, or flammable liquids is Halon 1301 (Designers and Planners 1975). A Coast Guard study (Sheehan 1972) shows that Halon very effectively extinguishes fire by quickly depriving it of oxygen. If the automatic Halon system on the CG 47 works, the fire should not last long enough nor get hot enough to damage the RL glass tubes. No water is involved with the Halon system, and thus, even if tubes rupture, contamination by tritiated water is minimized.

For other spaces in the CG 47 (Designers and Planners 1975), an aqueous film-forming foam (AFFF) system is used which employs a concentrate that is a type of synthetic detergent. Unlike domestic detergent, however, it is specially compounded so that it holds together and persists. This medium extinguishes fires through a combination of radiation-absorption, blanketing and cooling by absorbing the latent heat of the water fed to the fire. The AFFF system can be introduced rapidly and is very effective against fire. Once again, rapid extinction of the fire minimizes the chances of RL fixtures failing and lowers the probability of even a minor radiation hazard.

\subsection{LOGISTICS ISSUES}

Any assessment of potential risks associated with the use of RL lights must consider logistic problems, primarily transportation and storage. For the latter, Jensen and Martin (1988) have shown that a fire in which $3000 \mathrm{Ci}$ of tritium was released resulted in little contamination. The implications 
of the study are that quantities of tritium RL devices stored in any one place should be limited to some number yet to be determined. The requirement should be established solely to ensure that even a catastrophic accident would not incur an unacceptable risk.

The risk of shipping and handling can be lowered by selecting proper containers. A study for the NRC (Gause et al. 1984) has looked at various containers for shipping wastes containing large amounts of tritium. The results show that certain metals, aluminum for example, are superior to steel as a barrier to tritium. One may infer from these tests that an aluminum container would prevent contamination of the surrounding area even if the RL tubes inside were damaged or broken.

\subsection{RADIOLUMINESCENT EGRESS LIGHTING ON NUCLEAR-POWERED SHIPS}

The use of emergency egress lighting on nuclear-powered naval vessels is beyond the scope of this study. Specifics related to the chemical form, use, and possible release of tritium from propulsion systems is classified and not necessarily available to the present effort. However, it is the authors " belief that RL emergency egress lighting is compatible with these systems if properly designed and installed.

\subsection{BENEFITS OF RADIOLUMINESCENT EGRESS LIGHTS}

Some of the benefits of using RL lights have been summarized earlier in this report (see Radioluminescent Egress Lighting for Ships). A few of these benefits, along with some others, will now be examined from the Navy's viewpoint.

\subsection{CREW SURVIVABILITY}

The potential for saving human life is probably the single greatest reason for the Navy to install RL egress lighting on its ships. There is a reasonably high probability that a ship's power will be down during a fire or combat energency. Although the probability is less, there is also at least a reasonable chance that backup generators and other energency lighting gear will fail to operate. Unless directly destroyed by weapons or fire, RL 
lights would be in place, functioning, and completely reliable to assist the crew in moving to safety or to their assigned duties. In this way RL lights would not only save lives, they may well serve to save the ship.

\subsection{PERFORMANCE}

RL egress lights will be acceptable to the Navy only if it is shown that they will function reliably to guide personnel out of a ship during emergency. To do this, the lights must be visible at required distances (40 ft maximum for most ships) and legible when required, under both normal and smoky conditions. Three technical reports will now be discussed which relate to the visibility and legibility of RL lights as compared to conventional lights.

Schooley et al. (1974) investigated the use of self-powered exit signs in comnercial buildings. The purpose was to modify the National Uniform Building Code to establish requirements for the use of self-luminous signs. Analysis and calculation supported the justification for use of such signs, and suggested code revisions were presented. In general, the report concluded that self-powered signs, such as tritium RL lights, have significant advantages over conventional signs in safety, reliability, and economy. Certain minimum constraints were established such as 1) luminance no less than 0.02 footlambert and 2) a sufficient contrast ratio to be provided by proper construction of the sign.

A report (U.S. Radium Corporation 1978) for Underwriters Laboratories (U.L.) investigated the usefulness of RL lights as emergency exit signs that would not be subject to failure during power outages or disasters in general. Performance capabilities for self-luminous lights were studied under clear air and smoke-laden conditions. The results established that the RL signs provide an effective means of indicating egress, with viewing legibilities adequate from distances of 75 to $100 \mathrm{ft}$. On this basis, U.L. established recommended installation limitations for these signs which were intended to supplement current exit devices.

A report (Schooley and Reagan 1978) discusses perceptual tests of exit signs for commercial buildings. Perception of a self-powered sign manufactured by American Atomics was compared to that of an energized electric sign 
in both clear air and smoke-laden conditions. In clear air, the selfluminous sign performed somewhat better under darkened conditions (legible at $125 \mathrm{ft}$ as compared to $75 \mathrm{ft}$ for the electrical sign). Under smoke-filled room conditions, both the electric and self-luminous signs were legible at 40 to $50 \mathrm{ft}$. RL light performance can therefore be considered highly acceptable. It is interesting to note that this satisfactory performance occurred in smoke conditions with about 10 times the total obscuring power of that generated by crude oil fires.

The reports just discussed established the visibility and legibility performance capabilities of tritium RL lights for distances greater than any likely to be required on Navy ships. These capabilities, along with high reliability and low maintenance costs, make RL lights ideally suited as egress markers for surface ships.

\subsection{RADIOLOGICAL SAFETY}

Based on the dose calculations for both normal and off-normal events, in all cases, the radiation doses are sufficiently low to meet the NRC's dosimetric criteria that would permit the lights to be classed as exempt radioluminous devices. (See the section Radiological Assessment.)

\subsection{MAINTENANCE}

As stated earlier, failure to maintain backup generators or batteries for lanterns leads to a high probability that such equipment will not function in an emergency. RL lights, on the other hand, require no maintenance except an occasional dusting by the cleaning detail. Routine walk-through inspections show at a glance whether a light is still functional. In the unlikely event that a light is not working, it would mean that the tube had been damaged and the tritium had escaped. In this case, the area would have to be checked for contamination and the RL light would need to be replaced. It is extremely unlikely that an RL light would be damaged during normal use, but if it were, the risk to personnel would be negligible. (See discussion under Destruction of One Light in Each

Compartment.) 


\section{$8.5 \quad \underline{\operatorname{COST}}$}

No data were readily available on the original cost or the maintenance costs of relay lanterns and other emergency ship lanterns; hence a direct life-cycle cost comparison with RL lights is not possible. Furthermore, the direct cost of shipboard RL egress lights would be driven primarily by the cost of the light fixture, and the fixture design details have not yet been established. On a qualitative basis, however, a few conclusions can be drawn:

1. Routine maintenance costs on RL lights are essentially zero over a 10-year period. For conventional lighting, however, the cost of required maintenance, including battery replacement, would be significant.

2. As RL lights must be installed with tamper-proof fixtures, the installation cost could be significant. It is believed, however, that a tamper-proof design using special tools can be created that would minimize the cost of installation and recycling.

3. It is estimated that RL aircraft exit signs cost between $\$ 50$ and $\$ 75$ to produce. It is believed that acceptable shipboard egress lights will cost no more, and perhaps less, than the aircraft signs.

4. The July 1988 cost of tritium was about $\$ 1.35 / \mathrm{Ci}$, or $\$ 13.50$ for a $10-\mathrm{Ci}$ RL light. This cost is insignificant compared to many other radioactive materials or to the cost of replacing a single battery for a relay lantern.

\subsection{DOE SUPPORT OF DOD RADIOLUMINESCENT PROGRAM}

The Congressionally mandated DOE ART Program provides DOE support for RL programs in several areas that would greatly benefit the Navy. Regarding any Navy effort related to the application of RL technology, we were told that $D O E$ is prepared to support the Navy in the following ways: $(a, b)$

(a) DOE-HQ Radioluminescent Lights Program Briefing for U.S. Navy, August 9, 1987, NAVSEA, Crystal, Virginia.

(b) Radioluminescent Program Description. November 1987. Department of Energy, Washington, DC. 
1. DOE will provide matching funds for appropriate R\&D efforts to advance RL technology.

2. DOE has extensive R\&D capability to support RL efforts and will make this capability available for Navy programs.

3. DOE will assume responsibility for supplying tritium to the Navy and for recycling and disposing of spent tritium RL devices.

4. DOE will provide contract support for procuring and acquiring RL systems.

5. DOE will assist in obtaining required licenses and approvals for $R L$ systems.

\subsection{LICENSING ISSUES}

It is expected that RL light units for Navy vessels would contain quantities of tritium that are found in units manufactured, 1icensed, and sold under existing Nuclear Regulatory Commission (NRC) regulations found in the Code of Federal Regulations, Title 10, Sections 30-35. Thus the RL emergency egress light units can be licensed using published NRC procedures and guidelines for the issuance of a general license. Generally licensed RL lights can be manufactured for the Navy by persons holding a specific license for their manufacture. The manufacturer needs to maintain records to identify the Navy as the original purchaser of the devices. Also, the items must be returned to persons specifically licensed or exempt (DDE and it contractors are exempt) by the NRC at the end of their useful life for proper disposal. As such, RL emergency egress lights could be inventoried, handled, and controlled by the Navy using established procedures for handling governmentowned equipment.

An alternative to the general license would be to obtain an exemption from the NRC for RL devices used for emergency egress illumination. For an exemption to be granted, it would have be shown that the exempted devices "will not endanger life or property or the common defense and security and are otherwise in the public interest" (10CFR30.11). As an example, exempt status has been granted for "marine compasses containing not more than 750 millicuries ( 0.75 Curies) of tritium gas and other marine navigational 
instruments containing not more than 250 millicuries (0.25 Curies) of tritium gas" (10CFR30.15)(a)(5) and other self-luminous products containing lesser quantities of tritium, promethium-147, and krypton-85 (10CFR30.15). It has also been demonstrated that light units containing larger quantities of tritium, perhaps as high as 10 or $15 \mathrm{Ci}$ of tritium, if properly designed and manufactured, can meet the safety criteria outlined in 10CFR32.23 and 10CFR32.24 for Exempt Concentrations and Items, should the emergency egress lights be damaged or destroyed. No RL lights are proposed in this study that contain more than $10 \mathrm{Ci}$ of tritium, and most contain $2 \mathrm{Cj}$ or less. Crews' enhanced safety and survivability should certainly establish a benefit/risk ratio sufficient to demonstrate to the NRC that RL lights for this purpose should be granted exemption as this is in the public interest and for national defense. Obtaining an exemption for devices used for emergency egress on Navy ships will, however, require careful coordination among the DOE, the Navy, and the NRC and can include many pitfalls. The desired end cannot be guaranteed but is certainly possible.

The DOE RL Lighting Program management has indicated that they are ready to assist the Navy in pursuing either option: general licensed or an exempted RL lighting for emergency egress on Navy ships. In addition, as stated earlier, DOE and its contractors could handle the disposal of RL emergency egress light units and the recovery and recycle of the remaining tritium after their useful life is completed for Navy use.

\subsection{SUMMARY AND CONCLUSIONS}

This study is a preliminary investigation to establish the safety and efficiency of RL lighting as emergency egress markers on naval surface ships. A brief history of the evolution of RL technology was presented, and the basis for selecting tritium as the radionuclide to be used in the proposed egress lighting was established.

Although there are many potential applications for RL technology on naval ships (see Appendix D), the scope of this effort was limited to its potential for guiding ship's personnel to safety in emergencies. This specific application was selected to demonstrate to the U.S. Navy the 
reliability and performance of RL lights for the following three principal reasons:

1. An effective RL egress lighting system has significant potential for saving human life; the benefits are high.

2. RL egress route markers would require such small quantities of tritium that the radiation hazard even under the worst damage scenarios was not expected to be unacceptable; the risks are low.

3. The application provided an excellent vehicle to develop a proposed RL egress lighting systen for a specific class of ships (CG 47). The proposed design could be conceptual, yet with enough specific parameters defined that performance could be demonstrated and health and safety issues could be examined realistically.

When this jointly sponsored Navy/DOE study began, the plan was to have the Navy Radiation Safety Comittee define limits of allowable radiation doses to the ship's crew based on current Navy radiological safety requirements. Designs for RL egress lights were then to be conceived which, even under worst-case damage scenarios, would not create radiation environments exceeding the Navy's established limits. The Navy representatives, however, chose not to define allowable radiation limits, probably in part because they did not want to give de facto endorsement permitting even small amounts of radioactive material on Navy ships. The Navy decision placed the burden of proof on the research team. Thus the study was required to establish that the benefits of using RL systems as egress markers on ships are greater than any risks that might be involved. The benefits of using RL lights for egress are relatively easy to identify and will be summarized later. To ensure that the risks would be acceptable, it was decided to attempt to propose an RL system that would under no condition exceed the safety criteria set forth in the Code of Federal Regulations, 10CFR32.23 and 10CFR32.24. These criteria were described earlier in this report under Diffusion Through Glass.

For reasons discussed in this report, current shipboard emergency lighting systems may not always be reliable. Some of the proposed options for egress markers, such as luminescent paint, have specific disadvantages. It is believed that RL lights are a preferable alternative for both existing 
and other proposed egress systems. This report has discussed the benefits/ advantages of RL lights at length. In brief, RL lights provide a selfcontained, highly reliable, high-performance, rugged, low-maintenance and low-cost lighting system that does not adversely affect night vision and requires replacement only once every ten years.

In this study, an RL egress lighting system is proposed for specific compartments in a CG $47 \mathrm{class}$ of naval ships. The RL system was conceived based on safety and performance criteria that are considered widely acceptable. The RL lights are hypothetically installed in a vertical athwartship slice of the CG 47 containing a variety of compartments, ladders, vertical escape trunks, and watertight and nonwatertight doors. RL markers of varying brightness $(0.5$ to $10.0 \mathrm{Ci}$ ) are placed at appropriate points to mark egress routes. The sizes of the compartments and the ventilation requirements are defined. Some options for types of markers are described, and a conceptual generic design is suggested. A prototype of a bulkhead marker is described only to illustrate what can potentially be accomplished using small quantities of tritium.

Using the RL light system as proposed, the compartment sizes, and the ventilation requirements, a thorough analysis of the potential radiation hazard was conducted. It was shown that the hazard from normal diffusion through glass was so small it was insignificant. In a worst-case "normal" accident, whereby all RL fixtures in a compartment are broken, the radiation dose was shown to be within the safety limit set by 10CFR32.24. All assumptions used in the hazard analyses were extremely conservative. Even so, the results clearly show that the radiation hazard to personnel due to the use of RL lights is extremely low.

The risk from radiation was analyzed also for scenarios involving damage from fires and a missile hit on the ship. In these cases as well, the results showed that the radiation did not exceed the CFR safety criteria and thus would allow these devices to be classified as exempt items by the Nuclear Regulatory Commission. Based on the results of the radiation risk analyses and on the performance capabilities of RL lights as established in this report, the following conclusions are reached: 
1. RL lights are the best option available to be used as emergency egress markers on naval surface ships.

2. As egress markers, RL devices perform as well as or better than electric lights under both normal and smoky conditions.

3. RL egress lights are safe; they meet the dosimetric criteria of the NRC for exempt radioluminous devices.

4. DOE is willing and able to assist the Navy in a program leading to the possible installation of RL egress lights on Navy ships.

\subsection{RECOMMENDATIONS}

It is recommended that the Navy implement a program in cooperation with DOE with the ultimate goal of installing RL lights as emergency egress markers on naval ships. The program should begin with a 6.3 feasibility demonstration task and, if the results are positive, conclude with the acquisition and installation of RL systems. The following outlines a recommended program plan:

1. Using conceptual designs provided by this study, design and construct prototype RL lights for shipboard egress applications. RL light designs should conform to existing specifications for shipboard equipment.

2. Plan and conduct an experimental program to confirm the analytical predictions from this study. The following objectives should be a part of the 6.3 Phase I program:

a. Assure that RL systems meet Navy egress lighting requirements for surface ships.

b. Establish the limits of performance of RL systems under fire and smoke conditions, with particular emphas is on fuel fires.

c. Experimentally confirm analytical findings on radiological safety for RL lights.

3. After demonstrating the performance capability of RL systems for surface ship egress lighting in Phase I, implement Phase II to accomplish the following objectives: 
a. Study concepts for hardening RL lighting systems to minimize risks associated with their use and to meet Navy design requirements.

b. Design prototype RL system(s) in accordance with the results of (a) above.

c. Construct sufficient prototypes to perform an extensive experimental program that will include the following:

(1) Conducting a comprehensive series of tests to ensure that the prototype RL system(s) will meet applicable requirements in Navy specifications and design data sheets. These requirements will relate to shock, vibration, fragmentation, shipping and handling, and other environmental stresses.

(2) Conducting a series of tests to provide data to support a request for "exempt item" status to the NRC.

4. Phase III: Upon successful completion of the experimental program, DOE would assist the Navy in preparing the required documentation for fleet use. The documentation would include the following:

a. a detailed drawing, approved by the NRC, of the exempt RL system

b. drawings showing egress lighting locations on ships (new construction and backfit)

c. a manual for the ship's crew on emergency egress procedures

d. a revision of the technical manual for lighting on Navy ships

e. a revision of applicable parts of the Navy's general specifications for ships (new construction and overhaul)

f. preparation of appropriate design data sheets.

5. During Phase III, DOE would assist the Navy in procuring RL systems for fleet use and in disposal and recycling. 


\section{REFERENCES}

Code of Federal Regulations. 1988. Title 10 "Energy," Part 20 "Standards for Protection Against Radiation." U.S. Government Printing Office, Washington, D.C.

Code of Federal Regulations. 1988. Title 10 "Energy," Part 32 "Specific Domestic Licenses to Manufacture or Transfer Certain Items Containing Byproduct Material." U.S. Government Printing Office, Washington, D.C.

Department of Energy. 1988. Radioluminescent Lighting Program Description. Washington, DC, November 1987 (Revised March 1, 1988).

Designers and Planners, Inc. 1975. Fire Protection System Studies for DG-AEGIS, Final Report for the Naval Ship Engineering Center.

Flanagan, T. M., M. L. Rogers, and N. R. Wilkes. 1978. Experiments with a Tritium Emergency Containment System. Monsanto Research Corporation, Mound Laboratory, Miamisburg, Ohio.

Gause, E. P., B. S. Lee, D. R. Mackenzie, and R. Wiswal1, Jr. 1984. Alternative Containers for Low-Level Wastes Containing Large Amounts of Tritium. NUREG/CR-3973, BNL-NUREG-51814.

General Specifications for the Ships of the United States Navy. 1986. Department of the Navy, Washington, DC, 1986 Edition.

International Commission on Radiological Protection (ICRP). 1975. Report of the Task Group on Reference Man. ICRP Publication 23, Pergamon Press, New York.

Jensen, G. A., and J. B. Martin. 1988. Investigation of Fire at Council, Alaska: A Release of Approximately 3000 Curies of Tritium. PNL-6523, Pacific Northwest Laboratory, Richland, Washington.

NAVSEA 802-5773686 (WDBL Change No. 2). 1987. Air Conditioning, Ventilation and Heating Design Criteria Manual for the CG 52. Department of the Navy. Washington, DC, May 31, 1987.

NAVSEA 0964-LP-000-2000. 1977. Lighting on Naval Ships, Technical Manual. Naval Sea Systems Command, Washington, DC, July 15, 1977.

Niemeyer, R. G. 1969. Tritium Loss from Tritium Self-Luminous Aircraft Exit Signs. ORNL-TM-2539, 0ak Ridge National Laboratory, Oak Ridge, Tennessee, March 25, 1969.

Report on Supplemental Self-Luminous Exit Signs and Markers, 1978. U.S. Radium Corporation, Bloomsburg, Pennsylvania (now Safety Light Corp.), March 20, 1978. 
Schooley, L. C., and J. A. Reagan. 1978. Perceptual Tests of Exit Signs. University of Arizona, May 5, 1978.

Schooley, L. C., J. A. Reagan, and D. Byrne. 1974. Application of Self-Powered Exit Signs. University of Arizona, August 16, 1974.

Sheehan, D. F. 1972. An Investigation into the Effectiveness of Halon 1301 (Bromotrifluoromethane) as an Extinguishing Agent for Shipboard Machinery Space Fires. Office of R\&D, U.S. Coast Guard, Washington, DC.

Sours, P. 0. 1986. Hydrogen Properties for Fusion Energy. University of California Press, Berkeley, California.

Tompkins, J. A., K. W. Hoff, and F. J. Schultz. 1987. Fiscal Year 1987

Annual Report - Radioluminescent (RL) Airfield Lighting Program. Oak Ridge National Laboratory, Oak Ridge, Tennessee.

52 
APPENDIX A

DETAILED DRAWINGS OF SHIP'S SECTIONS

USED FOR EGRESS LIGHTING DESIGN 


\section{APPENDIX A \\ DETAILED DRAWINGS OF SHIP'S SECTIONS \\ USED FOR EGRESS LIGHTING DESIGN}

The following five figures comprise detailed drawings of the ship's sections used for the egress lighting design in this report. They are from the vertical athwartship slice of the ship from port to starboard selected for this study. The reader can use these detailed drawings in conjunction with Figures 1 through 5 (under The Proposed Radioluminescent System in this report) showing the proposed lighting system. 


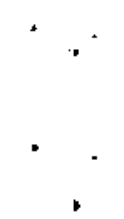


ANO

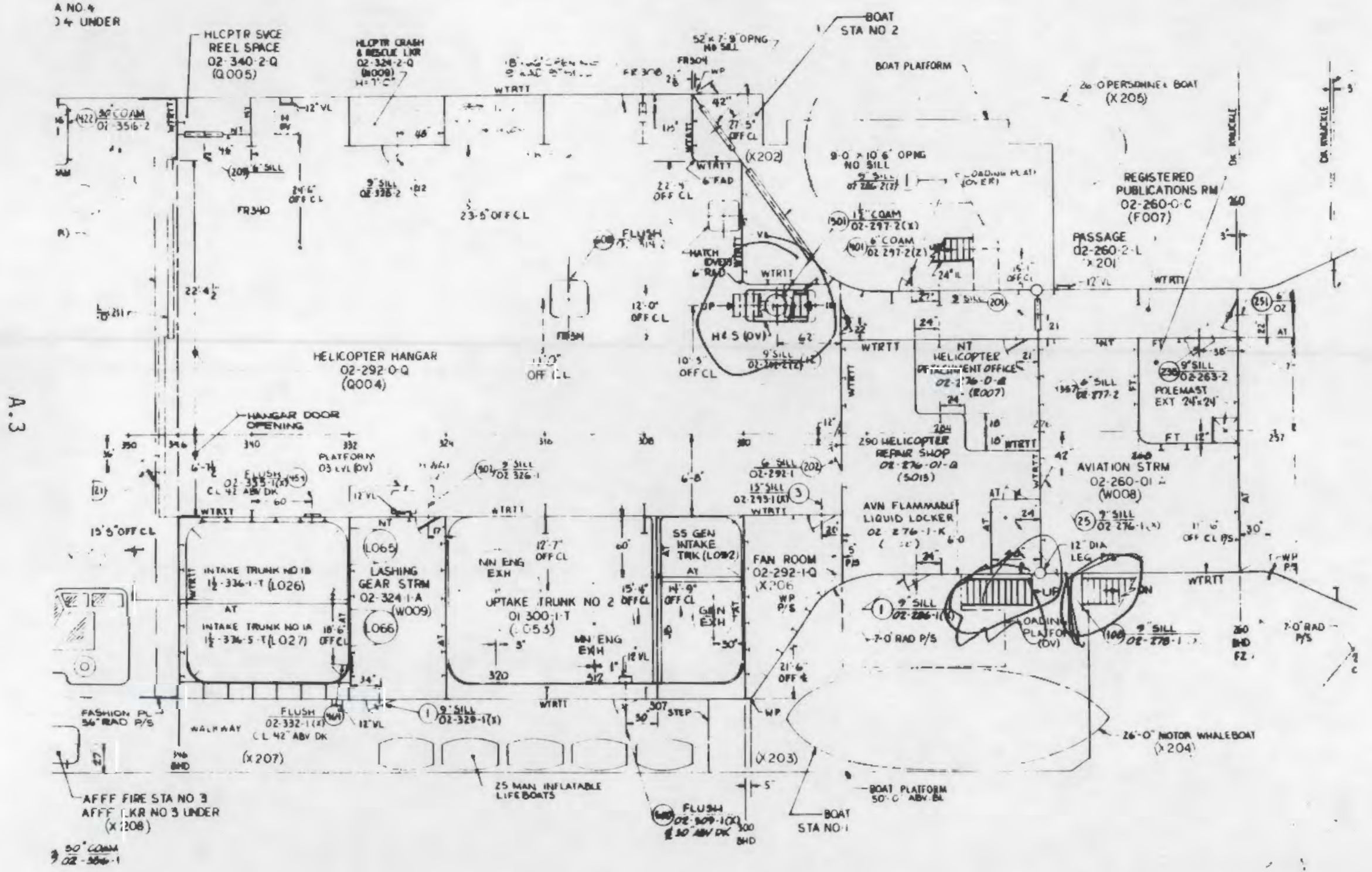

FIGURE A.1. CG 47, 02 Level, Compartments and Access 



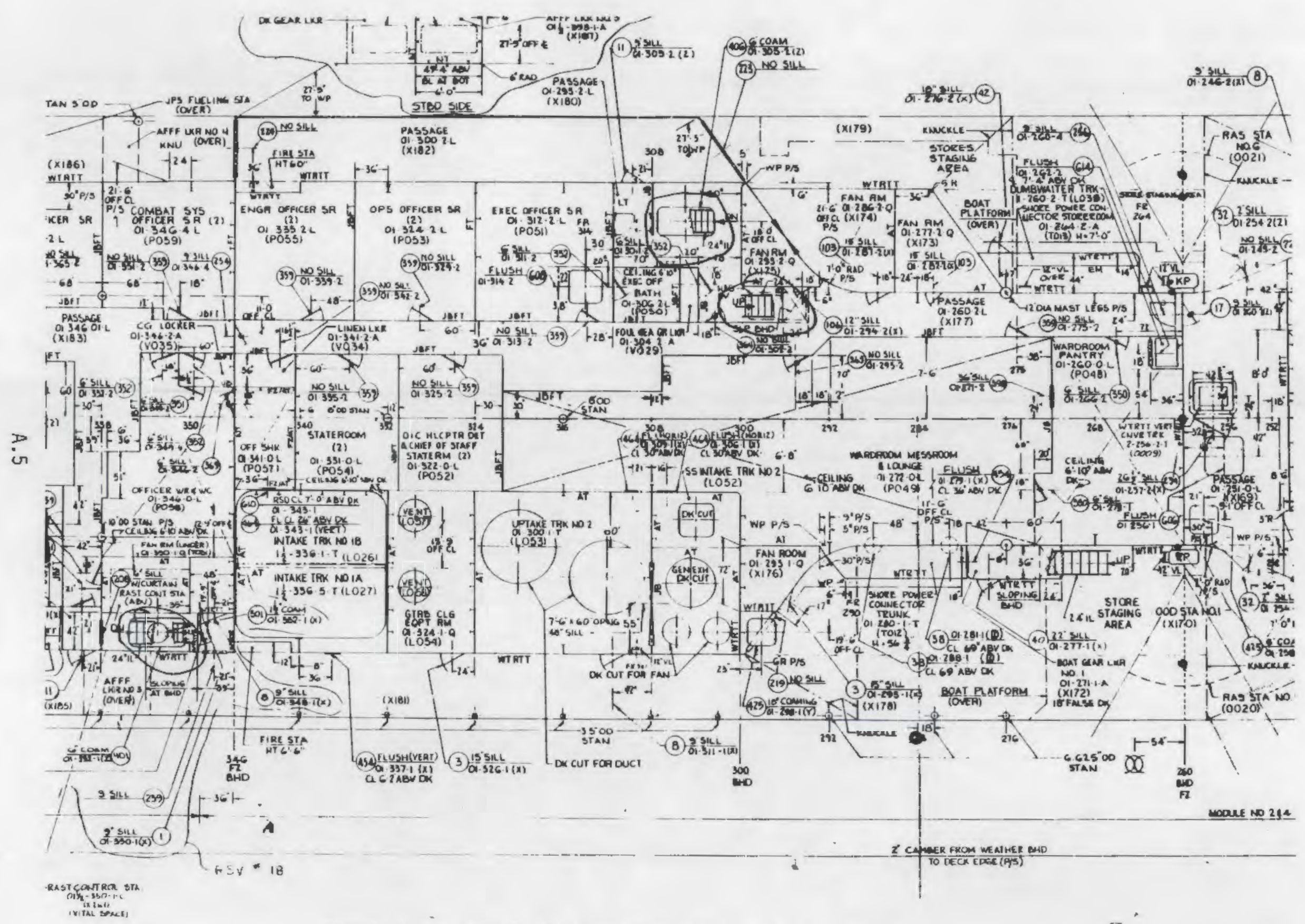

FIGURE A.2. CG 47, 01 Level, Compartments and Access 



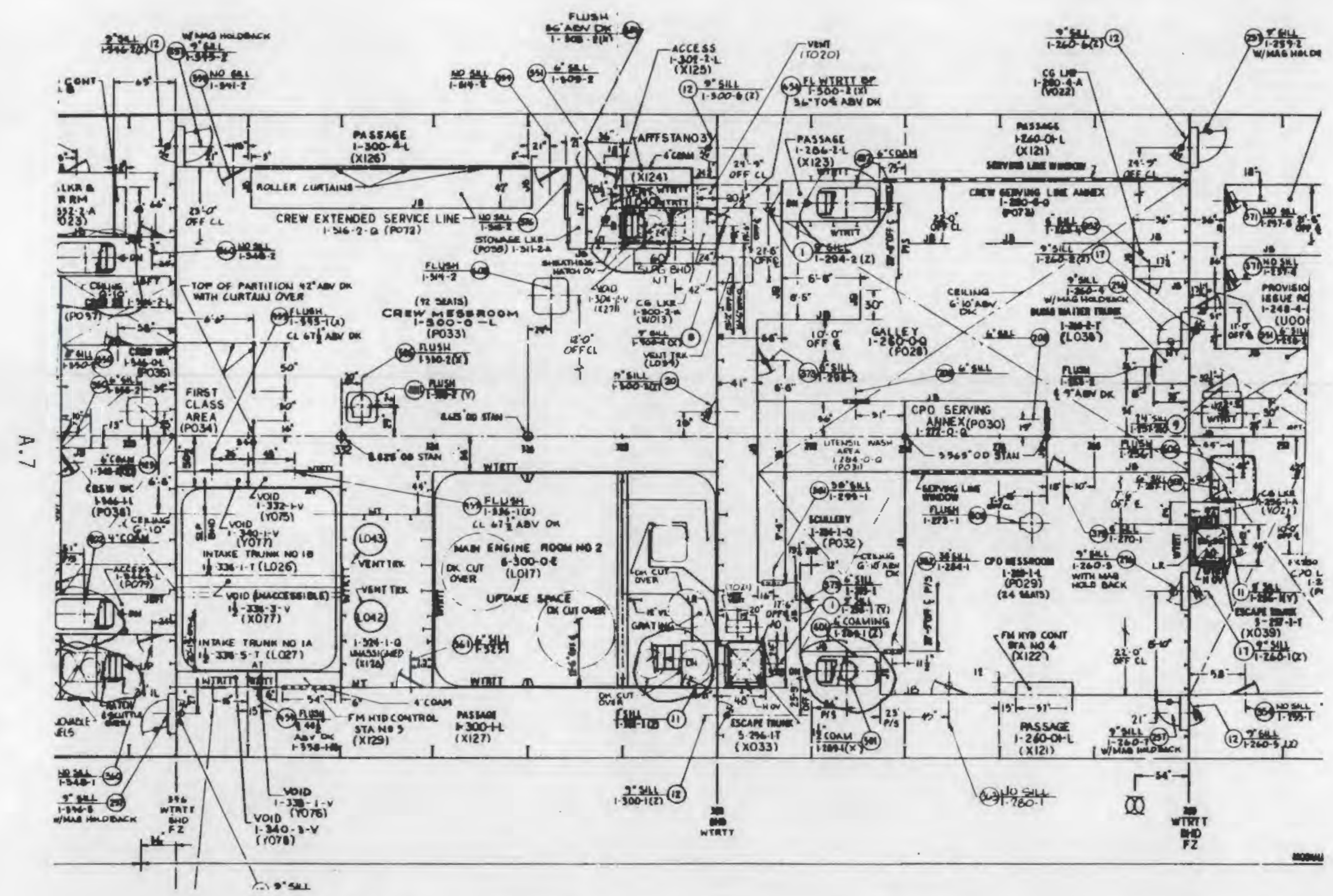

FIGURE A.3. CG 47, Main Deck, Compartments and Access 



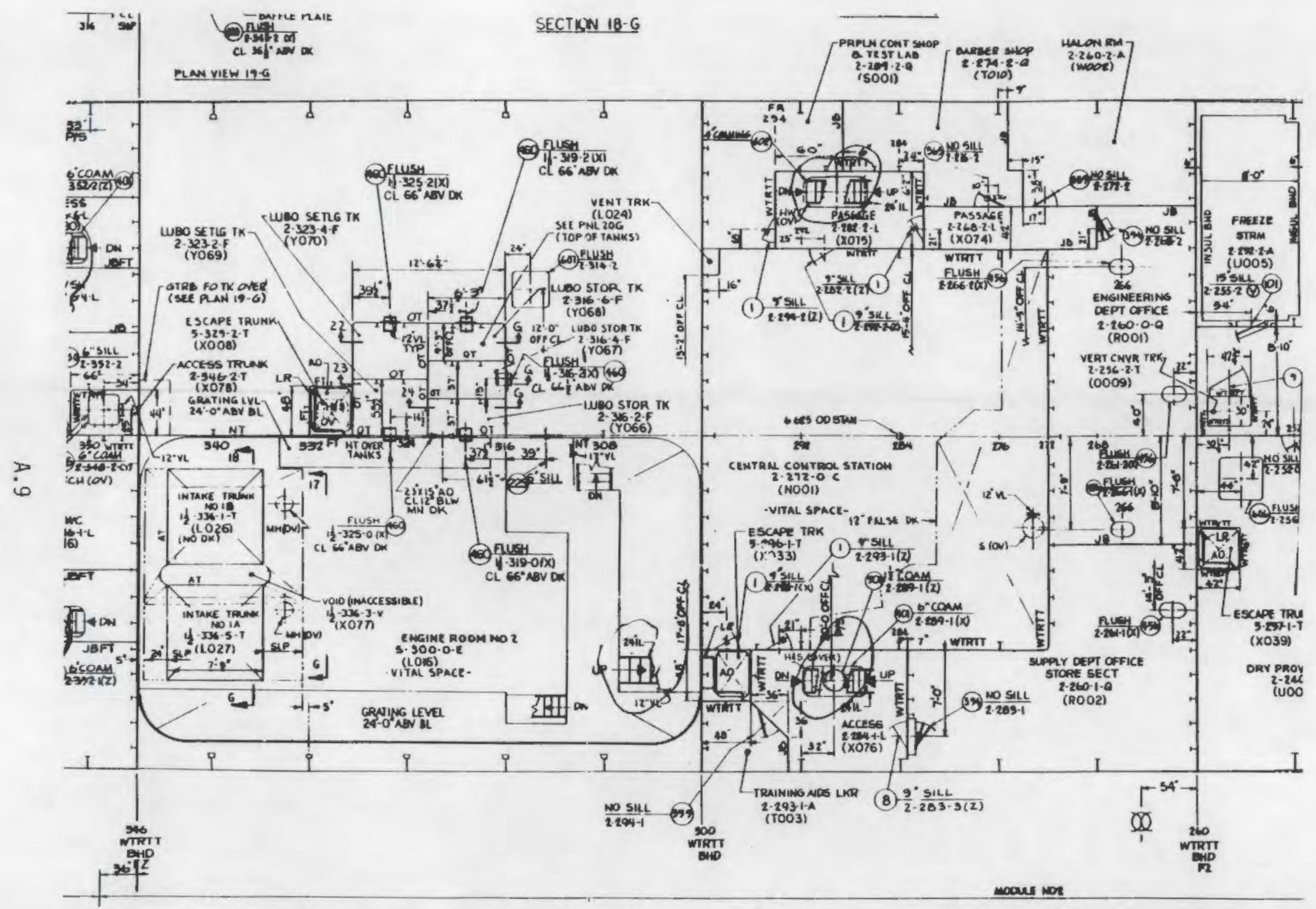

FIGURE A.4. CG 47, First Platform, Compartments and Access 



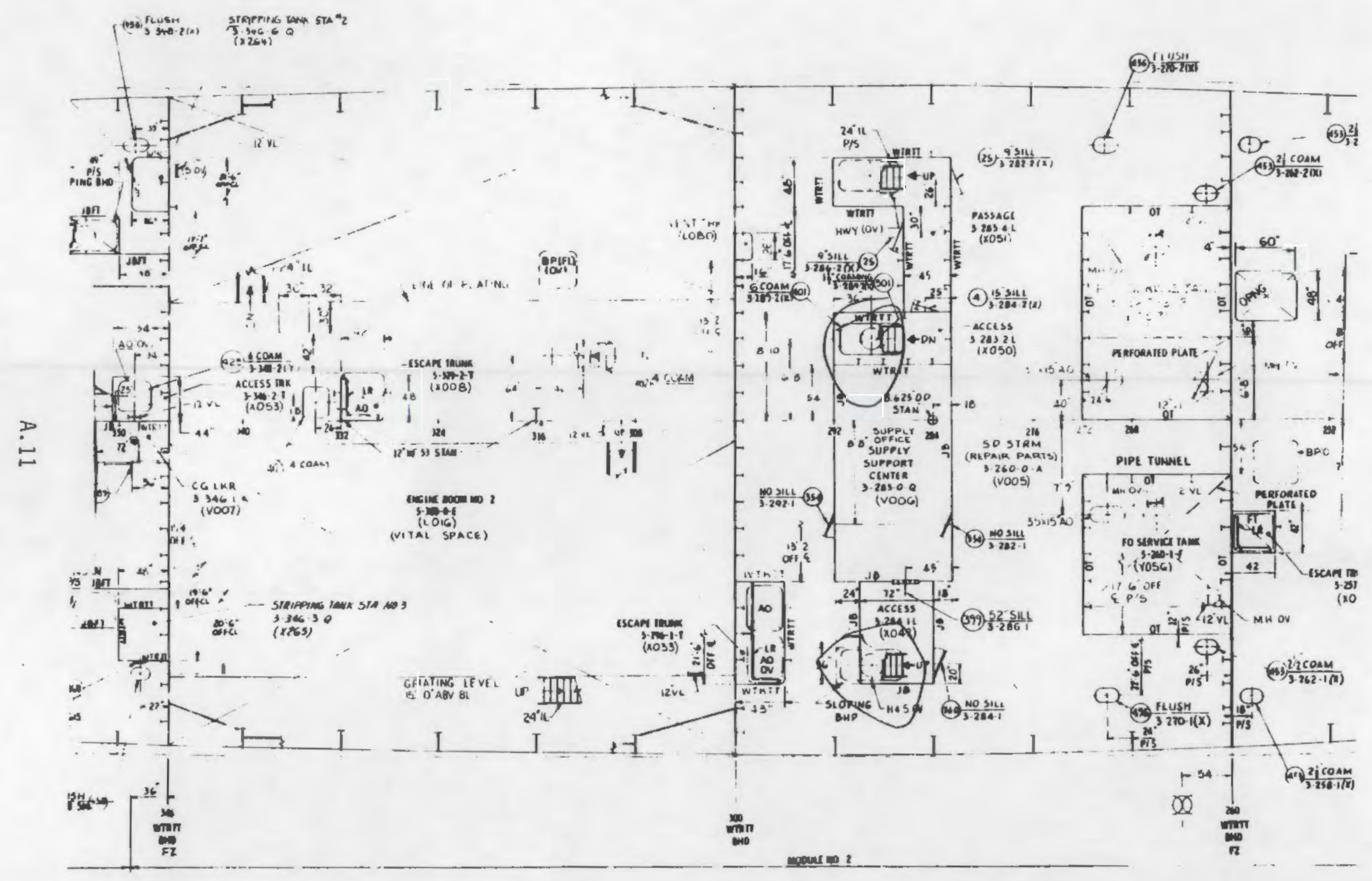

FIGURE A.5. CG 47, Second Platform, Compartments and Access 



\section{APPENDIX B}

UNDERSTANDING RADIATION DOSIMETRY 
APPENDIX 8

\section{UNDERSTANDING RADIATION DOSIMETRY}

Radiation dosimetry has two components, external dosimetry and internal dosimetry. External dosimetry refers to the radiation dose that will result from radiation emitted from sources outside the body. Internal dosimetry refers to the radiation dose that results from radioactive material inside the body. The dosimetric terms used in this report are "dose," "absorbed dose," "dose equivalent," "comitted dose equivalent," and "effective dose equivalent." The definitions below are based on available sources (IAEA 1986; ANSI 1976; ICRP 1984; ICRU 1980).

\section{$\underline{\text { DOSE }}$}

Dose is a term used in radiation protection that serves as a measure of the radiation energy "received" or "absorbed" by a target. The concept of "receiving" dose by a target is usually expressed as "absorbed dose" or "dose equivalent." The word "dose," as conmonly used, means either absorbed dose or dose equivalent, depending on the context.

\section{ABSORBED DOSE}

Absorbed dose is defined as the mean energy imparted by ionizing radiation to matter. Mathematically, absorbed dose is defined as

$$
D=\frac{d \epsilon}{d m}
$$

where $D$ is the absorbed dose, de is the mean energy imparted, and $d m$ is an element of mass. The traditional unit of absorbed dose is the rad, which is the deposition of 100 ergs per gram of material. Under the International System of Units (SI), the SI unit for absorbed dose is the gray, which is the deposition of 1 Joule per kilogram of material. One gray $=100 \mathrm{rad}$. 


\section{DOSE EQUIVALENT}

Some radiations are more effective at producing radiation damage than others; consequently, equal absorbed doses of different radiations are not always associated with the same degree of harm. In radiation protection, the difference in effectiveness has been related to the quality factor, $Q$. The quality factor is a type of weighted average of the effectiveness of radiation to produce an effect as compared to a standard type of radiation ( $x$ or ganma rays). The quality factor is defined as a function of linear energy transfer in water.

The dose equivalent is the product of the absorbed dose and the quality factor; when absorbed dose is in terms of rad, the corresponding dose equivalent term is rem; when absorbed dose is in terms of gray, dose equivalent is expressed in terms of sievert. Dose equivalent allows for the addition of the effects of different types of radiation; for radiation protection purposes, 1 rem of alpha radiation is equivalent to 1 rem of beta radiation.

In this report, the dose equivalent is computed according to the following equation:

$$
H=D Q
$$

where $H=$ the dose equivalent, $O$ is the absorbed dose, and $Q$ is the quality factor.

The quality factor for tritium may range from 1 to 2 , depending on the source of the information. Suggested values of $Q$ for tritium are shown in TabTe B.1. Because the quality factor used may depend on regulatory concerns, in this report computation of dose equivalent from absorbed dose will require an explicit step. The reader should be aware that computational formulas presented in the literature often contain assumptions about the quality factor (and other factors) that are not often explicitly stated.

\section{COMMITTED DOSE EQUIVALENT}

The ICRP has suggested (ICRP 1977) that, when considering the consequences of an intake of radioactive material, the total dose equivalent 
TABLE B.1. Published Values of the Quality Factor for Tritium

\begin{tabular}{lll}
$\begin{array}{ll}\text { Quality } \\
\text { Factor }\end{array}$ & & \multicolumn{2}{c}{ Reference } \\
1 & & ICRP 1977, 1979; NCRP 1987 \\
1.7 & & Brodsky 1983; NRC 1988 \\
2 & & ICRP 1986
\end{tabular}

received for 50 years after the intake be computed and recorded. This 50-year dose equivalent is the committed dose equivalent. In the case of tritiated water and elemental tritium the vast majority of the committed dose is received within 3 months of an intake. Thus for tritium the committed dose equivalent is identical to the annual dose equivalent (the dose equivalent received the first year after the intake). In this report, equations provide for computation of dose equivalent for any time after an intake of tritium.

\section{EFFECTIVE OOSE EQUIVALENT}

The ICRP in its Publication 26 (ICRP 1977) has recommended that the dose equivalents from external and internal radiation be summed. To facilitate this summation, the ICRP has introduced a weighting system for the dose equivalent received by individual organs. The purpose is to weight the risk received by an organ to the risk that would be encountered by an individual uniformly irradiated over the whole body. The weighting factors are shown in Table B.2. In those instances where only a few organs are irradiated or the dose equivalent varies greatly between organs, the dose equivalent received by each organ is multiplied by the weighting factor for that organ. The sum of all such products is the effective dose equivalent for the irradiation. In the case of tritiated water, which is uniformly distributed throughout the body following an intake, it is sufficient to compute a dose equivalent for the whole body and use a weighting factor of unity. However, in the case of inhalation of elemental tritium, a large fraction of the dose equivalent is received by the lung to the virtual exclusion of other organs. In this case, the dose equivalent to the lung is multiplied by the weighting factor for the lung to provide the effective dose equivalent. 
IABLE B.2. Weighting Factors Recomended by the ICRP (1977)

\begin{tabular}{lll}
\multicolumn{1}{c}{ Tissue } & & $\begin{array}{c}\text { Weighting } \\
\text { Factor }\end{array}$ \\
Gonads & & 0.25 \\
Breast & & 0.15 \\
Red Bone Marrow & & 0.12 \\
Lung & & 0.12 \\
Thyroid & & 0.03 \\
Bone Surfaces & & 0.03 \\
Remainder & & 0.30
\end{tabular}

The chemical forms of tritium emphasized in this report are tritium gas ( $H T$ or $\mathrm{T}_{2}$ ) and tritiated water (HTO or $\mathrm{T}_{2} 0$ ). The dose from an intake of tritiated water will be evenly distributed throughout the body. In this case the weighting factor is (1), and the effective dose equivalent is numerically equal to the dose equivalent to the whole body. In contrast, an intake of tritium gas will irradiate the lungs to a much greater extent than the rest of the body. In this case the effective dose equivalent, due to irradiation of the lung, is the product of the dose equivalent to the lung times the weighting factor of 0.12 . Other chemical forms of tritium, not discussed to any extent here, may concentrate in specific organs, in which case the weighting factors for these other organs should be employed.

\section{REFERENCES}

American National Standards Institute (ANSI). 1976. American National Standard Glossary of Terms in Nuclear Science and Technology. ANSI N1.1-1976, American National Standards Institute, Inc., New York.

Brodsky, A. 1983. Information for Establishing Bioassay Measurements and Evaluations of Tritium Exposure. NUREG-0938, U.S. Nuclear Regulatory Commission, washington, DC.

International Atomic Energy Agency (IAEA). 1986. Radiation Protection Glossary. Safety Series No. 76, International Atomic Energy Agency, Vienna. 
International Commission on Radiation Units and Measurements (ICRU). 1986. The Quality Factor in Radiation Protection: Report of a Joint Task Group of the ICRP and the ICRU to the ICRP and the ICRU. ICRU Report 40, International Comission on Radiation Units and Measurements, Bethesda, Maryland.

International Commission on Radiation Units and Measurements (ICRU). 1980. Radiation Quantities and Units. ICRU Report 33, International Commission on Radiation Units and Measurements, Washington, DC.

International Commission on Radiological Protection (ICRP). 1984. A Compilation of the Major Concepts and Quantities in use by ICRP. ICRP Publication 42, Pergamon Press, New York.

International Commission on Radiological Protection (ICRP). 1979. Limits for Intakes of Radionuclides by Workers. ICRP Publication 30, Part 1, including Addendum, Pergamon Press, New York.

International Commission on Radiological Protection (ICRP). 1977. Recommendations of the International Commission on Radiological Protection. ICRP Publication 26, Pergamon Press, New York.

National Council on Radiation Protection and Measurements (NCRP). 1987. Recommendations on Limits for Exposure to Ionizing Radiation. NCRP Report No. 91, National Council on Radiation Protection and Measurements, Bethesda, Maryland.

U.S. Nuclear Regulatory Commission (NRC). 1988. Criteria for Establishing a Tritium Bioassay Program. Regulatory Guide 8.32, U.5. Nuclear Regulatory Cominission, Washington, DC. 


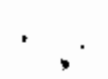

,

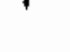


APPENDIX C

CALCULATION METHODS USED TO

ESTIMATE DOSES 


\section{APPENDIX $C$}

\section{CALCULATION METHODS USED TO}

\section{ESTIMATE DOSES}

This appendix first describes the basic concepts of dosimetry for tritium and then provides the specific equations that may be used for prospective dose estimations. This information can be used together with the report section Assessment of the Radiation Hazard and specifically with Tables 3,4 , and 5 .

\section{DOSE EQUIVALENT RATE}

Using the definitions of absorbed dose and dose equivalent (from Appendix $B$ ), the equation for the dose equivalent rate to an organ containing a beta-emitting radionuclide can be written as:

$$
\dot{H}=051.22 \frac{\epsilon}{M} q(t) \frac{r e m}{d a y}
$$

where $\dot{H}=$ the dose equivalent rate, rem/day

$$
\begin{aligned}
Q= & \text { the quality factor } \\
51.22= & \text { a conversion factor }(\mathrm{rad}-\mathrm{g}) /(\mathrm{MeV}-\mu \mathrm{Ci} \text {-day }) \\
\epsilon= & \text { the radiation energy absorbed in the organ per } \\
& \text { disintegration, MeV. } \\
\mathrm{q}(\mathrm{t})= & \text { the activity of the radioactive material in the } \\
& \text { tissue, } \mu \mathrm{Ci} \\
M= & \text { the mass of the organ, } g .
\end{aligned}
$$

The retention of tritiated water in the body can be described by a single exponential curve so that

$$
q(t)=q(0) \exp -\left(\lambda_{e} t\right)
$$


where $q(0)$ is the initial amount of activity in the body, $\lambda_{e}$ is the retention coefficient for tritium, and $t$ is the time after the intake.

COMMITTED DOSE EQUIVALENT

The dose equivalent rate can be integrated over time to calculate the total dose equivalent that may be received following an intake of tritium. Integration of Equation (C.1) with respect to time, following substitution of Equation (C.2) for $q(t)$ and $0.00568 \mathrm{MeV}$ for $\epsilon$, results in the following equation:

$$
H=0.42 Q T_{e} \frac{q(0)}{M}\left[1-\exp -\left(\lambda_{e} t\right)\right] \mathrm{rem}
$$

where $H=$ the committed dose equivalent, rem

$$
\begin{aligned}
0.42= & \text { a constant (product of } 51.22 \times 0.00568 \times 1.44), \\
& (\text { rad-g }) /(\mu C i-d a y) \\
T_{e}= & \text { the effective half-time of tritium in the body, days } \\
Q= & \text { the quality factor, dimensionless } \\
q(0)= & \text { the activity taken into the body, } \mu C i \\
M= & \text { the mass of the soft tissue, } g \\
\lambda_{e}= & \text { the effective removal constant of tritium from the body, } \\
t= & \text { the time since the uptake, days. }
\end{aligned}
$$

To compute the comitted dose equivalent, it is necessary to integrate the dose equivalent rate over the 50 years following the intake (ICRP 1977). Although the integration is for 50 years (in accordance with the formality of the ICRP [1977]), virtually all the dose from tritiated water will have been received within 3 months after an intake. Substituting $t=50$ years $(18,250$ days), the above equation becomes:

$$
H_{T, 50}=0.42 Q T_{e} \frac{q(0)}{M} \text { rem }
$$

where the variables are as defined above. 
The effective half-time of tritium in the body is a function of both the biological half-time and the radioactive half-life of tritium. In practice, for tritiated water the effective half-time equals the biological half-time.

Because the mass of the body is normally given in kilograms, the above equation may be rewritten as:

$$
H_{T, 50}=4.20 \mathrm{E}-4 \quad Q \mathrm{~T}_{\mathrm{e}} \frac{\mathrm{q}(0)}{\mathrm{M}} \mathrm{rem}
$$

where $H_{T, 50}=$ the committed dose equivalent, rem

$4.20 \mathrm{E}-4=$ a constant $(0.42 \times \mathrm{kg} / 1000 \mathrm{~g}),(\mathrm{rad}-\mathrm{kg}) /(\mu \mathrm{Ci}$-day $)$

$\mathrm{T}_{\mathrm{e}}=$ the effective half-time of tritium in the body, days

$Q=$ the quality factor, dimensionless

$q(0)=$ the activity taken into the body, $\mu \mathrm{C} i$

$M=$ the mass of the soft tissue, $\mathrm{kg}$.

\section{PROSPECTIVE DOSE CALCULATIONS}

In this section the equations are derived that may be used to perform prospective dose calculations. Throughout this section we explicitly show $Q$ in the equations. In some cases, the addition of $Q$ to the equation is not correct because the formalism employed by the ICRP includes a quality factor of one. The $Q$ is included in the equations to remind the reader that some regulatory agencies may require a $Q$ greater than one (Brodsky 1983).

Prospective dose calculations are often used to estimate the radiation dose to an individual who may be exposed to a radioactive material. Because the dose estimations are hypothetical, the doses are computed for an individual who has the characteristics of the ICRP reference man (ICRP 1975).

The prospective dose calculations described in this section are for the situations of ingestion of tritiated water, submersion in tritiated water vapor (along with subsequent inhalation), inhalation of tritium gas, and submersion of an individual in tritiated water. 


\section{Ingestion of Tritiated Water}

The committed dose equivalent to reference man from ingestion of tritiated water is from Equation (C.5) and substitution for assumed values for $M(63 \mathrm{~kg})$ and $T_{e}$ (10 days) as follows:

$$
H_{T, 50}=Q 62.9 \mathrm{E}-6 \quad q(0) \text { rem }
$$

where $H_{T, 50}$ = the effective dose equivalent, rem

$Q=$ the quality factor, dimensionless

$62.9 \mathrm{E}-6=$ conversion factor, $\mathrm{rad} / \mu \mathrm{Ci}$

$q(0)=$ the quantity of tritiated water ingested, $\mu \mathrm{Ci}$.

Submersion in Tritiated Water Vapor

When an individual is submerged in tritiated water vapor, there are two primary sources of radiation dose: 1) the dose due to the inhaled tritiated water vapor and 2) the dose due to the tritiated water absorbed through the skin.

\section{Inhaled Water Vapor}

All the inhaled water is taken up by the body. Consequently, the previous equation may be used by computing the intake, $q(0)$, from the equation:

$$
q(0)=20.0 \mathrm{E} 3 \mathrm{C} \mathrm{T} \mu \mathrm{Ci}
$$

where $C$ is the air concentration of tritiated water, in $\mu \mathrm{Ci} / \mathrm{mL}$; $T$ is the exposure time in minutes; and $20.0 \mathrm{E} 3$ is the "light work" breathing rate in $\mathrm{mL} / \mathrm{min}$. Substitution into Equation (C.6) yields

$$
\mathrm{H}_{\mathrm{T}, 50}=\mathrm{Q} 1.26 \mathrm{C} \mathrm{T} \text { rem }
$$

where $\mathrm{H}_{T, 50}=$ the committed dose equivalent, rem

$$
\begin{aligned}
& Q=\text { the quality factor, dimensionless } \\
& C=\text { the air concentration of tritiated water, } \mu \mathrm{Ci} / \mathrm{mL} \\
& T=\text { the exposure time, min. }
\end{aligned}
$$




\section{Percutaneous Absorption of Tritiated Water Vapor}

The quantity of tritiated water that may be absorbed through the intact skin can be estimated. For estimating this prospective dose, it is convenient to employ the ICRP assumption (1977) that the total percutaneous absorption will equal about one-half of the intake due to inhalation of the "light work" breathing rate. NRC licensees, however, should be aware that a footnote to 10CFR20.103(a)(1) indicates that the assumption employed to prepare the tables of maximum permissible concentrations was that intakes by inhalation and by skin absorption are equal. For this report intakes by the two routes were assumed to be equal. The committed dose equivalent due to percutaneous absorption of tritium is then:

$$
H_{T, 50}=Q 1.26 C \mathrm{~T} \text { rem }
$$

where $H_{T, 50}=$ the committed dose equivalent, rem.

$$
Q=\text { the quality factor, dimensionless }
$$$$
\mathrm{C}=\text { the air concentration of tritiated water, } \mu \mathrm{Cj} / \mathrm{mL}
$$$$
\mathrm{T}=\text { the exposure time, min. }
$$

Thus the total committed dose equivalent due to submersion in tritiated water vapor is the sum of that due to inhalation and percutaneous absorption:

$$
H_{T, 50}=02.52<\mathrm{T} \text { rem }
$$

where the variables are as previously described.

Inhalation of Tritium Gas

Following inhalation of tritium gas, radiation dose will be accrued from three sources: dose to the lung from tritium in the lung, dose to the whole body from elemental tritium absorbed in the blood, and dose to the whole body from tritiated water formed from the inhaled tritiated gas. 


\section{Dose to Lung from $\mathrm{T} 2$ Gas Inhaled}

ICRP 1979, supplement to part 1, lists the dose equivalent rate to the lung due to tritium gas in the air as $611.2 \mathrm{E}-6$ (rem-inL)/(min- $\mu \mathrm{Ci})[9.9 \mathrm{E}-15$ $\left.\left(S v-m^{3}\right) /(B q-h)\right]$. The dose to the lung from exposure to elemental tritium at an air concentration, $\mathrm{C}, \mu \mathrm{Ci} / \mathrm{mL}$ for time $\mathrm{T}$ minutes is then

$$
H=Q 611.2 E-6 C T \text { rem }
$$

where $H=$ the dose equivalent to the lungs, in rem

$$
\begin{aligned}
& C=\text { the air concentration of tritium gas, } \mu \mathrm{Ci} / \mathrm{mL} \\
& Q=\text { the quality factor, dimensionless } \\
& T=\text { the exposure time, min. }
\end{aligned}
$$

Since the dose to the lung will cease when the source is removed, the above dose represents also the committed dose equivalent to the lung from elemental tritium in the lung. The effective dose equivalent from the lung dose is computed by multiplying Equation (C.11) by the lung weighting factor of 0.12 (ICRP 1977). The equation for the effective dose equivalent in the lung is then:

$$
H_{E, 50}=073.33 E-6 C \text { T rem }
$$

where $H_{E, 50}$ is the committed effective dose equivalent, in rem, due to irradiation of the lung by elemental tritium in the air taken in.

\section{Elemental Tritium Dissolved in the Blood}

To compute the dose to the whole body from gaseous tritium dissolved in the blood, the following assumptions are made. First, elemental tritium in blood will uniformly irradiate the whole body. Second, the solubility of tritium in blood is equal to the solubility of hydrogen in water at the same temperature. Third, the dose to the whole body from $\mathrm{T}_{2}$ dissolved in body fluids is equal to the dose to the whole body from tritiated water. Based on this last assumption, the dose equivalent rate conversion factor is $1.9 \mathrm{E}-7 \mathrm{rad} /(\mu \mathrm{Ci}-\mathrm{day})$. 
The dose equivalent to the body from tritium dissolved in the blood is then given by the equation:

$$
H=\frac{3.2 \times 10^{-9} 1.713 \mathrm{Eg} \mathrm{CT}}{2.37 \mathrm{E} 6}
$$

where $3.2 \times 10^{-9}=$ a conversion factor, $\mathrm{rad} / \mu \mathrm{Ci}$

$$
\begin{aligned}
1.712 \mathrm{Eg}= & \text { the quantity of } \mathrm{T}_{2} \text { dissolved in blood at } \\
& \text { saturation, } \mu \mathrm{Ci}
\end{aligned}
$$

$2.37 \mathrm{E} 6 \mu \mathrm{Ci} / \mathrm{mL}=$ the maximal air concentration of tritium gas

$$
\begin{aligned}
& \mathrm{T}=\text { the exposure time, min } \\
& \mathrm{C}=\text { air concentration of } \mathrm{T}_{2} \text { gas, } \mu \mathrm{Ci} / \mathrm{mL} .
\end{aligned}
$$

which is

$$
H=Q 2.32 E-6 C T \text { rem }
$$

where the units are as defined above. The dose to the whole body from dissolved tritium gas is a small fraction of the effective dose equivalent received due to gas in the lung.

\section{Tritiated Water Converted from Inhaled Tritium Gas}

Approximately $0.003 \%$ to $0.004 \%$ of the inhaled tritium gas is oxidized to tritiated water in the body (Brodsky 1983). The dose to the whole body from this intake route is then:

$$
H=Q C 20,000 \text { T } 4 E-562.9 E-6
$$

where $4 \mathrm{E}-5$ is $0.004 \%$ (percentage of ${ }^{3} \mathrm{H}$ gas oxidized to tritiated water), 20,000 is the "light work" breathing rate in $\mathrm{mL} / \mathrm{min}$, and $62.9 \mathrm{E}-6$ is a conversion factor in $\mathrm{rad} / \mu \mathrm{Ci}$ [see Equation (C.6)], which is

$$
H=Q 50.32 E-6 \text { C T rem }
$$


where $H=$ the committed dose equivalent, rem

$Q=$ the quality factor, dimensionless

$C=$ the air concentration, $\mu \mathrm{C} i / \mathrm{mL}$

$T=$ the exposure time, $\min$.

In summary, the committed effective dose equivalent due to conversion of tritium gas to tritiated water is nearly equal to the committed effective dose equivalent due to irradiation of the lung by tritium gas. In this report the committed effective dose equivalent due to inhalation of tritium gas includes all three components of dose. The committed dose equivalent from inhalation of tritium gas is the sum of the three preceding equations and is given by the equation

$$
H_{E, 50}=0126.0 E-6 C T
$$

where $H_{E, 50}=$ the committed dose equivalent, rem.

$Q=$ the quality factor, dimensionless

$C=$ the activity concentration of tritium in air, $\mu \mathrm{Ci} / \mathrm{mL}$

$T=$ the exposure time, min.

NOTE: Approximately 5 to $10 \%$ differences can be obtained for the constants in the above equations, depending on whether one uses the integrated values listed in ICRP 30 (1977) or uses the dose rate values and then integrates. These differences are rounding errors.

\section{CALCULATION OF AIR CONCENTRATIONS}

The equations shown above indicate that the effective dose equivalent is dependent on the air concentration to which an individual was exposed and the time during which the individual was exposed to it. The equations, as written, are most readily used when the air concentration of the tritium remains constant. Constant air concentrations, however, are not often encountered. The actual air concentration may be replaced by an average, or alternatively, the fluctuating air concentration can be integrated over time to yield an integral air concentration which has the same units as the 
product of the air concentration and time and which may be substituted for the product "C T."

\section{Indoor Accident - Ventilated Area}

The radiation dose to a worker exposed to tritium in an enclosed area is a function of the initial concentration of the material in the air, the rate at which the material is vented from the area, and the total time that the individual remains in the area. For this situation, we have prepared a calculational equation that has the following underlying assumptions: a light breaks while an individual is in the area, the tritiated water is instantly dispersed throughout the area, and the tritiated water is removed from the air volume as defined by the air turnovers of the area.

The air concentration at any time, $t$, following the release of radioactivity into a room can be estimated from the equation:

$$
c_{t}=c_{0} \exp -\left(\lambda_{e} t\right)
$$

where $C_{t}=$ the air concentration at any time, $\mu \mathrm{Ci} / \mathrm{mL}$

$$
C_{0}=\text { the original air concentration, } \mu \mathrm{Ci} / \mathrm{mL}
$$$$
=\frac{\text { activity released, } \mu \mathrm{Ci}}{\text { room air volume, } \mathrm{mL}}
$$

$\mathrm{e}=$ the base of the natural logarithms

$\lambda_{e}=$ the effective removal constant, $\min ^{-1}$

$$
\begin{aligned}
\lambda_{\mathrm{e}}=\lambda_{\mathrm{p}} & +\lambda_{1} \\
\lambda_{\mathrm{p}} & =\text { physical decay constant, } \mathrm{min}^{-1} \\
\lambda_{1} & =\text { exfiltration removal constant, } \mathrm{min}^{-1}
\end{aligned}
$$

$t=$ the time at which the activity is to be calculated, $\min ^{-1}$.

The cumulative air concentration is the time integral of the above equation as follows:

$$
\tilde{\imath}=c_{0} \frac{1}{\lambda_{e}}\left[1-\exp -\left(\lambda_{e} t\right)\right]
$$


where $\mathcal{C}=$ cumulative air concentration, $\mu \mathrm{C} i-\min / \mathrm{mL}$

$$
\begin{aligned}
& \lambda_{e}=\text { the effective removal constant, } \min ^{-1} \\
& \lambda_{e}=\lambda_{p}+\lambda_{1} \\
& \lambda_{p}=\text { physical decay constant, } \min ^{-1} \\
& \lambda_{1}=\text { exfiltration removal constant, } \min ^{-1}
\end{aligned}
$$

$t=$ the time at which the activity is to be calculated, min.

The value of the exfiltration removal constant for a space in a Navy ship is the quotient of the ventilation rate for the space divided by the volume of the space.

Buildup of Tritium in a Room from Diffusion Through Glass

Tritium can diffuse through glass very slowly. If the radioluminescent devices are contained in a sealed area, the tritium activity will build up with time. Simultaneous with the buildup due to diffusion through glass out of the light sources, the tritium will decrease due to radioactive decay and to exfiltration from the room. The equation that describes the buildup of tritium with time is:

$$
C_{t}=\frac{\int^{t} i \exp \left[-\lambda_{e}(t-\tau)\right] d \tau}{v}
$$

where $C_{t}=$ the cumulative air concentration in the area, $\mu C_{i-m i n} / m L$

$\mathrm{i}=$ the diffusion rate from the tubes, $\mu \mathrm{C} i / \mathrm{min}$

$\lambda_{e}=$ the effective removal constant, $\min ^{-1}$

$$
\begin{aligned}
\lambda_{e}=\lambda_{p} & +\lambda_{1} \\
\lambda_{p} & =\text { physical constant, } \min ^{-1} \\
\lambda_{1} & =\text { exfiltration removal constant, } \min ^{-1}
\end{aligned}
$$

$t=$ the time at which the activity is to be calculated, min 


$$
\begin{aligned}
& \tau=\text { the elapsed time between when the }{ }^{3} H \text { was leached and the time } \\
& \text { for estimating the } 3 \mathrm{H} \text { activity, min } \\
& v=\text { volume of the space, } \mathrm{mL} \text {. }
\end{aligned}
$$

The above equation is readily solved.

$$
c_{t}=\frac{\dot{L} 1 / \lambda\left[1-\exp \left(-\lambda_{e} t\right)\right]}{v}
$$

where the symbols are as described for the previous equation. The cumulative air concentration is the integral of the above equation:

$$
x=\frac{o^{f^{t} i 1 / \lambda\left[1-\exp \left(-\lambda_{e} t\right)\right] d t}}{v}
$$

which is:

$$
\tilde{C}=\frac{i}{v \lambda_{e}}\left[t-\frac{1-\exp \left(-\lambda_{e} t\right)}{\lambda_{e}}\right]
$$

where $\mathcal{C}=$ the integral air concentration, $\mu \mathrm{Ci}-\mathrm{min} / \mathrm{mL}$

$\dot{L}=$ the rate of diffusion of tritium through the walls of the tubes, $\mu \mathrm{Ci} /$ unit time

$\lambda_{e}=$ the effective removal constant, $\min ^{-1}$

$$
\begin{aligned}
\lambda_{\mathrm{e}}= & \lambda_{\mathrm{p}}+\lambda_{1} \\
\lambda_{\mathrm{p}} & =\text { physical decay constant, min } \\
& \lambda_{1}=\text { exfiltration removal constant, } \min ^{-1}
\end{aligned}
$$

$t=$ the time at which the activity is to be calculated, min

$v=$ volume of the space, $m L$.

The diffusion rate of tritium through the walls of the tubes can be: computed in the following manner. The diffusion rate of tritium gas through 
the glass containers used for lights can be described by Equation (C.24) below (Niemeyer 1969; Souers 1986). Permeability constants for selected glasses are presented in Table 1 of the text. Those permeability constants do not have the correct units for use in Equation (C.24); multiplying the tabulated values by $4.6 \times 10^{14} \mu \mathrm{Ci} \cdot \mathrm{Pa} \cdot \mathrm{mm} \cdot \mathrm{m}^{2} \cdot \mathrm{sec} / \mathrm{mol} \cdot \mathrm{cm} \mathrm{Hg} \cdot \mathrm{cm}^{2} \cdot \mathrm{min}$ will effect the conversion.

$$
\dot{i}=\frac{K A\left(p_{2}-p_{1}\right)}{d}
$$

where $\dot{L}=$ rate of ${ }^{3} \mathrm{H}$ at standard temperature and pressure permeating the glass at constant temp., $\mu \mathrm{Ci} / \mathrm{min}$

$A=$ surface area of the lights, $\mathrm{cm}^{2}$

$p_{2}=$ partial pressure of ${ }^{3} \mathrm{H}$ inside the tube, $\mathrm{cm} \mathrm{Hg}$

$p_{1}=$ partial pressure of ${ }^{3} \mathrm{H}$ outside the tube, $\mathrm{cm} \mathrm{Hg}$

$d=$ wall thickness of the tube, $\mathrm{mm}$

$K=$ permeability constant (at $0^{\circ} \mathrm{C}$ and $76 \mathrm{~cm} \mathrm{Hg}$ ); $\mathrm{cm}^{3} \mathrm{~mm} / \mathrm{cm}^{2}$ min $\mathrm{cm} \mathrm{Hg}$.

Since hydrogen diffuses through glass as a molecule rather than as an atom (Sovers 1986, p. 370), it seems reasonable to expect that most, if not all, of the diffused tritium will be in the form of elemental gas.

When using the above equation, the diffusion rate may be assumed a constant if the calculation is carried out for short time intervals; in 1 year the tritium activity in the devices will decrease by only about $5 \%$. Example calculations are provided below.

\section{Example Calculations}

Example 1. Compute the effective dose equivalent to an individual in a compartment from tritium gas that diffuses through the glass tubes. For this example assume a compartment volume of $1259 \mathrm{ft}^{3}$ and a ventilation rate of $75 \mathrm{cfm}$. Assume that the marker in the compartment contains $3.5 \mathrm{Ci}$.

The method used in this example is to assume that the tritium is encapsulated in tubes that contain $2 \mathrm{Ci}$ each, compute the effective dose 
equivalent from a $2-\mathrm{Ci}$ tube, and then multiply the result by the number of tubes that may be present.

a. Compute the diffusion rate through glass using Equation (C.24). As the size of the glass tubes for the lights has not yet been defined, assume that the glass tube is a cylinder $5 \mathrm{~cm}$ long whose volume is sufficient to contain $2 \mathrm{Ci}$ of tritium gas at standard temperature and pressure. (This volume is about $1 \mathrm{~mL}$, and the tube dimensions will be $5 \mathrm{~cm}$ in length and $0.25 \mathrm{~cm}$ radius.) Assume that the glass is $1 \mathrm{~mm}$ thick. The value for $\mathrm{K}$ is taken to be $5.6 \mathrm{E}-13 \mu \mathrm{Ci}-\mathrm{mm} / \mathrm{cm}^{2}-\mathrm{min}-\mathrm{cm} \mathrm{Hg}$. The diffusion rate is then estimated to be $3.3 \mathrm{E}-4 \mu \mathrm{Ci} / \mathrm{min}$.

b. Compute the cumulative air activity in the compartment using Equation (C.23). Since the tritium concentration will reach equilibrium in about one day, it is acceptable to estimate the cumulative release during the first year. The effective removal constant is 0.06 min-1 (radioactive decay is very long compared to air removal by the ventilation system). The cumulative air concentration is estimated to be $8.22 \mathrm{E}-5 \mu \mathrm{Ci}-\mathrm{min} / \mathrm{mL}$.

c. Calculate the effective dose equivalent using Equation (C.17). Using a quality factor of 1.7, the effective dose equivalent is then about 1.76E-8 rem. This effective dose equivalent is for a single 2-Ci light tube. Since the compartment contains $3.5 \mathrm{Ci}$ of tritium, a simple correction is to multiply the 2-Ci value by the entire number of tubes present, in this case 2 . The estimated effective dose equivalent for this example is then 3.53E-8 rem. (See Table 3, Compartment 2.)

Example 2. Calculate the effective dose equivalent to an individual from the destruction of a light that contains $3.5 \mathrm{Ci}$ of tritium activity, of which $1 \%$ is in the form of THO. The ventilation rate for the space is $75 \mathrm{cfm}$, and the volume of the space is $1259 \mathrm{ft}^{3}$. (See Table 3, Compartment 2.) Assume that the individual remains in the space for $8 \mathrm{hr}$.

a. First compute the cumulative air concentration for tritium gas and tritiated water. The exfiltration rate is 
$75 \mathrm{cfm} / 1259 \mathrm{ft}^{3}=0.06 \mathrm{~min}^{-1}$. The initial air concentration is $2.78 \mathrm{E}-5 \mathrm{Ci} / \mathrm{ft}$ and $2.75 \mathrm{E}-3 \mathrm{Ci} / \mathrm{ft}$ for THO and $\mathrm{T}_{2}$ ' respectively. Use Equation (C.19) to compute the integral air concentrations, which turn out to be $1.65 \mathrm{E}-2 \mathrm{Ci}-\mathrm{min} / \mathrm{m}^{3}$ and $1.63 \mathrm{Ci}-\mathrm{min} / \mathrm{m}^{3}$ for HTO and $\mathrm{T}_{2}$, respectively.

b. Compute the effective dose equivalents. For water vapor use Equation (C.10) and for tritium gas use Equation (C.17). The integral air concentration (given immediately above) substitutes for the " $C T$ " portion of the equations. The effective dose equivalents are then, assuming a quality factor of 1.7, $7.05 \mathrm{E}-2$ rem and $3.53 \mathrm{E}-4$ rem for tritiated water and tritium gas, respectively. (See Table 5, Compartment 2.)

\section{REFERENCES}

Brodsky, A. 1983. Information for Establishing Bioassay Measurements and Evaluations of Tritium Exposure. NUREG-0938, U.S. Nuclear Regulatory Commission, Washington, DC.

International Conmission on Radiological Protection (ICRP). 1975. Report of the Task Group on Reference Man. ICRP Publication 23, Pergamon Press, New York, New York.

International Conmission on Radiological Protection (ICRP). 1977. Recommendations of the International Conmission on Radiological Protection. ICRP Publication 26, Pergamon Press, New York.

Niemeyer, R. G. 1969. Tritium Loss From Tritium Self-Luminous Aircraft Exit Signs. ORNL-TM-2539, Oak Ridge National Laboratory, Oak Ridge, Tennessee.

Souers, P. C. 1986. Hydrogen Properties for Fusion Energy. University of California Press, Berkeley, California. 


\section{APPENDIX 0}

INVESTIGATION OF TRITIUM RADIOLUMINESCENT (RL) LIGHT SOURCES FOR U.S. NAVY REQUIREMENTS 
APPENDIX D

FINAL REPORT

INVESTIGATION OF TRITIUM RADIOLUMINESCENT

LIGHT (RL) SOURCES FOR U.S. NAVY REQUIREMENTS

\author{
Submitted by \\ DONALD R. ADRIAN \\ and \\ HENRY C. PUSEY \\ IN FULFILLMENT OF THE REQUIREMENTS OF \\ CONTRACT NUMBERS: $B-N-2427-A-P$ \\ $B-P-6540-A-P$
}

June 27,1986 
INVESTIGATION OF TRITIUM RADIOLUMINESCENT

LIGHT(RL) SOURCES FOR U.S. NAVY REQUIREMENTS

\section{INTRODUCTION}

As a part of the Byproduct Utilization Program, the Department of Energy(DOE) and the Battelle Pacific Northwest Laboratories(PNL) have developed large RL sources $(50+C i)$ which are now available and being tested for airfield lighting applications. This program, with sponsorship from the U.S. Air Force, the State of Alaska, and the City of st. Petersburg in Florida, is well under way and the results are promising. The U.S. Air Force, looking for RL lights useful in runway applications for high performance aircraft, has been the strongest supporter of the program. Alaska and St. Petersburg are each providing more than $\$ 300,000$ to sponsor the development of RL lighting for civilian airports.

The RL fixtures use tritium, a radioactive isotope of hydrogen, in a sealed glass tube coated on the interior surface with a phosphor. Beta emissions from the tritium activate the phosphor to produce luminescent light in a choice of colors, or in infrared, depending upon the phosphor selected. Since tritium is a pure beta emitter, there is no external radiation through the light tube. Existing light fixtures have been ruggedized to minimize the probability of accidental release of the tritium. Should such a release occur, the tritium gas is rapidly dispersed so that human radiation exposure is normally expected to be well within acceptable limits. Results of the investigation of an unplanned accident at an Alaska airport support this conclusion. Tritium has a half-life of approximately twelve years. RL sources will therefore operate with no external power for at least ten years. Furthermore, these lights are essentially maintenance free.

It is useful to note that RL sources have been used for applications other than those considered under the DOE/PNL program. FOr example, during the Grenada operation, the U.S. Marines used experimental RL wands to establish a helicopter evacuation pad. The United Ringdom also employed this type of lighting during night operations in the Falklands and has, for some applications, begun to install RL fixtures in UR Combatants. Reportediy, the results of these efforts have been favorable.

with the apparent success in the developments of RL airfield lighting, DOE/PNL have concluded that RL sources should be useful for a number of military applications on ships, submarines, aircraft, other vehicles, or at shore installations. As a first step, DOE/PNL sponsored a preliminary study to identify potential uses of RL technology for U.S. Navy applications. This report presents the results of that study. 


\section{OBJECTIVES}

Considering the advantages and disadvantages of RL sources, the general purpose of this study is to examine U.S. Navy lighting requirements to determine which of these requirements could conceivably be met with advantage by the use of RL fixtures. Specifically, the objectives of the study are

1. to identify potential applications of RL sources

a. on surface ships and submarines.

b. for aircraft(avionics) uses.

c. for shore installations.

2. to identify possible benefits of RL lighting with respect to reliability, survivability, safety, security and related considerations.

3. to identify Navy points of contact(POC's), persons having a major interest in any program to implement RL technology for Navy applications.

4. to provide the Navy with information on the advancements in $\mathrm{RL}$ technology and to develop a proposed strategy to implement the use of RL sources for Navy applications.

\section{CHARACTERISTICS OE RI SOURCES}

It has been known for many years that nuclear radiation will excite luminescent materials to produce visible light. In this process, beta particles(electrons) strike and excite a phosphor causing light to be emitted from the phosphor. The color of the emitted light is dependent upon the particular phosphor being used, while the brightness of the light depends on the quantity and strength of the nuclear radiation source. At present, phosphors are available for a full range of colors and for infrared emissions. Research is underway which may produce new phosphors that influence brightness. At the limits of allowable strength of the nuclear radiation source(in this case, tritium), brightness may be enhanced by special optical or reflector design.

Self-luminous light sources have particular appeal for lighting applications such as safety lighting and continuous markering devices These sources are also attractive candidates for a number of other potential applications. The appeal derives largely from several strong advantages over conventional sources of light. The advantages are that $\mathrm{RL}$ sources are

1. fully self-contained, i.e., no external power or hookup is required.

2. continuous sources of light which provide a uniform output over an extended period of time (years). 
3. maintenance-free sources of light that will not "burn out".

4. Sources which can be used effectively over a wide temperature range(nominally - $1000^{\circ}$ to $+1500^{\circ}$ )

5. sources which are unaffected by humidity.

6. Sources which are free of spark and(electrical) shock hazards.

7. sources with resistance to static and dynamic loads dependent upon the design of the containment fixtures.

There are only three principal disadvantages of RL sources.

1. These sources must be licensed by the Nuclear Regulatory Commission (because they contain radioactive material). Currently, there is a limit on the amount of tritium in each tube (55 Ci).

2. In any application being considered, one must be concerned about the potential radiation hazard.

3. These sources are primarily useful in darkness (not effective in daylight).

\section{POTENTIAL NAVY APPLICATIONS OF RI TECHNOLOGY}

In general terms, Navy lighting requirements may be grouped in three broad categories.

1. Fixtures and light sources to provide general illumination.

2. Fixtures and light sources to provide detail illumination for applications where the intensity of general illumination is not sufficent, such as desks, work benches, gages and chart boards.

3. Special purpose lighting applicatins such as for replenishment-at-sea, navigation and signal lights, and special color(blue, red) lighting.

The first two lighting categories are quite broad. The third category includes requirements for Navy applications that are unique.

Within the limits of this study, it would not be possible to develop a list of all potential Navy applications of RL lighting. The applications that are listed were selected on the basis of potential benefits to the Navy should the use of RL sources for these 
applications prove to be feasible. In the three sections that follow, the potential Navy applications are listed, along with brief descriptions when required. A general discussion of potential benefits to the Navy follows the listings.

Surface Ships and submarines

Potential applications of RL sources for conventional lighting on board ships and submarines are as follows.

1. Portable hand lanterns (to replace current portable relay and battery-powered lanterns used by damage control parties after power failures).

2. Emergency lighting in vital spaces(to substitute for current emergency lighting system which requires a special generator and automatic bus transfer equipment).

3. RL fixtures(to substitute for current watertight fixtures required in battery, machinery and reactor spaces on submarines).

4. Emergency fixtures(to substitute for present DC battery-powered emergency lighting system on submarines).

5. Exit signs, exit route, and access route markings on ships and submarines.

6. Compartment identification markings.

7. Safety lights for elevators(aircraft, ammunition, stores, etc.).

B. RL lighting to illuminate ladders, vertical trunks, life preservers, life boats, etc.

9. RL red illumination(to substitute for conventional low level red lighting for enhanced night vision and sleeping comfort).

10. RL blue illumination(to substitute for conventional blue lighting requirements for CIC's).

11. RL sources for Replenishment-at-sea requirements (including task lights, aircraft warning red light, wake light, wands, and required multi-colored flashlights).

12. RL sources for night signal lights.

13. RL sources to illuminate all watertight compartments (to eliminate bulkhead penetrations for compartment lighting). 
14. RL sources to illuminate weapon magazines

(to eliminate potentially hazardous electric sparks).

15. Helicopter nighttime drop and landing zone marking(infrared or blue).

16. RL infrared decoys.

Naval Aircraft and Related Apolications

Potential applications of RL technology for lighting requirements (interior and exterior) for Naval aircraft are as follows.

1. Instrument Lighting: includes illumination of instrument panel, indicators, gauges as well as marking of controls, ingress and egress systems.

2. Emergency Escape Lighting: includes designation of aircraft exits, rescue controls, emergency egress, aircrew ejection controls and marking of onboard firefighting equipment.

3. Survival kit Beacon: light source to pinpoint downed pilots or aircrew members.

4. Cargo Bay Illumination: includes permanently illuminated markings for cargo compartment doors, steps, ladders, switch plates, control panels or accessways.

5. Personal Illumination: includes flashlights, and similar systems carried as personal equipment by aircrews or contained in tool kits or survival kits.

6. Navigation Lights: includes any exterior illumination devices, in colored or white lights, used as aids to in-flight navigation(i.e., wingtip lights).

7. Running Lights: include all other exterior lighting used to illuminate the aircraft or parts thereof as aid to visual identification.

8. Maintenance Access Illumination: involves permanently affixed lighting inside of aircraft maintenance panels or accessways. 
Shere Installations and Ground Based Aircraft Apolications

Potential applications for RL technology are as follows.

1. Runway Marking: includes all illuminated aids to navigation installed on or around aircraft runways, taxiways and parking aprons.

2. Warning Beacon Lights: include all lighted fixtures on tall structures bordering airport approaches; used as warnings.

3. Vehicle Running Lights: includes all border lighting on aircraft tow tractors, cargo handling gear, fuel or fire trucks and similar vehicles. Could be both as safety and identification aids.

4. Markings for Emergency Fixtures: include illuminated markings for fire standpipe, electrical connections or gateways, etc., reserved for aircraft emergency use.

5. Marking for Access Panels: include small illuminated markings for accessway/hatches for underground fuel storage tanks, manholes, etc.

6. Doorway Markings: include any permanently illuminated identification markings for exit doors, airport gates, hangers, emergency doors or similar places where ease of access, even during electrical failure, is required.

7. Control Tower IIlumination: includes both safety work lighting for control towers, which require permanent lighting even in electrical emergencies.

Why Should the Navy Consider RL Technology?

Throughout this report, it has been emphasized that the suggested RL lighting applications for the Navy represent only potential uses. To be fully acceptable for Navy use, RL systems, like all Navy equipment, would have to qualify to a rigorous set of specified reguirements on various factors related to performance and integrity. Some of these factors are discussed in the following section of this report. At this point, however, it will be assumed that RL systems can be designed and built to perform as well as conventional lighting systems and that these systems will gualify to all Navy requirements. with this assumption in mind, some of the advantages and disadvantages of RL systems can be examined from the Navy's viewpoint. The use of such systems would likely result in the following benefits.

1. Enhanced ship survivability during combat. Effective Iighting is provided even if ship's power is lost. More efficient battle damage control and 
repair can result.

2. Increased personnel survivability in the event of imminent sinking of the ship. Escape routes can be clearly marked by Iights that require no power.

3. Reduced cost, particularly for new construction. Less cabling would be required. Penetrations through watertight bulkheads can be avoided. Maintenance costs would be minimal.

4. Increased safety in hazardous areas. No potential electric spark to cause an explosion or fire.

5. There is the potential to "deceive" the enemy with decoys using RL systems.

On the minus side, consider the following.

1. RL sources are light sources, not power sources. They cannot replace the requirement for ship's power.

2. RL systems are only effective in the dark.

3. RL systems operate continuously. To turn them off requires a shutter or a blind.

In general, it can be concluded that the Navy should at least investigate the potential applications of RL technology. UndoubtedIy there are additional potential benefits that could be listed to support this conclusion.

\section{FACTORS IN A NAVY RL ARPIICATIONS STUDY}

If the Navy should be interested in pursuing a program in RL technology, there are a number of constraining factors that would have to be considered. Some of the more important requirements are discussed in the following sections.

\section{Reliability}

Reliability of equipment is somewhat analogous to the reliability of a person. By its nature the equipment promises to perform certain functions. Its reliability is a measure of how long it does this well without failure when operating under stresses that are normally expected in its operating(life cycle) environments. Anong others, the stressful environments for Navy equipment may be vibration, temperature, humidity, salt spray and so forth. There are a number of related specifications that implement Navy reliability requirements and describe how reliability is to demonstrated. RL systems for Navy use would have to qualify under these requirements. With knowledge of the Iife cycle environments and good design practice, it is believed that highly reliable RL systems could be developed for 
Navy use. A Navy program on RL technology would have to verify this conjecture.

Survivability

From the Navy viewpoint, let us think of survivability as a measure of the capability of a ship to survive and continue to perform its mission during combat. In this context, chances for survivability can be enhanced by (1) avoiding detection by the enemy, (2) if detected, avoid attack by using evasive tactics, (3) if attacked, avoid being hit(using decoys or destroying incoming weapons), (4) if hit, minimize damage by design, protective methods, redundancy, etc., and (5) if damaged, optimize battle damage control and repair techniques. Assuming RL systems can be hardened to survive combat environments, their "Iight without power" may provide the edge during damage control operations or a required "abandon ship". An infrared RL decoy could also conceivably put an enemy IR missile off track. A detailed study on $\mathrm{RL}$ contributions to survivability should be included in a Navy program on RL applications.

\section{Safety}

A Navy RL program would need to look very carefully at both the positive and negative aspects of safety. For example, the "spark free" tritium lights would be quite safe in weapons magazines. On the other hand, there is always the gessibility that tritium could be released. This could be a hazard, particularly in enclosed, poorly ventilated spaces. Studies would be required to define the extent of the hazard and to develop methods for detection and control. Studies under the Air Force program indicate that the hazard is within acceptable limits.

\section{Security}

Security is mentioned here in the context of protection against theft or pilferage. RL fixtures can be fascinating - a nice item to "take home". Particularly since these items would be under NRC Iicense, the Navy would need to address this problem in its RI program.

\section{Cost and Availability}

In a Navy RL program, cost considerations would have to be factored in as part of the decision process. Cost comparison between RL systems and conventional lighting is not simple, but it will need to be done. It must also be determined that sufficient tritium to meet Navy needs will be available for many years to come.

\section{Compatibility with Nayy Design. Reguirements}

A Navy RL program would have to assure that RL sources in their fixtures could be designed to meet all requirements imposed on other shipboard equipment with equivalent mission importance. As lighting systems, RL units would have to conform to the illumination requirements in the General Specifications for Ships of the United states 
Navy, Section 322. Because RL systems are often described in different terms, the General Specifications may have to be modified to accommodate the differences. Furthermore, appropriate material on RL units would have to be incorporated in NAVSEA 0964-LP-000-2000, "Lighting on Naval Ships", a Technical Manual. Most lighting systems must pass Grade A requirements under MIL-S-90lC for shipboard shock and the shipboard vibration requirements of MIL-STD-167. Design requirements for other potential weapons effects may also be imposed, for example, air blast, nuclear EMP, or fragmentation.

\section{NAVY POC'S FOR RI LIGHTING IMPLEMENTATION}

Ultimate approval for the Navy implementation of RL technology would rest with the Commander, Naval Sea Systems Command and, of course, the Chief of Naval Operations. A Navy progran to stuay RL technology for Navy applications would likely be managed by DTNSRDC (Mr. John Wehrle, 30I-227-2006), although the decision on this would have to be made by the Navy. No matter who managed the program, there would be a number of persons/offices interested in the results. Some might wish to be active participants. A partial list of Points of Contact(POC's) follows.

1. Officé of Nayal Technology - Monitoring 6.2 programs. (Possibility Gene M. Remmers or Code 20E(Cdr. Wald)).

2. DTNSRDC - Annapolis - Art Marchand (301) 267-2839.

3. Naval Research Laberatery - Chemistry Division, Fire Damage Control, Homer Carhart (202) 767-2262.

4. Naval Air Systems_Command - Combat Survivability Branch, Dale B. Atkinson (202)692-2120.

5. Naval Sea systems Command -

a) Ship Technology Programs - Code 05R2, Anthony F. Johnson (202)692-0122.

b) Program Manager, Electrical systems - Code 05R31, John 日. Harrison (202)692-9462.

c) Ship Protection Division - Code 55XI, John A. Schell (202)692-8962.

d) Damage Control \& Safety Division - Code 55x2, Cdr. John D. Hadley (202)692-0328.

e) Safety office - Code $06 \mathrm{H}$, Milton Van Slyke, (202)692-2080.

f) Ship Arrangements Division - Code 55Wl, Donald R. Cebulski (202)692-7971.

g) Electrical Systems Subgroup - Code $56 \mathrm{z}$, Capt. David C. Kane (202)692-7440. 
h) Underway Replenishment Systems Branch - Code 56W24, Kenneth C. Morisseau, (202)692-9530.

i) Habitability Branch, Code 55w5l, Rick Hartzell, (202)692-1591.

6. Naval Safety Center, Norfolk, VA.

7. Naval Medical Command, Radiation Health Branch, Code 212

It should be noted that there may be other interested parties or participants. If the Navy should initiate an RL technology program, one of the early tasks would be to identify all offices that should be advised of program activities.

IMPLEMENTING THE USE OF RL LIGHTS FOR NAVY ARPLICATIONS

Since the Navy has not yet formally considered the use of RL lights, it would be logical to seek funds from the Navy's 6.2 (Exploratory Development) program to support studies on factors impacting on the decision to implement this technology. Initially, the program should concentrate on surface ship and submarine applications, with considerations of aircraft and shore based uses to be investigated at a later date. In connection with the fleet study, there are a few fundamental questions to be answered before the Navy would consider the possibility of proceeding with a full-blown program in the RL lighting area. 1. Can RL lights provide illumination comparable to
conventional lights?

2. Can RL light fixtures be designed to meet Navy specifications such as MIL-S-901C and MIL-STD-167?

3. Is there or is there not substantial radiation hazard to Naval personnel under a worst case scenario?

4. If the Navy should decide to use RL systems, will there be a guaranteed supply of tritium available for Navy needs?

If these questions can be answered favorably, and it is believed that they can, a Navy RL program could proceed to select potential lighting applications, develop the design and test requirements, and design the light fixtures. If the results are favorable, the technology developed by the Navy can be transferred for U.S. Coast Guard applications.

On 12 June 1986, Mr. John Wehrle from the David Taylor Naval Ship Research and Development Center attended a DOE RL Sponsors meeting as an observer. Among other things, Mr. Wehrle is responsible for the survivability R\&D program administered by DTNSRDC. Although he seemed genuinely interested in the potential for RL lighting applications in the Navy, it is believed that a concrete proposal from DOE is in order. That proposal should take the form of a Plan of Action and Milestones(POA\&M) for a multi-year program for Navy RL lighting 
development and applications. Several of the milestones should be decision points, at which it would be determined whether to stop or continue the program depending upon the results at that time.

It is recommended that DOE support the development of a POA\&M for a Navy program on RL lighting. The proposed program should be submitted to the Navy along with a request for funds to sponsor the program. If the Navy reacts favorably and plans to proceed with the program, DOE should provide management support to coordinate the Navy program with the efforts of other $R L$ technology sponsors. 
PNL -6774

UC -510

\section{DISTRIBUTION}

No. of

Copies

OFFSITE

10 DOE/Office of Scientific and Technical Information

15 L. E. Leonard

Advanced Radiation Technology Program

Office of Remedial Action and Waste Technology, NE-24

Department of Energy

Washington, OC 20545

R. B. Chitwood

Advanced Radiation Technology Program

Office of Remedial Action and Waste Technology, NE-24

Department of Energy

Washington, DC 20545

J. A. Tompkins

Oak Ridge National Laboratory P.0. Box $X$

Oak Ridge, TN 37830

D. K. Adrian

26717 Haney Road

Damascus, MD 20650

H. C. Pusey

4139 Sudley Road

Haymarket, VA 22069
No. of

Copies

ONSITE

3 DOE Richland Operations Office
R. B. Goranson
(2) $A 5-90$
E. C. Norman
A5-90

26 Pacific Northwest Laboratory

H. C. Burkholder P7-41

J. H. Jarrett K1-12

G. A. Jensen (15) K2-12

J. L. McElroy

P7 -46

G. L. Tingey

K2-18

R. J. Traub

$\mathrm{K} 3-57$

Publishing Coordination

Technical Report Files (5) 
$i$

,

1

:

, 